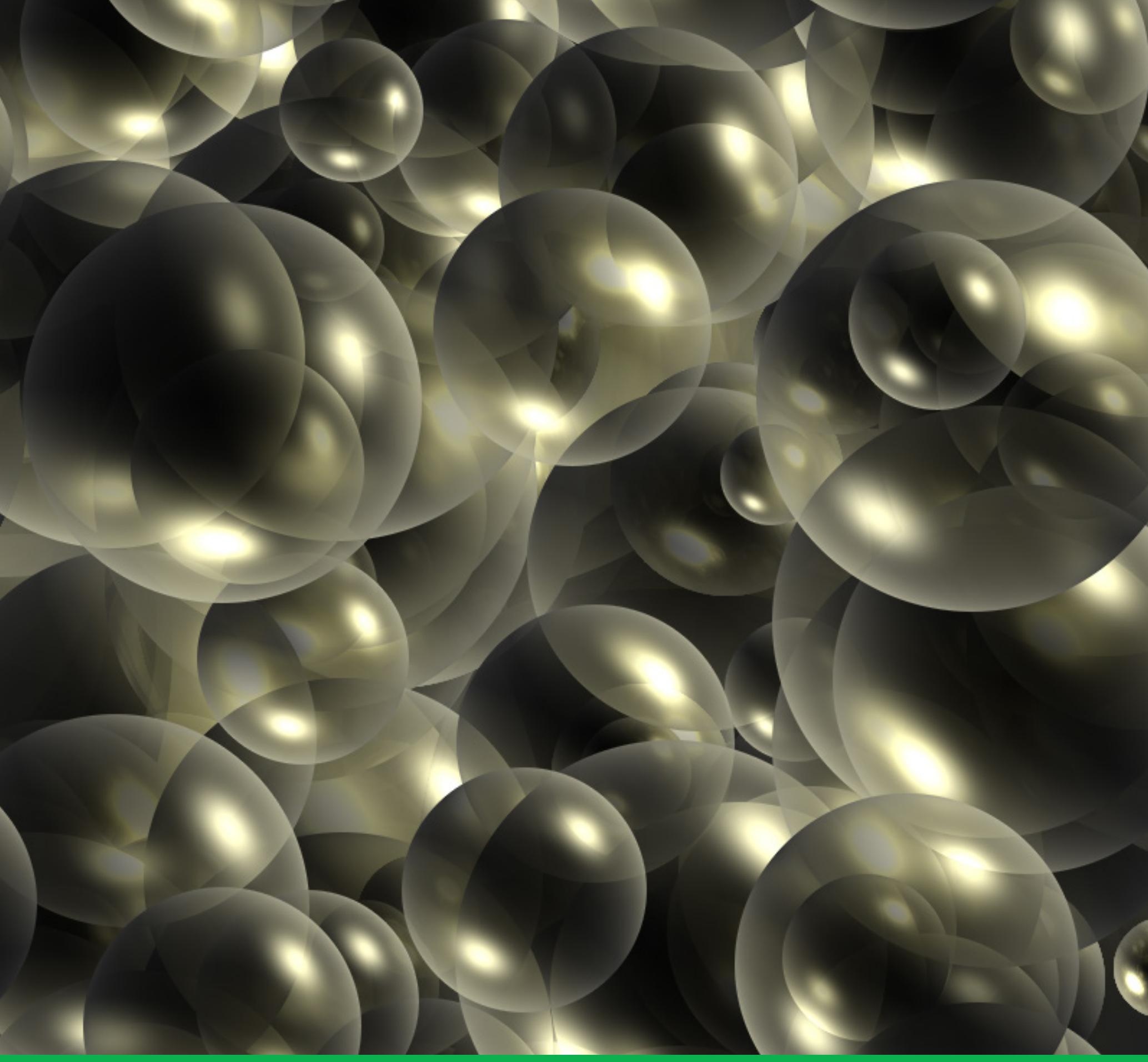

\title{
User manual for FOCUSPEARL version 5.5.5
}



User manual for FOCUSPEARL version 5.5.5 
This WOt-technical report was produced in accordance with the Quality Management System of the Statutory Research Tasks Unit for Nature \& the Environment, part of Wageningen University \& Research.

The mission of the Statutory Research Tasks Unit for Nature and the Environment (WOT Natuur \& Milieu) is to carry out statutory research tasks on issues relating to nature and the environment. These tasks are implemented in order to support the Dutch Minister of Agriculture, Nature and Food Quality, who is responsible for these issues. We provide data about agri-environment, biodiversity and soil information to compile reports as part of national and international obligations, and we work on products of the PBL Netherlands Environmental Assessment Agency, such as the Assessment of the Human Environment reports.

\section{Disclaimer WOt-publicaties}

The 'WOt-technical reports' series presents the findings of research projects implemented for the Statutory Research Tasks Unit for Nature \& the Environment by various centres of expertise.

This report/publication presents the findings of a research project by Wageningen Environmental Research together with PBL Netherlands Environmental Assessment Agency. PBL is an autonomous research institute in the fields of the environment, nature and spatial planning, as is safeguarded in the Protocol for the Policy Assessment Agencies (Aanwijzingen voor de Planbureaus), Staatscourant (government gazette) 3200, 21 February 2012.

This document contributes to the body of knowledge which will be incorporated in more policy-oriented publications such as the National Nature Outlook and Environmental Balance reports, and thematic assessments.

The research was funded by the Dutch Ministry of Agriculture, Nature and Food Quality (LNV). 


\section{User manual for FOCUSPEARL version 5.5.5}

F. van den Berg ${ }^{1}$, A. Tiktak $^{2}$, D.W.G. van Kraalingen ${ }^{1}$ \& J.J.T.I Boesten ${ }^{1}$

1) Wageningen Environmental Research

2) PBL Netherlands Environmental Assessment Agency

Project WOT-04-008-024

Statutory Research Tasks Unit for Nature \& the Environment

Wageningen, December 2019

wot-technical report 164

ISSN 2352-2739

DOI: $10.18174 / 509006$ 


\begin{abstract}
Berg, F. van den, A. Tiktak, D. van Kraalingen \& J.J.T.I. Boesten (2019). User manual for FOCUSPEARL version 5.5.5. Wageningen, the Statutory Research Tasks Unit for Nature \& the Environment (WOT Natuur \& Milieu). WOt-technical report 164. 76 p.; 36 Figs; 1 Tab; 16 Refs; 3 Annexes.

In the EU registration procedure, the assessment of the leaching to groundwater and the exposure of soil organisms as a result of the use of plant protection products is based on the use the FOCUS groundwater scenarios and the EFSA soil exposure scenarios, respectively. This user manual describes the use of the graphical user interface of the new FOCUSPEARL version, i.e. version 5.5.5, that facilitates the application of the scenarios for these assessments. In addition a description of the input and output files is given which helps the user to use the FOCUSPEARL model without the interface.
\end{abstract}

Keywords: crop protection product, FOCUS, PEC-Soil, groundwater, soil organisms, leaching, pesticide

\title{
(c) 2019 Wageningen Environmental Research
}

PO Box 47, 6700 AA Wageningen

Phone: (0317) 4807 00; e-mail:erik.vandenberg@wur.nl

The Statutory Research Tasks Unit for Nature and the Environment (WOT Natuur \& Milieu; an unit under the auspices of the Stichting Wageningen Research), PO Box 47, NL 6700 AA Wageningen, T +31 3174854 71, info.wnm@wur.nl, www.wur.nl/wotnatuurenmilieu. WOT Natuur \& Milieu is part of Wageningen University \& Research.

This report can be downloaded free of charge from https://doi.org/10.18174/509006 or from www.wur.nl/wotnatuurenmilieu. WOT Natuur \& Milieu provides no printed copies of reports.

- Acquisition, duplication and transmission of this publication is permitted with clear acknowledgement of the source.

- Acquisition, duplication and transmission is not permitted for commercial purposes and/or monetary gain.

- Acquisition, duplication and transmission is not permitted of any parts of this publication for which the copyrights clearly rest with other parties and/or are reserved.

WOT Natuur \& Milieu assumes no liability for any losses resulting from the use of the research results or recommendations in this report. 


\section{Preface}

This manual has been prepared to support the user of the new version of FOCUSPEARL, i.e. version 5.5.5. In this version, the EFSA soil exposure scenarios have been implemented in order to accommodate the assessment of the exposure of soil organisms.

The FOCUS groundwater scenarios have not changed in this version, except for a few corrections in the scenario data.

The FOCUSPEARL database of this version no longer contains substance specific data. To edit, store and archive these data a separate application has been developed, i.e. SPIN. The new version of FOCUSPEARL is coupled to SPIN version 3.3. 



\section{Contents}

$\begin{array}{lr}\text { Preface } & 5\end{array}$

$\begin{array}{lr}\text { Summary } & 9\end{array}$

$\begin{array}{lr}\text { Samenvatting } & 11\end{array}$

1 Introduction $\quad 13$

$\begin{array}{lll}1.1 & \text { Release versions of FOCUSPEARL } & 13\end{array}$

$\begin{array}{lll}1.2 & \text { Compatibility } & 14\end{array}$

$2 \quad$ Introduction to the FOCUSPEARL User Interface $\quad 15$

2.1 Overview of the FOCUSPEARL database 15

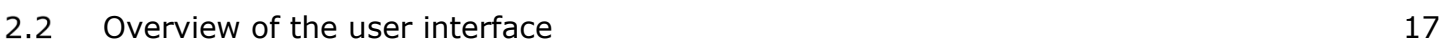

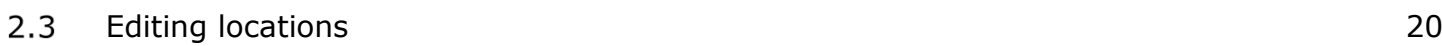

2.3.1 The Locations form $\quad 20$

2.3.2 The Soil Profiles form $\quad 22$

2.3.3 The Soil Building Blocks form

2.3.4 The Meteo Stations form $\quad 24$

2.3.5 Boundary conditions of the hydrological model 25

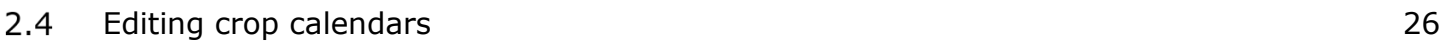

2.4.1 The Crop Calendar form $\quad 26$

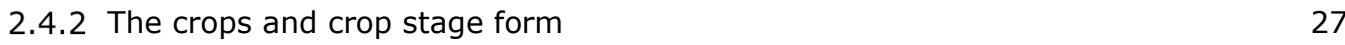

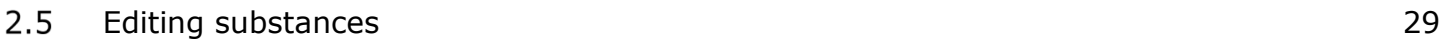

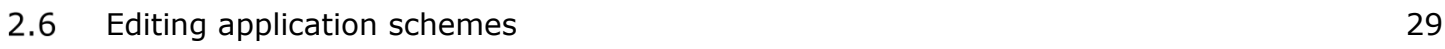

2.6.1 Application schemes $\quad 29$

2.6.2 Applications $\quad 29$

$\begin{array}{lll}2.7 & \text { Editing irrigation schemes } & 30\end{array}$

$\begin{array}{lll}2.8 & \text { Defining the output of the model } & 31\end{array}$

2.8.1 The Output Control tab of the main form 31

2.8.2 The Detailed Output Options form 31

2.9 Running the model $\quad 33$

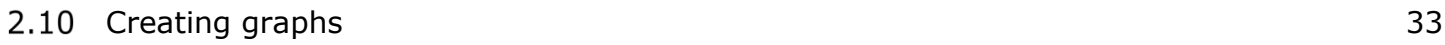

$\begin{array}{ll}2.10 .1 \text { Working with predefined graphs } & 33\end{array}$

$\begin{array}{ll}2.10 .2 \text { Working with user-defined graphs } & 34\end{array}$

$\begin{array}{ll}2.10 .3 T h e & X Y W I N \\ \end{array}$

3 Using FOCUSPEARL for the FOCUS groundwater scenarios 35

3.1 The Wizard for the creation of groundwater assessments $\quad 35$

3.2 Running the model $\quad 39$

$\begin{array}{lll}3.3 & \text { Viewing the results } & 40\end{array}$

4 Using FOCUSPEARL for the EFSA PEC-soil scenarios 445

4.1 The Wizard for the creation of soil exposure assessments in FOCUSPEARL $\quad 45$

\begin{tabular}{ll}
4.2 & Running the model \\
\hline
\end{tabular}

$\begin{array}{lll}4.3 & \text { Viewing the results } & 49\end{array}$

$\begin{array}{lc}\text { References } & 53\end{array}$

$\begin{array}{lr}\text { Justification } & 55\end{array}$ 
Annex 1 The FOCUSPEARL_555 PEARL input file

Annex 2 Description of the weather data file

Annex 3 The format of the PERSAM transfer ( $p t f$ ) file 


\section{Summary}

The FOCUSPEARL version 5.5.5 is presented in this report. PEARL is an acronym of Pesticide Emission Assessment at Regional and Local scales. This version supports the application of the FOCUS Groundwater scenarios and the EFSA Soil exposure scenarios.

The data for the groundwater scenarios are the same as those in FOCUSPEARL v.4.4.4, except that a few data were modified, because the data for these parameters in the database of the previous version were not correct. Other input data were adjusted to bring them in line with the parameterization of the soil exposure scenarios.

This report gives guidance on the use of the new FOCUSPEARL 5.5.5 version. The FOCUSPEARL software package consists of a set of computation kernels, a Graphical User Interface and a database with the scenario data for the FOCUS Groundwater scenarios and those for the EFSA Soil exposure scenarios.

The new version of the database of FOCUSPEARL does no longer contain the data on the physicochemical properties of the compound. Instead, the new FOCUSPEARL version is coupled to the SPIN application to enter, edit or archive all substance data needed for a FOCUSPEARL run. The new version of FOCUSPEARL is coupled with FOCUSSPIN version 3.3 



\section{Samenvatting}

Dit rapport introduceert FOCUSPEARL version 5.5.5. PEARL is een acroniem van Pesticide Emission Assessment at Regional and Local scales. Deze versie ondersteunt de toepassing van de FOCUS Grondwaterscenario's en de EFSA scenario's voor de blootstelling van bodemorganismen.

De gegevens voor de grondwaterscenario's zijn dezelfde als die in FOCUSPEARL v.4.4.4, behalve dat enkele gegevens zijn gewijzigd, aangezien de gegevens voor deze parameters in de vorige versie niet correct waren. Andere invoergegevens zijn gewijzigd om ze op een lijn te krijgen met de parameterisatie van de scenario's voor de blootstelling van bodemorganismen.

Dir rapport biedt ondersteuning voor het gebruik van de nieuwe FOCUSPEARL versie 5.5.5. Het FOCUSPEARL softwarepakket bestaat uit een set rekenmodellen, een gebruikersinterface en een database met de scenariogegevens voor de FOCUS Grondwaterscenario's en die voor de EFSA scenario's voor de blootstelling van bodemorganismen.

De nieuwe versie van de database van FOCUSPEARL bevat niet langer de gegevens over de fysischchemische eigenschappen van de stoffen. In plaats daarvan is de nieuwe versie van FOCUSPEARL gekoppeld aan de SPIN applicatie, waarmee de gegevens voor de stoffen die nodig zijn voor een FOCUSPEARL run ingevoerd, gewijzigd of gearchiveerd kunnen worden. De nieuwe versie van FOCUSPEARL is gekoppeld aan FOCUSSPIN versie 3.3. 



\section{Introduction}

The pesticides used in agriculture are mainly applied to soil-plant systems, e.g. cropped fields. Subsequently, they are subjected to various processes which determine the course of the concentration in the system and the emissions from the soil-plant system to the other environmental compartments. For the evaluation of the risk of leaching to groundwater (as the main source of drinking water) and the exposure of soil organisms to plant protection products pesticide fate models have been developed to support the exposure assessment using the FOCUS scenarios for groundwater (FOCUS, 2000; European Commission, 2014) and the EFSA scenarios for PEC soil (EFSA, 2017).

In the late nineties, the Dutch authorities asked for a model simulating the behaviour of pesticides in soil-plant systems and their emissions from these systems, that could be used as a standard model in pesticide regulation. The new model had to be based on consensus by the most-involved research institutes, i.e. the National Institute for Public Health and the Environment (RIVM, Bilthoven) and Alterra (Wageningen). This new model, i.e. FOCUSPEARL version 1.1.1, was later adopted as one of the models that could be used to evaluate the leaching of plant protection products at the EU level. It consisted of a user-friendly interface, a database containing the data for the FOCUS groundwater scenarios and the SWAP and PEARL model kernels. Since the first release in 2001, updates for FOCUSPEARL have been released, FOCUSPEARL v 2.2.2 in 2003 and FOCUSPEARL v.3.3.3 in 2006. In the subsequent years, the FOCUS groundwater scenarios have been revised and these scenarios have been implemented in FOCUSPEARL v. 4.4.4, which was released in 2011.

During the past years guidance has been developed to assess the exposure of soil organisms (EFSA, 2015, EFSA 2017). The resulting scenarios for the exposure of these organisms, the PEC-Soil scenarios, have been integrated into a new version of FOCUSPEARL, i.e. version 5.5.5. The groundwater scenarios in this version are the same as those in FOCUSPEARL version 4.4.4, except that a few errors have been corrected. These corrections are related to the crop parameterization of onions in the Porto and Thiva scenarios. Further, the irrigation option for permanent crops in the groundwater scenarios has been changed from "Sprinkler_Weekly" to "Surface_Weekly" to bring them in line with the irrigation option for these crops in the soil exposure scenarios.

The current document gives a description of the new version of FOCUSPEARL 5.5.5 and provides guidance to the user how to perform calculations for the assessment of the leaching to groundwater and the exposure of soil organisms. The new version of the FOCUSPEARL database does no longer contain the data on the physico-chemical properties of the compound. Instead, the new FOCUSPEARL version is coupled to SPIN (Substance PlugIN) version 3.3 to enter, edit or archive all substance data needed for a FOCUSPEARL assessment. More information on the SPIN application and as well as guidance to derive values for substance input parameters can be found in the SPIN Manual (2020).

The manual consists of three parts. In Chapter 2, the Graphical User Interface is described with reference to the input parameters in the PEARL input file. The Graphical User Interface gives easy access to the most important components of FOCUSPEARL, such as the generation of input files, model execution, output processing and generation of the most important output maps and tables. In Chapter 3 the use of the FOCUS Groundwater scenarios is explained and in Chapter 4 the use of the EFSA soil exposure scenarios. Most users will use only the Wizard functionality to perform assessments of the leaching to groundwater and the exposure of soil organisms.

\subsection{Release versions of FOCUSPEARL}

The FOCUSPEARL versions can be downloaded from the FOCUS DG SANTE website of the Joint Research Centre in Ispra (Italy) via https://esdac.jrc.ec.europa.eu/projects/pearl. The FOCUS DG SANTE website is the one and only definitive source of the currently approved version of the FOCUS 
scenarios and associated models and input files. On the download tab the latest version of the FOCUS PEARL model as well as older versions of the model can be downloaded.

\subsection{Compatibility}

FOCUSPEARL version 5.5.5 is not compatible with previous versions of FOCUSPEARL, since the substance related data have been taken out from the database and transferred to a separate application SPIN, that has to be used to enter, edit and archive properties of the substances for which the FOCUSPEARL model is to be applied.

To import data on substances as defined in FOCUSPEARL 4.4.4 into the SPIN database version 3.3, a separate application has been developed. This application and a document containing instructions how to use it can be downloaded from the FOCUSPEARL website.

FOCUSPEARL version 5.5.5 has been tested on Windows 764 bits and Windows 1064 bits platforms. The new version supports the use of multiple cores to execute the assessments. Before the start of FOCUSPEARL runs, the interface checks how many cores are available and keeps one available for other processes on the computer. All other cores can be used for the distribution of the PEARL model runs of the assessment. 


\section{Introduction to the FOCUSPEARL User Interface}

This chapter gives an overview of the FOCUSPEARL user interface, which is an integrated environment for data storage and data retrieval, model control and viewing the output data (Figure 2.1). Basically, the user can access the system through the user interface. The user interface is linked with a relational database for easy data access. The user interface generates the input files for the PEARL model and calls the model. Summary outputs are transferred back to the FOCUSPEARL database where they can be accessed. More comprehensive model outputs (particularly time-series) can be viewed with a separate graphical program, XYWIN.

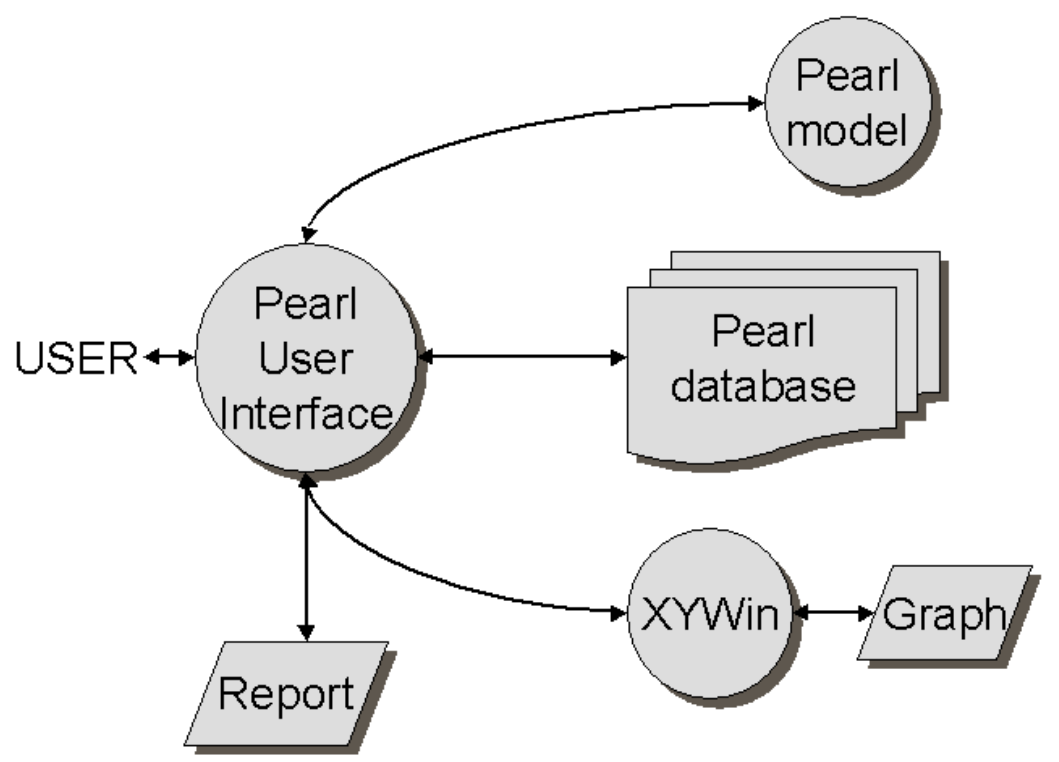

Figure 2.1 Overview of the FOCUSPEARL modelling system.

The FOCUSPEARL User Interface makes it easy to:

- organize and edit additional data in the FOCUSPEARL database

- import weather data in the FOCUSPEARL database

- access the scenarios for groundwater and soil organisms

- select one or more model-runs for execution

- perform one or several model runs

- display summary reports containing annual water and mass balance and the target output of the run, either the $80^{\text {th }}$ percentile of the leaching concentration in soil or one of the required concentrations in the soil or in the pore water.

- display model results graphically

- import graphs in Word processor files, using e.g. enhanced Windows metafile format (.emf).

\subsection{Overview of the FOCUSPEARL database}

As described in Chapter 1, the model will primarily be used in combination with the groundwater or soil exposure scenarios. The groundwater scenarios have been developed for 9 locations and approximately 14 crops per location (FOCUS, 2000; European Commission, 2014). The soil exposure scenarios have been developed for the EU regulatory zones (North, Central and South) for either the total content of the ecotoxicological relevant layer or the pore water concentration in this layer (EFSA, 2017). 
The large number of scenarios and model inputs required for one model run leads to a large amount of data. It is clear that organization of all the data is important to i) establish a hierarchy, (ii) minimize data redundancy, and (iii) optimize the data accessibility. An efficient way of handling the data is to use a relational database.

Figure 2.2 shows the hierarchy within the FOCUSPEARL database. The highest level of the database (level 1 ) is the project level. Here, the user can group several model runs, based on a common criterion (e.g. all model runs for one single field-study or all model runs for one single pesticide). The second level is the model run level. Parameters needed to perform a model run are scenario data, pesticide data, the annual application schedule and the model controls, such as the begin and end time of the simulation. These three major building blocks of a model run are stored at level 3.

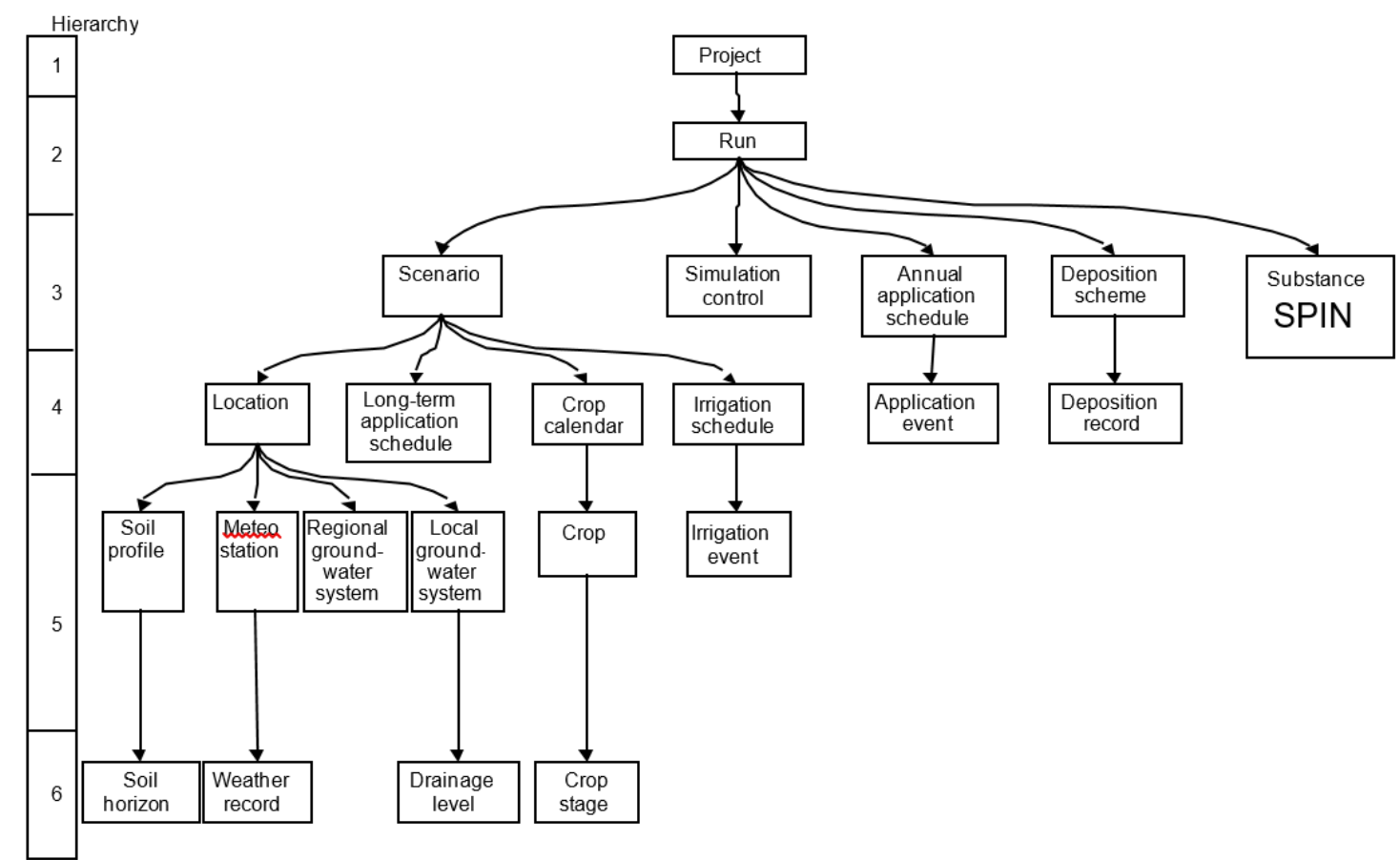

Figure 2.2 Overview of the FOCUSPEARL database.

The left hand side of the diagram shows the building blocks of the FOCUS scenarios. These scenarios are a combination of crop, location, the long-term application schedule (i.e. annual, biennial or triennial applications) and agronomic parameters (particularly irrigation data) to be used in the simulation. Parameters referring to a location can be further classified into soil parameters, weather data, parameters describing the regional groundwater system (i.e. the lower boundary of the hydrological model) and parameters describing the local groundwater system (i.e. water flow to ditches and field drains). Note that in the PEARL context, the crop calendar does not relate to a location. Instead, it is one of the building blocks of a scenario, which is at a higher hierarchical level. As shown in the figure, the crop calendar relates to individual crops. The crop calendar may refer to one single crop (monoculture) or several crops. At the lowest hierarchical level are the basic data, relating to a single crop stage, a single soil horizon, etc.

The right hand side of the diagram contains the pesticide data, not including application schedules. The pesticide entry is only used to refer to the name of the compound that has been applied (the parent compound), the actual data are entered in the SPIN database. Using SPIN, the compound data are entered into tables containing data on general compounds properties, sorption parameters, diffusion parameters and crop interaction parameters. For a compound with one or more metabolites, the data on the transformation scheme are also entered and stored in SPIN. More details on the use of SPIN are given in the SPIN manual (Van Kraalingen et al., 2020). It should be noted that when 
starting SPIN by clicking the Substance button in FOCUSPEARL 5.5.5, only substance data required for runs using FOCUSPEARL need to be entered.

The application schedule and pesticide deposition data are both pesticide and location dependent. This table relates to the table describing the individual application events, which contains information about such parameters as dosage, application mode, application date, etc. As the annual application schedule cannot be directly linked with the pesticide or location tables, they are directly linked with a model run (level 2). The long-term application schedule (i.e. whether a pesticide is applied annually, biennially or triennially) is part of a scenario (FOCUS, 2000; European Commission, 2014).

All other parameters can be accessed through the 'simulation and output control' entries. Here parameters are listed such as start-time of the simulation, minimum time-step, output options, etc.

\subsection{Overview of the user interface}

After installation of FOCUSPEARL 5.5.5 and the required substance application FOCUSSPIN 3.3, FOCUSPEARL can be started by clicking on the FOCUSPEARL 5.5.5 icon on the desktop or laptop or select the FOCUSPEARL program using the search function for programs or apps. The main screen as presented in Figure 2.3 is shown on the screen.

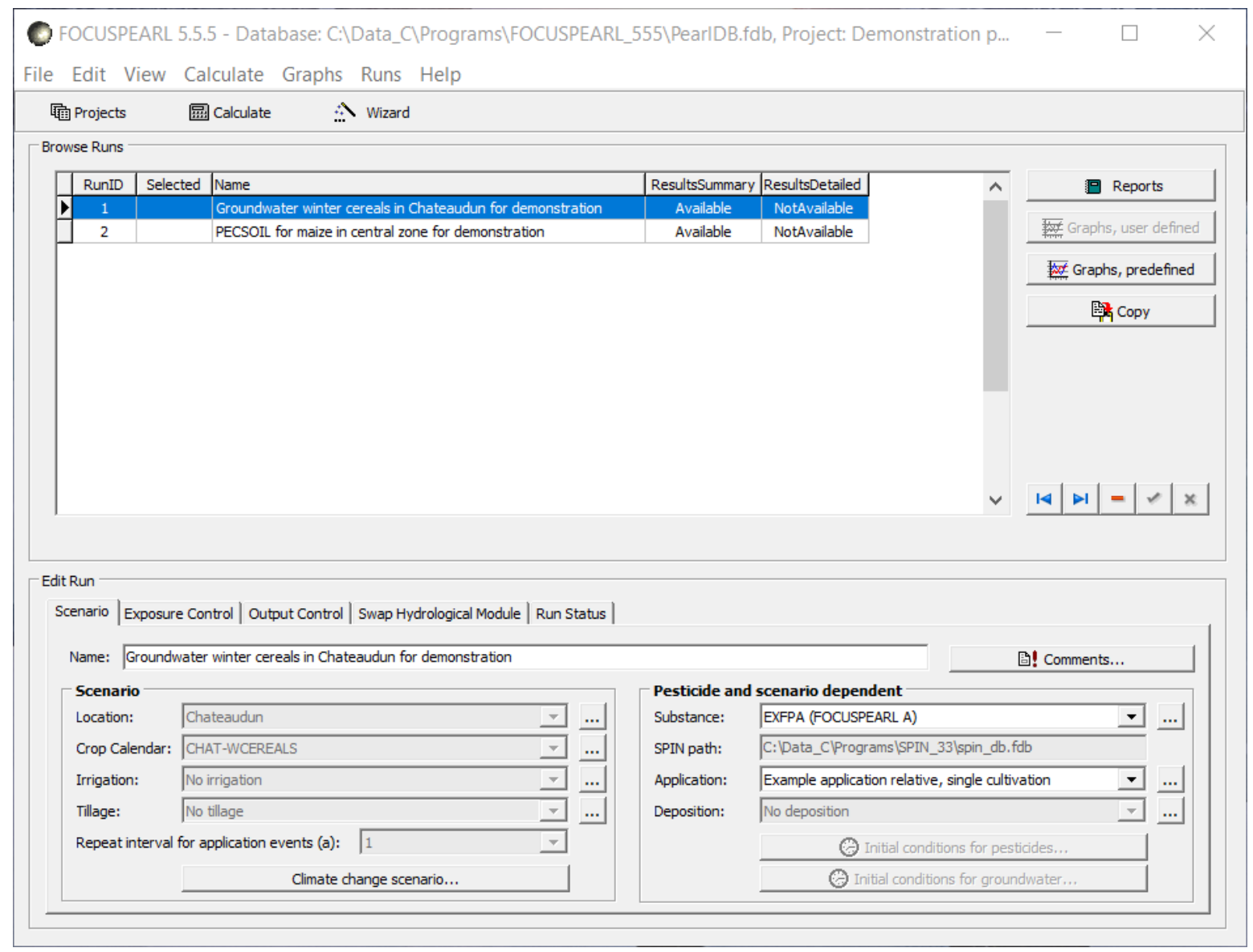

Figure 2.3 Main screen of FOCUSPEARL 5.5.5.

On top of the main screen three buttons are shown, the 'Projects', 'Calculate' and 'Wizard' buttons. The 'Projects' button is to allow the user to open the Projects form. On this form the user can add or edit projects. An appropriate description can be added in the 'Description' field of the edit section of the Project form. Additional information can be entered after clicking on the 'Comments' button.

The Calculate button is necessary to start the runs of the project shown that have been selected for execution. The Wizard button has been added to make it easy the user to generate the runs required 
using the groundwater or soil exposure scenarios. The use of the Wizard is explained in more detail in Chapter 3 for the Groundwater scenarios and in Chapter 4 for the soil exposure scenarios.

The browse section of the main screen allows the user to scroll through the records of a table (in this case runs). Please note that the information in the edit part changes when scrolling. At the bottom section of the BROWSE part a navigator bar is shown with the following buttons:

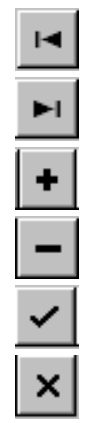

Go to the first record in the table

Go to the last record in the table

Add a new (empty) record

Delete a record

Confirm changes ('post edit')

Cancel changes

It should be noted that no ' + ' button is included on the navigator bar to add a run, because the Wizard function has been implemented to add runs.

In the edit section of the main screen the elements describing the run are shown. These are:

- Location

- Crop calendar

- Irrigation

- Tillage

- Substance

- Application

- Deposition

For each of these elements a button $\ldots$ is shown. After clicking on this button the form is shown for this element. These forms are presented in the next section. The main menu can be used for quick access to various parts of the FOCUSPEARL user interface:

- Use File-Exit (ALT-F-X) to quit the application.

- Use the Edit menu (ALT-E) to directly access a table in the database. As an example, use EditSubstances or ALT-E-S to jump to the substances form.

- Use the View menu (ALT-V) to view the PEARL input and output files.

- Use the Calculate menu (ALT-C) to execute selected runs.

- Use the Graph menu (ALT-G) to jump to the graphs section.

- Use the Help menu (ALT-H) to access the help file.

The edit section of the main screen consists of five tabs, i.e. the Scenario tab, the Exposure Control tab, The Output Control tab, the Swap Hydrological Module tab, and the Run Status tab. In the next sections, the labels mentioned between brackets refer to the labels as used in the PEARL input file. A detailed description of all input parameters for the PEARL model is presented in Annex 1.

\section{Scenario tab}

On this tab, the user has to select the major building blocks of a scenario, i.e. the location, the crop calendar, the irrigation scheme, the (parent) pesticide (substance), the application scheme and the deposition table. The application scheme gives access to tables of application dates. Also the repeat interval of applications (in years) must be specified (DelTimEvt). If set to 2, for example, biennial applications are simulated. If set to NoRepeat, the application table will not be repeated. The initial conditions of pesticide in the equilibrium domain (ConSysEql) and the non-equilibrium domain of the soil system (ConSysNeq) can be specified in the initial conditions form, which is accessible by clicking on the 'initial conditions button'.

It should be noted that only building blocks available in the database can be selected. Therefore, it may be necessary to add new crops, locations, etc to the database before proceeding. This can be done by clicking on the button to the right of the pick lists to go to a lower hierarchical level. It is also 
possible to use the Edit menu of the main menu or use key shortcuts (e.g. ALT-E-c to go directly to the crop calendar).

\section{Exposure Control tab}

This section contains general options for the simulation run. The time-domain for the simulation is specified in the Start and Stop date fields (TimStart and TimEnd). The date-format specified at page can be used. Please note that the time-domain is fixed if a FOCUS scenario has been selected.

According to guidelines of FOCUS (2000) a FOCUS run should start at 1-Jan-1901. The length of the run is set at 26 years in case of annual applications, 46 years in case of biennial applications and 66 years in case of triennial applications.

\section{The Output Control tab}

This section contains items that need to be specified in order to obtain the output in the required format. For the format of the time column of the PEARL output file the following options are offered:

- Number of days since the start of the simulation

- Number of days since 1900

- Years

Using the Print method option the available options for the time interval for the output are: Year, Month, Decade, Day, Hour, Other. If 'Other' is selected the user can specify the print interval in days in the box next to the Print Method option.

For the soil exposure scenarios the top and bottom boundary of the soil layer for the ecotoxicological assessment have to be specified. Other output options are 'Detailed output' and 'Output cumulatives'. If the checkbox for detailed output is selected, then output will be written to the .out file using the file format specification selected on this tab. By default the option for 'Output cumulative' is switched on, which means that amounts of the substance transformed, leached, etc. are reported in the .out file as cumulative amounts. If this checkbox has not been selected, then the amounts relate to the print interval. For example, mass or volume fluxes on a daily basis will be written to the .out file if the print method selected is 'Day'.

\section{The Swap Hydrological Module tab}

For runs created with the Wizard for the groundwater runs or the soil exposure runs, only one option can be changed: Option Hydrology. The hydrology option (OptHyd) defines how SWAP is run. The following options are available:

- $\quad$ Run SWAP if there is no existing SWAP output. This option saves computation time.

- $\quad$ Creates input for SWAP only.

- $\quad$ Assumes that SWAP has already been run; a bfo file must be provided.

- $\quad$ Runs SWAP and then PEARL. SWAP will always be run.

- $\quad$ Runs SWAP only (output in PEARL format). This option is interesting when testing or calibrating the hydrological model, without (yet) running the pesticide part.

For runs generated by the use of the Wizard button, other items in this section have been greyed out because default values are used for the groundwater and soil exposure scenarios. The minimum and maximum time-steps in the hydrological model swap (DelTimSwaMin and DelTimSwaMax). These variables determine the minimum and maximum time-steps in the swap model. The model will look for the optimal time step between the pre-set limits. Making the time-step too large could lead to instability, while making it too small will increase the computation time substantially. The tolerance of the iteration procedure (ThetaTol) defines the accuracy of the simulations. Choosing a too large value could introduce a numerical water balance error. The initial groundwater level (GrwLevIni) is also specified in this tab, because it is dependent on the start time of the simulation. It should be noted that other input parameters for SWAP are included in several other forms, such as the 'Soil Profiles' form (see Section 2.3.2).

The Run Status tab

On the 'Run Status' tab information is given on the characteristics and the status of the Run. The RunID is listed and what the status of the Summary and Detailed results is: 'Available' or 'NotAvailable'. The creation and modification dates of the run are also presented on this tab. 


\subsection{Editing locations}

After clicking on one of the $\ldots$ buttons next to the run elements on the 'Scenario' tab in the 'Edit run' section of the main screen, a form with detailed data on the specifications for this element is shown.

In the edit section of the form there are three categories of data fields:

- ordinary data fields, where a text string, a date string or numerical data can be entered. The PEARL user interface will perform range checking after the data have been entered.

- $\quad$ option fields or pick lists, where a choice can be made between a number of options. The button to the right of a pick list allows to edit the underlying tables (i.e. go to a lower hierarchical level).

- $\quad$ check boxes, where variables can be switched on or off.

Most forms are complemented with a comments button, which allows to add additional information or meta-data if needed.

\subsubsection{The Locations form}

After clicking on the $\ldots$ button on the right-hand side of the Location box on the main screen, the form presented in Figure 2.4 is shown. In the upper section of this form all the available locations in the FOCUSPEARL 5.5.5 database are listed. Upon selection of one of these locations, the data on this location are shown in the 'Edit Location' section of this form.

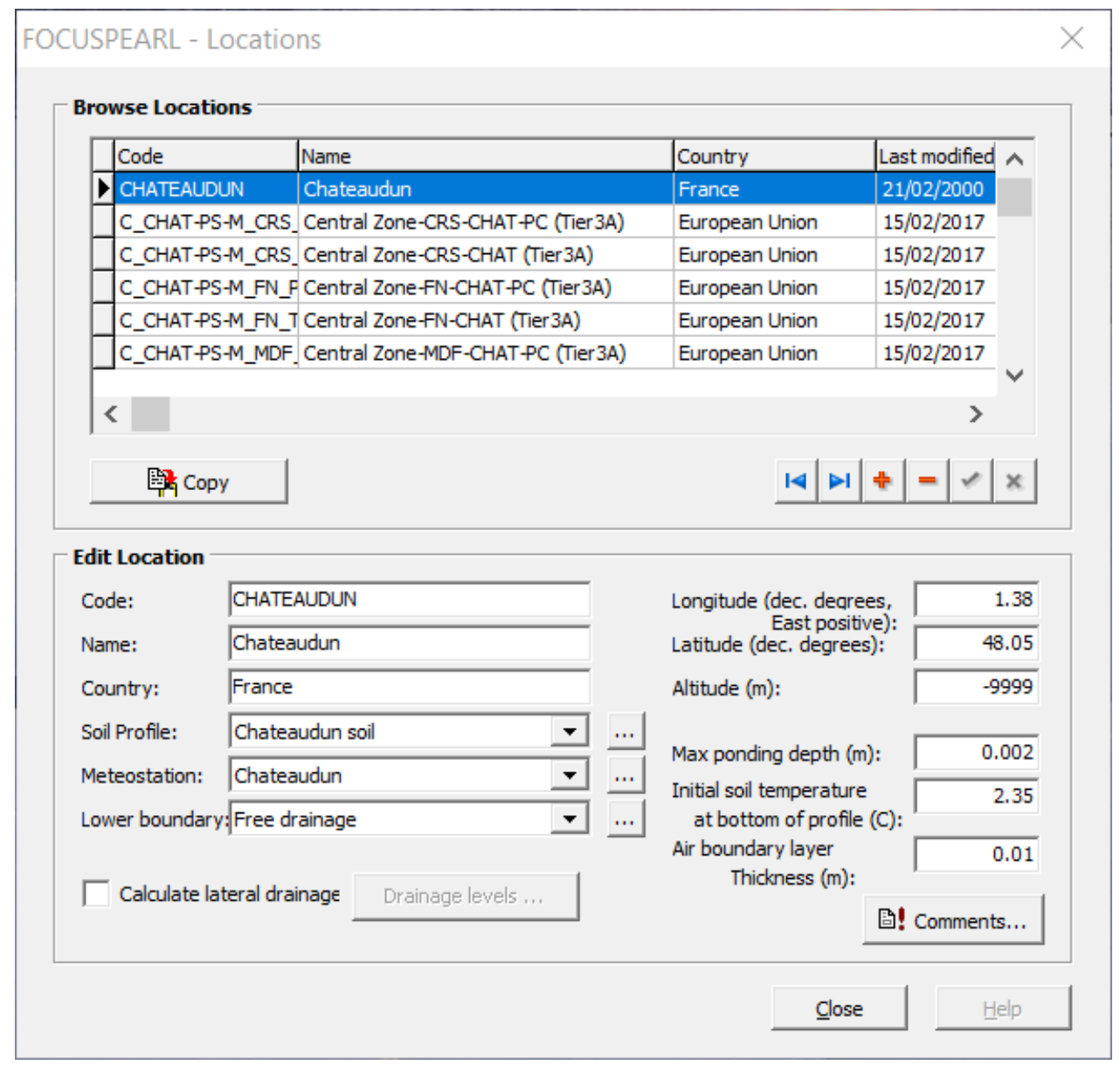

Figure 2.4 The Locations form.

In the 'Edit Location' section of this form general information on the site is given, such as the name and the altitude. The locations form can be accessed from the scenario tab of the main form, but the user can also use the edit menu of the main form. In the 'Edit Location' part a soil type and a weather station have to be selected. Please note that only one of the available soil types or weather station can 
be selected. To select a new soil type or weather station, a new soil type or weather station need to be created first on the 'Soil Profiles' form or the 'Meteo Stations' form, respectively.

From the Locations form the user has access to data that are usually spatially distributed, such as soil data, weather data and information about the local and regional groundwater system. Exceptions are the crop calendar and the irrigation schedules, which are at higher hierarchical levels according to definitions by the FOCUS (2000).

An option for the lower boundary condition of the hydrological model must be selected in the Lower Boundary Condition pick list (OptLbo). SWAP offers eight options for the lower boundary condition. For several of these conditions parameter values must be introduced in the lower boundary conditions form, which can be opened by clicking on the $\cdots$ button. On this form the option is given to include drainage by selecting the 'Calculate Lateral Drainage' checkbox (OptDra). Then the 'Drainage Levels' button can be used to get access to the form with the data needed for different drainage levels. For FOCUS groundwater and EFSA PEC Soil runs no drainage is considered. Therefore, the 'Calculate Lateral Drainage' checkbox is not selected and it cannot be changed by the user.

On the Locations form itself, the user must specify a unique code for the location, the location name and the country name. The altitude (Alt), longitude and latitude (Lat) are also required. Positive numbers refer to locations in the Eastern and Northern Hemispheres, respectively. The initial soil temperature $\left({ }^{\circ} \mathrm{C}\right)$, which is used to initialize the soil heat flux submodel must also be specified here. Further, the maximum ponding layer depth (ZPndMax) must be specified, which determines the maximum thickness of the water layer that can be present on the soil profile before surface runoff starts. The thickness of the air boundary layer must be specified in the ThiAirBouLay record. This parameter is relevant for the calculation of surface volatilization of pesticides. 


\subsubsection{The Soil Profiles form}

The Soil Profiles form consists of two parts as is shown in Figure 2.5. The 'Edit Soil profile' section of this form contains parameters that apply to the soil as a whole, whereas in the 'Edit Horizon in Soil' section the user can introduce properties of individual soil horizons.

\section{FOCUSPEARL - Soil Profiles}

Browse Soil Profiles

\begin{tabular}{|c|c|c|c|c|c|c|c|c|}
\hline Code & Name & $\wedge$ & & & & & & \\
\hline HAMB-S & Hamburg soil & \multirow[b]{4}{*}{$\checkmark$} & \multirow{2}{*}{\multicolumn{6}{|c|}{ 剭 Copy }} \\
\hline JOKI-S & Jokioinen soil & & & & & & & \\
\hline KREM-S & Kremsmuenster soil & & & & & & & \\
\hline MD-S & Medium texture & & 14 & $\triangleright 1$ & t & $=$ & $\checkmark$ & $\mathbf{x}$ \\
\hline
\end{tabular}

\section{Edit Soil Profile}

Code:

Name:

$$
\text { HAMB-S }
$$

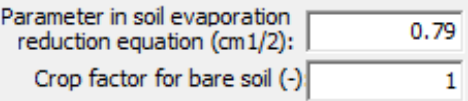

Parameter in soil evaporation reduction equation $(\mathrm{cm} 1 / 2)$ : 0.79

Crop factor for bare soil $(-)$ 1

\begin{tabular}{c|l|l|l|l}
$\begin{array}{c}\text { Relative diffusion } \\
\text { coefficient: }\end{array}$ & Millington Quirk & ... Comments...
\end{tabular}

Bulk density option: Input

Browse Horizons in Soil Profiles

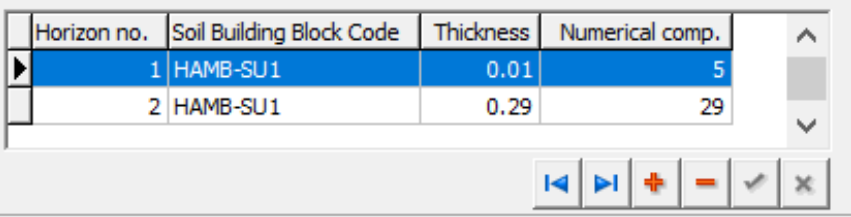

- Edit Horizon in Soil

Horizon number:

Soil Buildina Block code:

\begin{tabular}{|l|}
\hline HAMB-SU1 \\
\hline 圆! Comments... \\
\hline
\end{tabular}

$\ldots$

\section{Thickness of}

No. of numerical comp.: Dispersion length $(\mathrm{m})$ :
Non Default Factors for Depth Effect

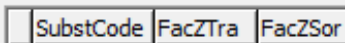

V

V

Edit...

Default Factors for the Effect of Depth

On Transformation (-):

On Sorption (-):
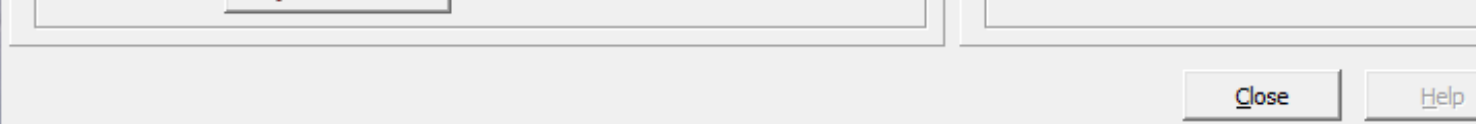

Figure 2.5 The Soil Profiles form.

In the 'Edit soil profile' section of the soil profiles form, the user must specify parameters that apply to the soil profile as a whole. First, specify a unique code and a name for the soil profile.

In the relative diffusion pick list, one of the functions for the calculation of the relative diffusion coefficient (OptCofDifRel) must be chosen. Three options are offered, i.e. the functions published by Millington and Quirk (1960), Currie (1960) and Troeh et al (1982). The actual parameters of these functions must be introduced in the 'relative diffusion function', which is accessible with the button to the right of the relative diffusion pick list. More information on the parameterization of the relative diffusion function is presented in Van den Berg et al. (2016).

The actual soil evaporation rate is calculated using hydraulic properties and an empirical reduction function. Parameter $\beta$ of the Boesten relationship must be provided in the CofRedEvp field The potential evaporation calculated corrected by a factor FacEvpSol, see Boesten and Stroosnijder (1986) for more details. This is particularly important in the case of a small soil cover fraction, because this equation has been derived for situations where the canopy shades the ground. FacEvpSol can be given a value between 0.5 and 1.5 .

If the bulk density is unknown, it can be calculated by the model. In this case, the bulk density option (OptRho) should be set to calculate. See Bollen et al. (1995) for details on the pedotransfer function used. If observed values on the bulk density are available, then these values can be introduced.

In Edit Horizon in Soil part the user has to specify the vertical discretization of the soil profile (i.e. the SoilProfile table). Soil horizons can be added by using the ' + ' button of the navigator. 
The user must specify the thickness of each soil horizon and the number of compartments used in the finite-difference scheme. For each horizon, the user must also specify a soil building block, which contains information on basic soil properties and hydraulic properties. If the appropriate soil building block is not yet available, then this soil building blocks form has to be entered before editing the soil profile. The number of soil compartments is a compromise between accuracy and computation time. Computation time increases approximately with the square of the number of soil layers. On the other hand, predictions may become inaccurate if the layer thickness is taken too large. This is particularly true if the expected concentration in the groundwater is lower than $0.001 \mu \mathrm{g} \mathrm{L}^{-1}$ (Van den Berg et al., 2016). A layer thickness ranging from $1.0 \mathrm{~cm}$ in the top $30 \mathrm{~cm}$ up to $10 \mathrm{~cm}$ in the layer below $1 \mathrm{~m}$ may be a fair compromise.

The dispersion length, Ldis (LenDisLiq) is entered directly in the soils screen (and not in the soil horizon screen), because it is considered a soil property that is not coupled to generic soil horizons. Please note that the distance between the nodal points, $\Delta z$, should be small enough (see Van den Berg et al. 2016, Chapter 11).

Factors for the effect of depth on transformation (FacZTra) and sorption (FacZSor) are also specified in the soil screen. The factor for the effect of depth on sorption is only relevant if the option for the calculation of Freundlich equilibrium sorption in the substance screen is set to CofFre. This factor must be 1.0 for the top-soil.

\subsubsection{The Soil Building Blocks form}

For each soil building block, the basic soil properties (oilProperties) and soil physical parameters have to be specified.

In the upper section of the form as shown in Figure 2.6, the textural distribution (FraSand, FraSilt and

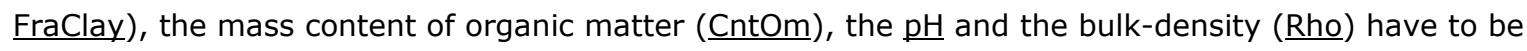
specified. Note that the textural distribution refers to the mineral part of the soil only, so the sum of the sand, silt and clay fractions should be equal to 1.0. The mass content of organic matter refers to dry soil. The $p \mathrm{H}$ is used for the sorption model of weak acids. As most sorption experiments are being carried out in $0.01 \mathrm{M} \mathrm{CaCl}_{2}$, the $\mathrm{pH}-\mathrm{CaCl}_{2}$ is preferred. If the $\mathrm{pH}-\mathrm{CaCl}_{2}$ is not available, the pHCorrection variable in the substance screen should no be equal to zero. On the form itself ' $\mathrm{pH}-\mathrm{H}_{2} \mathrm{O}$ ' is listed, but there is no requirement that only $\mathrm{pH}-\mathrm{H}_{2} \mathrm{O}$ values can be entered. The bulk density is only required if the option for the calculation of the bulk density in the soils screen has been set to 'Input'. 


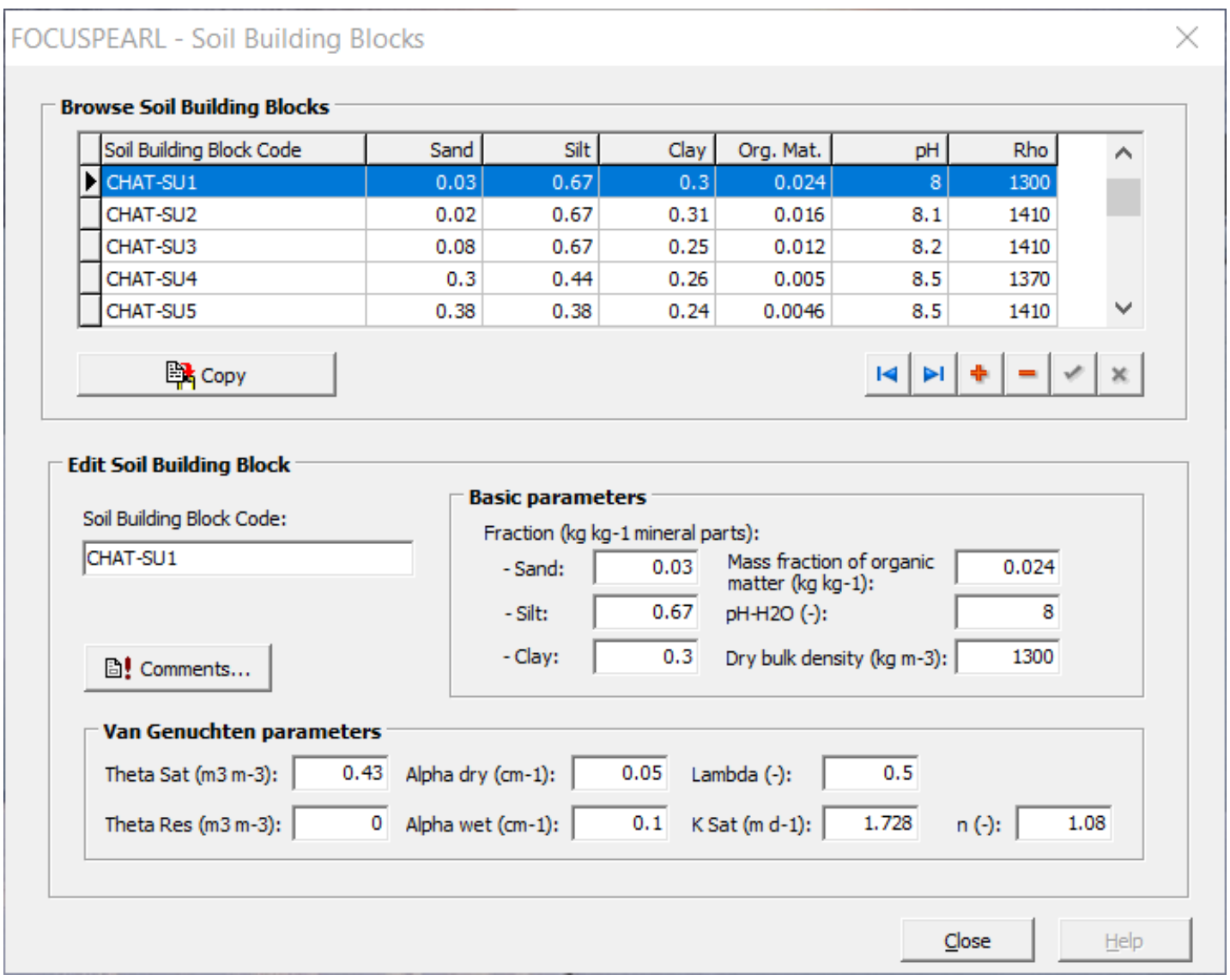

Figure 2.6 The Soil Building Blocks form.

In the lower half of the form, the user has to introduce the parameters of the Mualem-Van Genuchten functions. Values on $\theta_{s}$ (ThetaSat, $\theta_{r}$ (ThetaRes), a (lplphaDry and AlphaWet), $n(\underline{\mathrm{n}}), K_{s}$ ( $\left.\underline{\text { KSat }}\right)$ and $\lambda$ (I) need to be introduced. The parameter AlphaWet is only relevant if the option to take hysteresis into account has been selected.

\subsubsection{The Meteo Stations form}

The Meteo Stations form is shown in Figure 2.7. The user has to specify information about the weather station. First, the user must specify a unique code for the weather station (MeteoStation). Please note that this code may not exceed eight characters. The altitude (Alt), longitude and latitude (Lat) are also required.

The potential evapotranspiration can be obtained in different ways. The user must specify one of the available methods in the evaporation options field (OptEvp). Three options are available: (i) the potential evapotranspiration is input by the model, (ii) the Penman-Monteith equation is used, and (iii) the Makkink equation is used. If Penman-Monteith is selected, solar radiation, minimum and maximum air temperature, air humidity, wind speed and precipitation are required. If Makkink is selected, only minimum and maximum air temperature, solar radiation and precipitation are necessary.

Weather data from other weather stations can be imported into the FOCUSPEARL database. Before starting the import of the weather data, the meteo station code as specified in this file should already be available in the list of Meteo stations. The format of the file with weather data is described in Annex 2. 


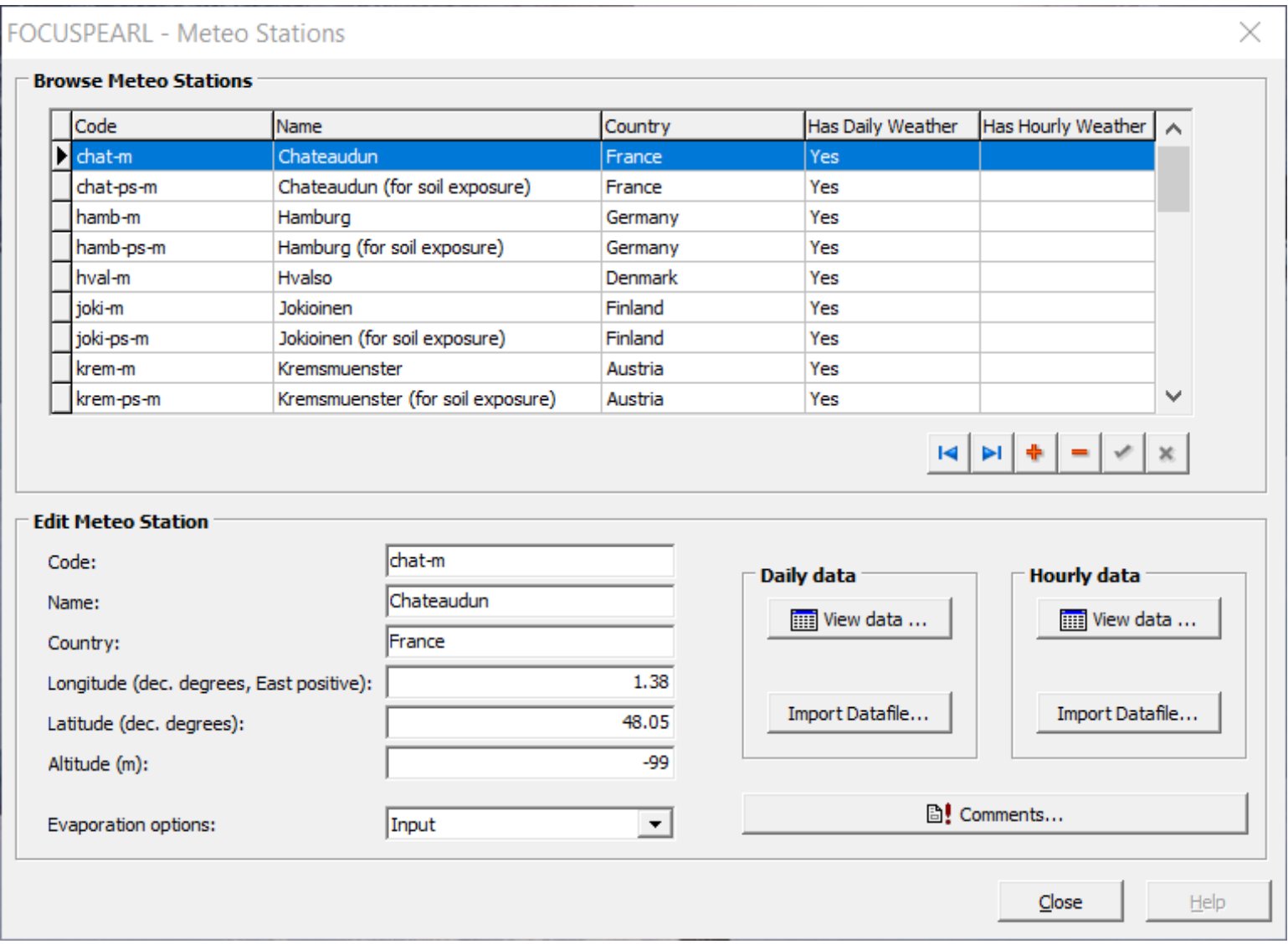

Figure 2.7 The Meteo Stations form.

\subsubsection{Boundary conditions of the hydrological model}

SWAP makes a distinction between the seepage flux due to regional groundwater flow and the local drainage flux to ditches and field drains. The seepage flux due to regional groundwater flow is the lower boundary condition of the model, and must be defined in the lower boundary conditions form, the local drainage flux is considered a sink term and must be defined in the drainage levels form.

The SWAP model offers eight options for the lower boundary condition, which must be specified in the locations form. Most options require additional input, which must be specified in the lower boundary conditions form. Depending on the option chosen, only the relevant tab is shown. Data fields on other tabs may be edited, but only the data on the option selected are used in the simulation.

If the lower boundary condition is set to 'time dependent groundwater level', the groundwater level must be specified as a function of time (table GrwLev). Normal data-format can be used.

If the lower boundary condition is set to 'flux boundary condition', a sine function is applied to generate the daily regional bottom flux. The user should specify the mean (FlvLiqLboAvg) and amplitude (FlvLiqLboAmp) of the annual bottom flux. Also the date at which the maximum of the sine wave occurs should be given (DayFlvLiqLboMax). Note that negative values denote downward fluxes and positive fluxes denote upward values.

If the lower boundary condition is set to 'flux from deep aquifer', the regional bottom flux is calculated using the head difference between the phreatic groundwater and the groundwater in the semiconfining aquifer. The average groundwater level in the field, $\Phi_{a v g}$, is affected by the drainage base (HeaDraBase) and by the shape of the groundwater table (OptShapeGrwLev), which can be Elliptic, Parabolic, Sinusoidal or NoDrains. The daily value of the hydraulic head in the semi-confining aquifer, $\Phi_{a q f}$ is described by a sine-wave. Then its annual average value (HeaAqfAvg, the amplitude ( HeaAqfAmp) and the date at which the maximum hydraulic head occurs (TimHeaAqfMax) must be specified. The bottom flux eqn. is also affected by the vertical resistance of the aquitard (RstAqt, Yaqt). See Kroes et al. (2008) for more details. 
If the lower boundary condition is set to 'groundwater-level-drainage relationship', the bottom flux is calculated as a function of the groundwater level. If this option is chosen, the model needs the coefficient ( CofFncGrwLev) and the exponent (ExpFncGrwLev). Please realize that this option is only valid for deep, sandy areas. The calculated bottom flux includes local drainage to surface waters and drains, so local drainage should be set to zero if this option is used.

If the lower boundary condition is set to pressure head boundary condition, the pressure head at the lower boundary should be specified in $\mathrm{cm}$ as a function of time (table $\underline{\mathrm{h}}$ ). Normal date format can be used (dd/mm/yyyy).

The FreeDrain, Lysimeter and ZeroFlux options do not require additional input.

If the lower boundary condition of the hydrological model is set to 'groundwater level as a function of time', 'flux boundary condition', 'flux from deep aquifer', 'pressure head boundary condition', or 'zero flux', a local drainage flux can be defined in addition to the regional seepage flux. First check the 'calculate local drainage' box, then enter the 'drainage levels screen'. Use the ' + ' sign of the navigator to add drainage levels. Up to five local drainage level systems can be specified.

For each local drainage system, a drainage flux is calculated. The model needs information about the bottom of the drainage system (ZDra) and the drainage resistance (RstDra). The procedure that distributes the drainage flux over the individual soil layers additionally requires information about the drainage type (DraTyp) and the distance between the drainage systems (DistDra). The user should also specify whether the local drainage system is a field-drain or an open channel.

\subsection{Editing crop calendars}

From the crop calendar form the user can access the data on the crop rotation, parameter values for individual crops and crop stages. The crop calendar is accessed directly from the scenario screen, because it is one of the main building blocks of a FOCUS scenario (FOCUS, 2000). PEARL uses a simple crop growth model, i.e. relevant crop parameters such as the Leaf Area Index and rooting depth have to be provided as a function of development stage (see below).

\subsubsection{The Crop Calendar form}

The definition of the crop calendar (table Crops) starts in the Crop Calendar form, which is accessible from the scenario tab of the main form. This form is presented in Figure 2.8. The crop calendar should be given a unique code and a name. It is very important to specify whether the same crop calendar must apply to all years (option RepeatCrops) or whether separate crop calendars are used for individual years.

The course of development stage with time can be defined by selecting 'Fixed' for the option OptLenCrp or it can be controlled by the temperature sum by setting the option OptLenCrp to 'Variable'. The advantage of defining the crop development stage dependent on the temperature sum is that regional differentiation of crop growth can be made on the basis of air temperature.

Crops can be added to the crop calendar in the browse crops section by clicking on the ' + ' button of the navigator. It may be necessary to add a new crop before proceeding. In this case, first go to the crops screen (see below). The emergence date (this is later than the date of seeding) and the harvest date are defined directly in the crop calendar page, all other crop parameters are entered on the 'Crops' form. Please note that a single crop can occur several times in the crop calendar, but a single crop is linked to one crop development stage table (see below). If the crop has different development stages over the years, a unique crop name must be specified for each year, e.g. Maize01, Maize02, etc. During periods that no crop is present, the model will use parameter values for bare soil. 


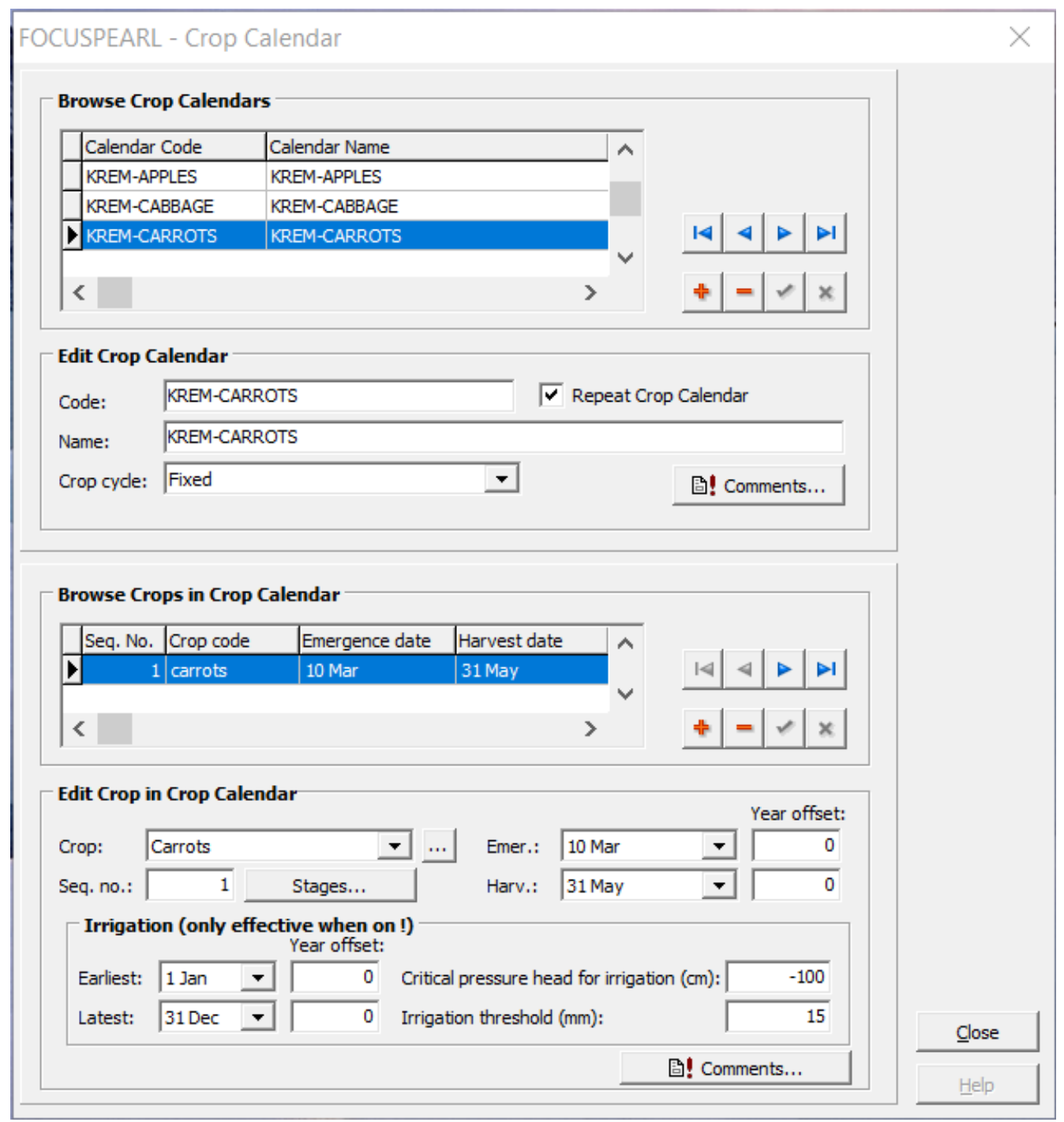

Figure 2.8 The Crop Calendar form.

\subsubsection{The crops and crop stage form}

The Crops form can be accessed using the $\ldots$ button next to the crop pick list, in the Crop calendar form (see above). In the Crops form, all time-independent crop properties are input, as shown in Figure 2.9. Dynamic crop properties are input in the crop stages form.

The user must enter the pressure heads defining the root water extraction function: $\underline{\mathrm{HLim} 1}$ is the anaerobiosis point, $\underline{\text { HLim2 }}$ is the reduction point at near-saturation, $\underline{\text { HLim } 3 \mathrm{U}}$ is the reduction point at dry conditions and at low evaporative demand, HLim3L is the reduction point at dry conditions and at high evaporative demand, and HLim4 is the wilting point (see Feddes et al. 1978). If these values are available for $p \mathrm{~F}$ values instead of pressure heads, they should be converted according to the $h=-10^{p F}$.

If the Penman-Monteith equation is used for the calculation of potential evapotranspiration, SWAP additionally requires the minimum canopy resistance. The minimum canopy resistance ranges from $30 \mathrm{~s} \mathrm{~m}^{-1}$ for arable crops to $150 \mathrm{~s} \mathrm{~m}^{-1}$ for trees in forests. See Allen et al. (1989) for parameter values.

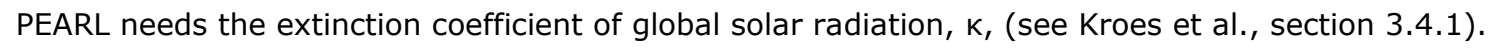
Parameter values for some common crops can be found in section The interception coefficient CofIntCrp controls the amount of interception of water by the crop canopy. In case of ordinary agricultural crops, this interception coefficient may be set to 0.025, see section 3.2.1 in Kroes et al. (2008). If set to zero, no interception will be calculated (in fact PEARL will write a very small value to the SWAP input file for the crop to prevent division by zero). Please note that at high precipitation rates, the interception rate asymptotically reaches a value of a.LAI (Eqn 2.52 in Kroes et al., 2008). 


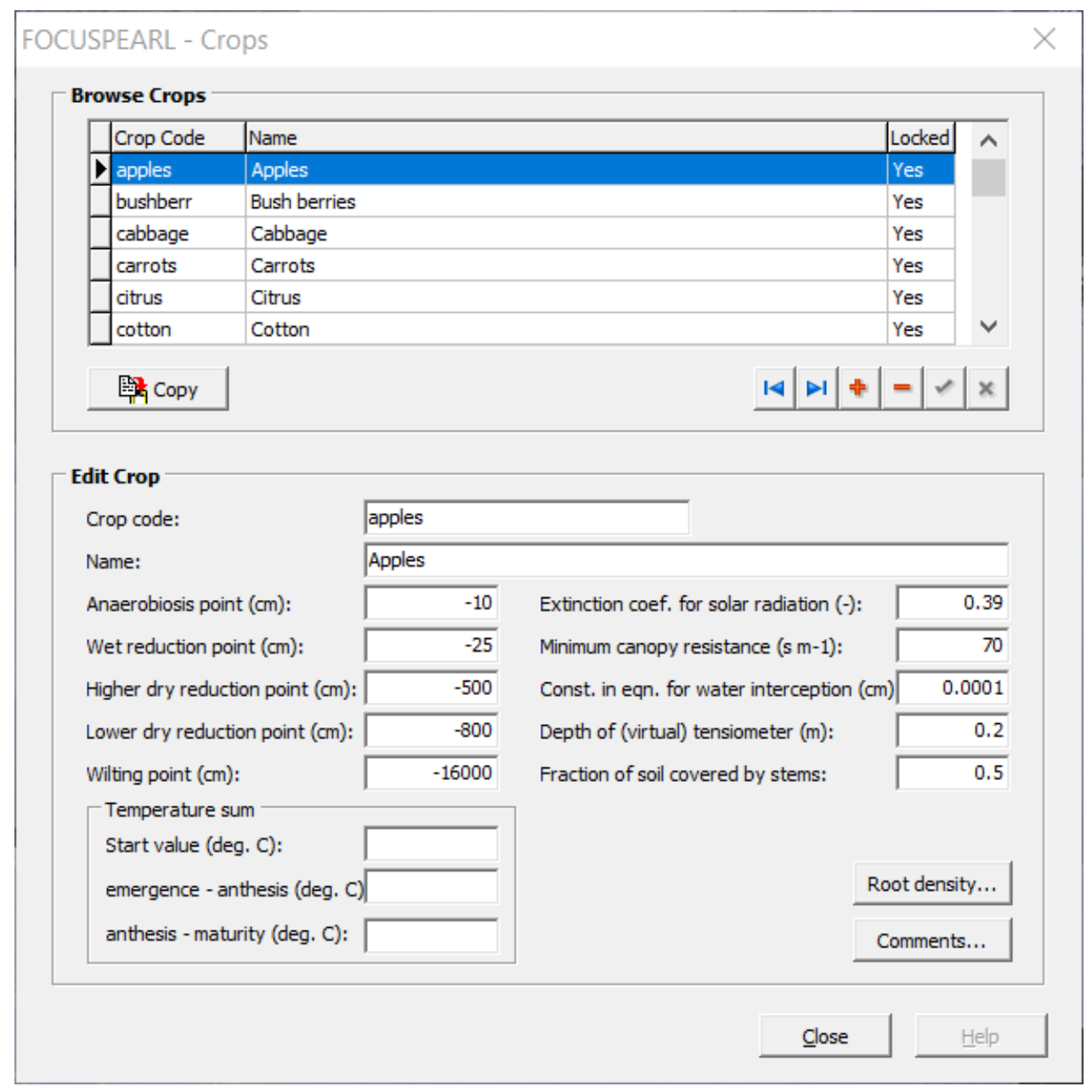

Figure 2.9 The Crops form.

The root density is specified in the relative root density form (press the relative root density button). The user may enter up to 11 data pairs to define the relative root density distribution as a function of the relative rooting depth (table RootDensity). Any unit can be used, the model will normalize the root density distribution in such a way that the integral of root density times depth over the root zone equals one.

If the course of development stage was set to 'Variable', the user must specify the temperature sum at emergence (TemSumSta) the temperature sum from emergence to anthesis (TemSumEmgAnt), and the temperature sum from anthesis to maturity (TemSumAntMat).

Dynamic crop properties are input in the 'Crop stages' form (See Figure 2.8), which is accessible through the stages button. These properties are input as a function of the development stage. The development stage is 0 at emergence, 0.5 at flowering (anthesis) and 1 at maturity (note that in the original publication by Van Heemst (1986), the development stage is between 0 and 2 ). Use the ' + ' button of the navigator to add development stages. A maximum number of 36 development stages is allowed for each crop.

For each development stage, the Leaf Area Index (LAI) and the rooting depth (ZRoot) have to be specified. If the potential evapotranspiration is calculated according to the Makkink equation, an empirical crop factors must be introduced (FacCrp). If the potential evapotranspiration is calculated according to Penman-Monteith, the crop height must be specified (HeightCrp). 


\subsection{Editing substances}

PEARL can simulate the fate of a parent pesticide and its formation products (metabolites) in soil. This implies that both the properties of the individual compounds, and the transformation scheme have to be parameterized. Substances can be added by clicking on the $\ldots$ button next to the 'Substance' field on the scenario tab of the main form. Then a separate application is started called SPIN (Substance Plug IN) and a form is opened which allows to create a new substance or edit a substance that already exist in the SPIN database. Detailed information and instructions how to use SPIN can be found in the user manual for SPIN version 3.3 (Van Kraalingen et al., 2020).

The definition of the transformation scheme, if relevant, can be defined in SPIN too. Further information on how to introduce a transformation scheme is presented in the SPIN manual (Van Kraalingen et al., 2020).

\subsection{Editing application schemes}

\subsubsection{Application schemes}

The 'Application scheme' form is accessible from the scenario tab of the main form, because it is considered a major building block of a FOCUS scenario (Applications table). The entire application scheme can be repeated annually, biennially or triennially using the 'repeat interval for applications' option.

Application schemes can be added with the ' + ' button of the navigator. The user can also copy an existing application scheme. Application schemes should be given a unique code for reference and a description. Use the 'Applications' button to define the individual applications.

\subsubsection{Applications}

The application form is shown in Figure 2.10. A new application scheme can be added by clicking on the ' + ' button of the navigator on the left-hand side or copy an existing application scheme using the 'Copy' button. After clicking on the ' $V$ ' (post edit) button, the data on the applications can be entered in the lower half of the right-hand pane. The date of application can be an absolute date or a relative date, i.e. relative to 'emergence' or 'harvest' of the crop. Next the data for each application can be specified. First define the application type: 'application to the soil surface' (AppSolSur), 'injection' (AppSolInj), 'incorporation' (AppSolTil), 'application to the crop canopy, interception fraction calculated by the model' (AppCrpLAI) or 'application to the crop canopy, interception fraction supplied by the user' (AppCrpUsr). Then enter the date (relative or absolute) and the dosage. For absolute dates the normal date format can be used, i.e. mm/dd/yyyy. A year number has to be entered, but the year will not be used if the repeat interval of applications is set to 1,2 or 3 (see section 2.2). In the case of injection or incorporation, the incorporation or injection depth must be supplied additionally. Note that an application scheme may contain a combination of applications with relative and absolute application dates. 


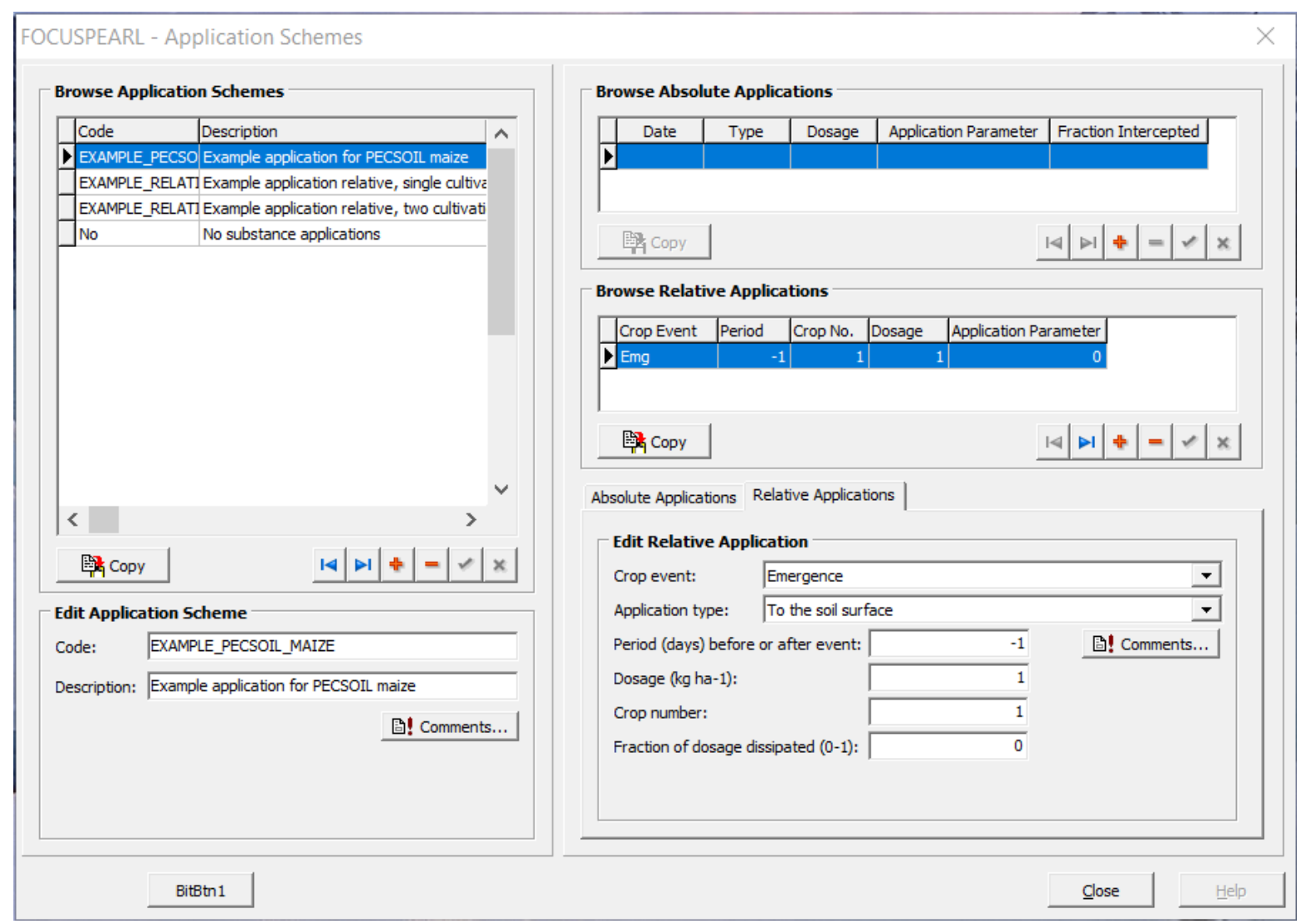

Figure 2.10 The applications form.

\subsection{Editing irrigation schemes}

The irrigation scheme form is accessible from the scenario tab of the main form, because it is considered a major building block of a FOCUS scenario. The irrigation method (OptIrr) can be set using the 'type' pick list of the 'Irrigation Schemes' form.

A new irrigation scheme can be added by clicking on the ' + ' button of the navigator or copy an existing scheme. The irrigation scheme must then be given a unique code and a description. Two types of irrigation can be specified in PEARL, i.e. sprinkler irrigation and surface irrigation. For each of these two types, irrigation amounts can be predefined by the user or the amounts can be calculated by the model. For the latter case, the option to be selected is either 'Sprinkler irrigation, irrigation depth calculated by the model' or 'Surface irrigation, irrigation depth calculated by the model'. Two options for the calculation method are available. The first option calculates the amount to be irrigated for any day on which the irrigation criteria is met, which is based on the moisture condition in the top soil. For the FOCUS scenarios with irrigation, an alternative option is available. During the growing season the moisture condition is checked once a week. If the amount of water required to bring back the moisture content in the top soil back to field capacity exceeds $15 \mathrm{~mm}$, then irrigation starts. If this amount is less than $15 \mathrm{~mm}$, then no irrigation takes place. However this parameter can be modified when running PEARL in batch mode.

After selecting the option to use predefined irrigation data, the actual irrigation data ( $\underline{\text { IrrTab) }}$ must be specified in the irrigations part on the right-hand side of the form. Use the navigator to add a new irrigation event. Both the date (column 1) and the irrigation depth (column 2) should be given. The user can import irrigation schemes from an ASCII file using the 'Import Datafile...' button. 


\subsection{Defining the output of the model}

Before running the model, the user has to define the output that has to be created with PEARL. A default selection of output variables settings has been made and usually this selection will be enough for most purposes. Output is controlled in the output tab of the main form. This tab contains three fields that affect all variables in the output file.

\subsubsection{The Output Control tab of the main form}

The Output Control tab is shown in Figure 2.11. On this form the user can set the print interval DelTimPrn. The default value for the print interval is 'Month'. The size of the output file can be reduced by setting the print interval to higher values. It should be noted that the output of PEARL is averaged over the print interval and that the time written to the out file is in the middle of the print interval.

The user can set the depth of the leaching target layer ( $\underline{\text { tgt }}$ ). The user can further set the following switches:

- $\quad$ specification whether the user want to include the detailed output file or not

- $\quad$ specification whether fluxes must be printed cumulative or not.

If 'Detailed output' is selected, specific output variables can be selected on the 'Detailed Output Options' form (see below). This form is opened after clicking on the button 'Detailed output options ...'

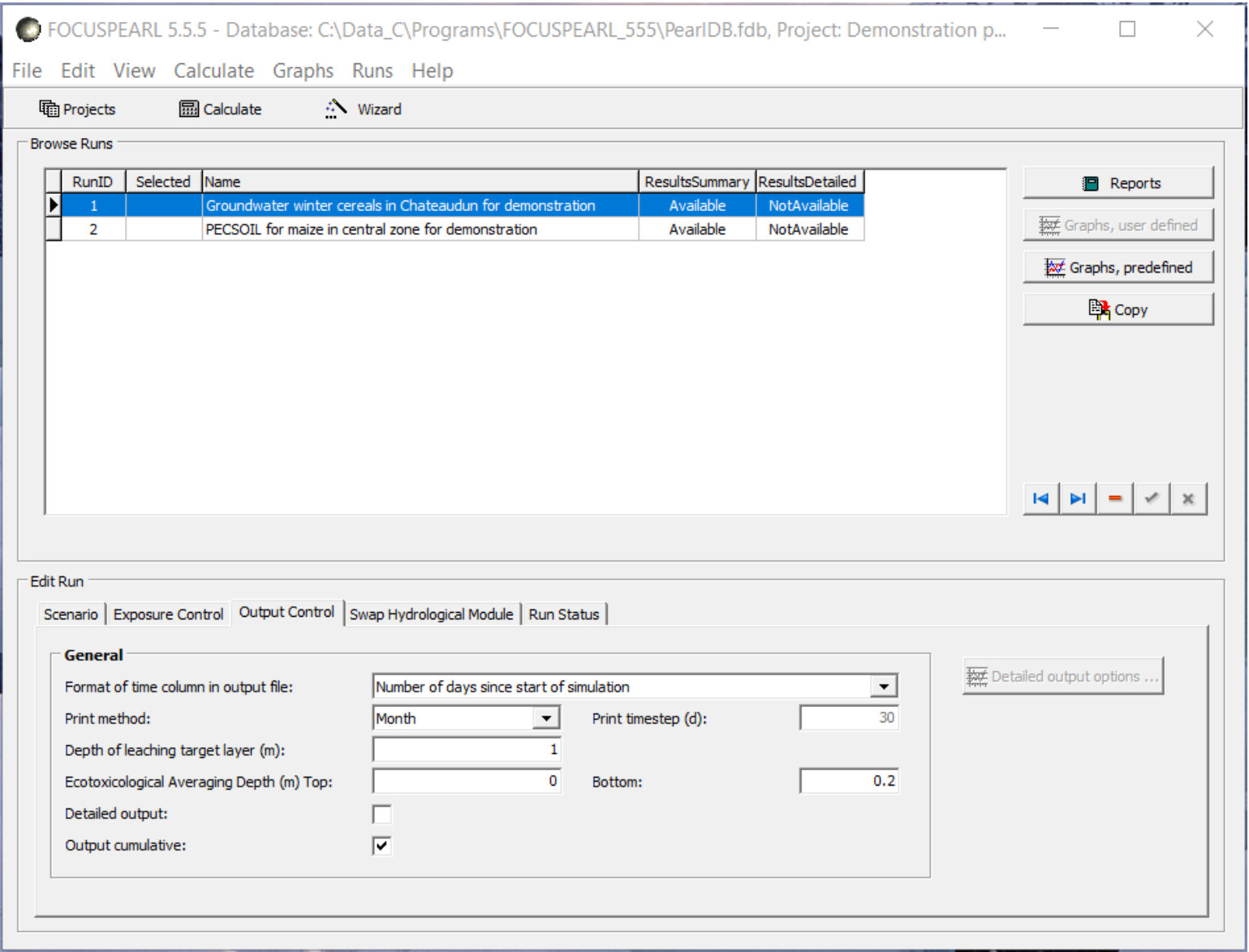

Figure 2.11 The Output Control tab.

\subsubsection{The Detailed Output Options form}

The detailed output options form is accessible from the output control tab of the main form. This form consists of three parts (see Figure 2.12): 
- In the upper part the user can browse the categories of available variables.

- In the lower-left section of the form the user can browse the individual variables within a category

- In the lower-right section of the form the intended output depths can be selected.

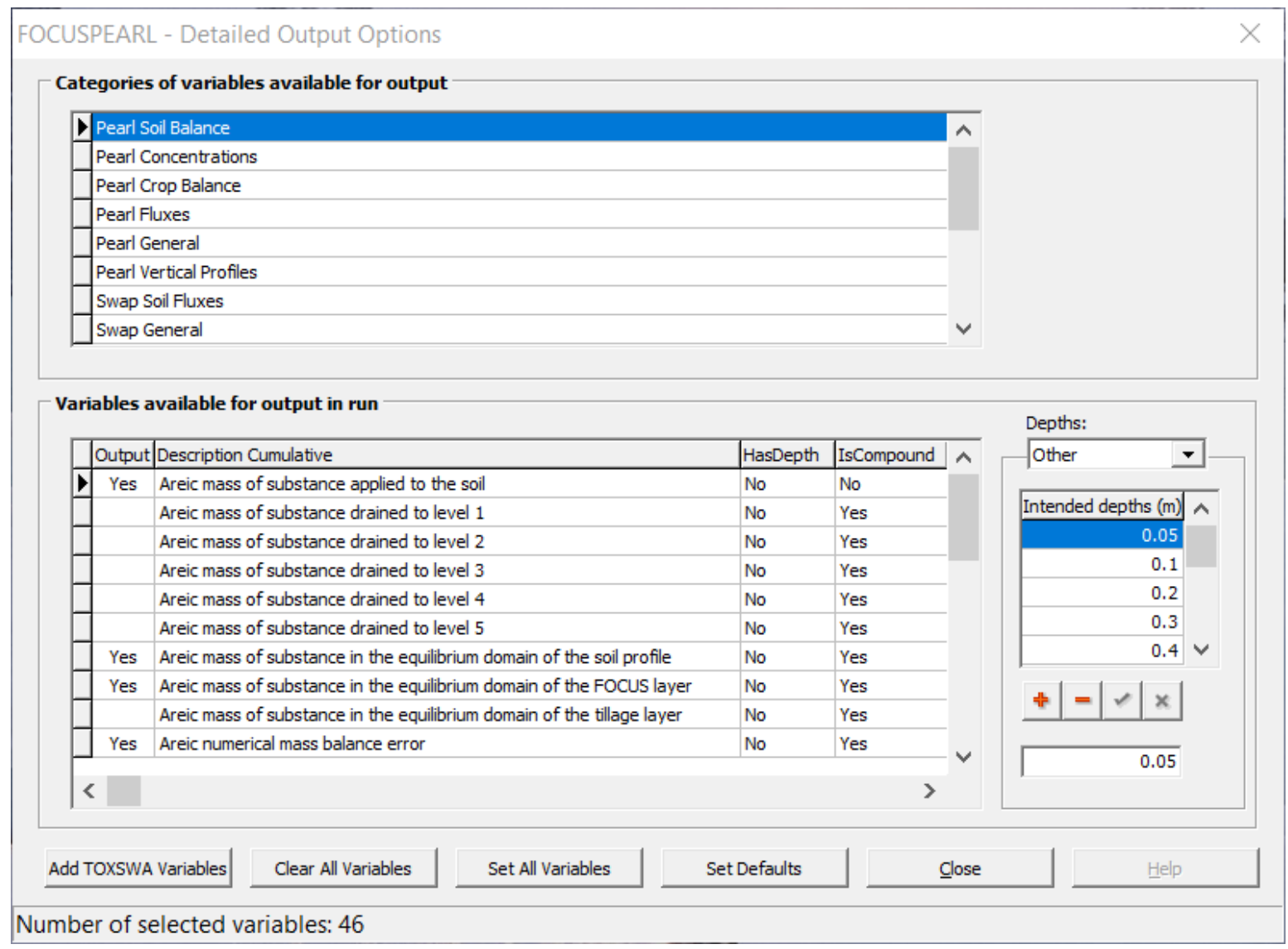

Figure 2.12 The Detailed Output Options form.

PEARL has the following categories of output variables available:

- Pearl balance: Mass balance of the soil system, which includes variables such as the areic mass of transformation and the areic mass of pesticide in the soil system.

- Pearl contents: Concentration of pesticide in the various phases of the soil system, such as the total mass content and the concentration in the liquid phase.

- Pearl crops: Mass balance of pesticide at the crop canopy.

- Pearl fluxes: Mass fluxes of pesticides, such as the total mass flux of pesticide.

- Pearl general: Miscellaneous variables, such as the time-step.

- Swap fluxes: Volume fluxes of water, such as the soil water flux.

- Swap states: State variables of the hydrological model, such as the soil water content.

- Swap general: Miscellaneous variables, such as the groundwater level.

In the lower section of the form, the user can select variables for output. Variables can be switched on and off by double-clicking. It is also possible to use the buttons at the bottom of the form:

- Clicking on the 'TOXSWA Variables' button selects all variables wanted by the TOXSWA model (Horst et al., 2016).

- Clicking on the 'Clear All Variables' button disables all variables.

- $\quad$ Clicking on the 'Set All Variables' enables all variables.

- $\quad$ Clicking on 'Set Defaults' enables the most important model outputs.

Use the ' + ' button of the navigator key to add additional output depths, use the - key to delete depths. By default, the model will produce output at 5, 10, 20, 30, 40, 50, 75, 100 and $200 \mathrm{~cm}$. Notce that the output depths form applies to all selected variables. Be critical in selecting output depths: more output depths will result in larger output files. 


\subsection{Running the model}

When ready with editing the model input and defining the output variables for the runs in the project, the runs can be selected or deselected for execution. In the column 'Selected' the selection status is shown. After a double click on the box for a run in the 'Selected' column, the selection status can be changed. If not selected then a double click changes the status into 'Yes'. When all runs to be executed have been selected, click on the 'Calculate' button to actually start the model for these runs. If all the runs in the project need to be executed then it is easier to select 'Runs' on the menu bar and select 'Select All runs for execution'. In the Runs menu the user can also deselect all runs for execution.

The first time a run is selected for execution, the PEARL user interface will generate the weather and irrigation data files. This can take some take. PEARL input files will always be generated after clicking on the 'Calculate' button. Next a console window with the logo of the PEARL simulation kernel appears on the screen which shows the progress of the run. The run can be interrupted by entering CTRL-C. The actual computation time depends upon the number of numerical compartments in the soil profile (Van den Berg et al., 2016). Computation time can be reduced by reducing the number of output variables selected for output or reducing the number of output depths (section 2.8.1).

The FOCUSPEARL user interface allows the execution of multiple runs, so there is no need to wait with starting the second run until the first is ready. Furthermore, FOCUSPEARL 5.5.5 supports the use of multiple cores to execute the runs in the project. Before starting the execution, the interface checks how many cores are available on the system and keeps one core available for other processes. All other cores are used for the distribution of the PEARL model runs to be executed. More information on this functionality is given in section 3.2.

When a model run is completed, the user will see the ResultsDetailed, ResultsSummary and Modified columns changing. Possible values for the Results columns are:

- NotAvailable: the model has not (yet) been run or the user has removed the output files

- Error: an error has occurred. Details can be seen in run status tab of the main form.

- Available: the model has successfully been run, and the model output is available for further processing (e.g. the creation of graphs).

\subsection{Creating graphs}

After a model run has been completed, the output can be analysed via the graphical function of the PEARL model interface. Using FOCUSPEARL a number of predefined graphs can be prepared, but userdefined graphs can also be created. The predefined graphs provide easy access to the most commonly used model outputs, such as the target concentration of pesticide in the groundwater, the areic mass balance of pesticide, etc. With user-defined graphs, the user can view the data in several different ways, which is an useful feature for those users who want to analyse several aspects of the leaching study.

\subsubsection{Working with predefined graphs}

Predefined graphs can be accessed with the 'predefined graph' button in the main form. The following graphs are available:

- Annual mass balance of the compound in the soil system and the FOCUS target layer, which shows the annual mass balance terms (i.e. annual application, transformation, lateral drainage, leaching, uptake and volatilization).

- Annual water balance of the soil profile and the FOCUS target layer (i.e. annual precipitation, irrigation, seepage, soil evaporation, transpiration and evaporation of intercepted water).

- FOCUS summary graph. The FOCUS summary graphs shows the frequency distribution of the leaching concentration, the $80^{\text {th }}$ percentile of the leaching concentration, etc. 


\subsubsection{Working with user-defined graphs}

PEARL can create graphs of all selected model outputs (see section 2.8.2). The custom graphs form is accessed from the main form. To create a graph perform the following actions:

- Select one of the categories in the upper box.

- Select one or more variables by double-clicking on the variable name in the lower box.

- If the selected variables are depth dependent, one or more depths can be selected by clicking in the output depths box (refer to the HasDepth column).

- If the selected variables are substance properties, one or more substances can be selected in the substances box (refer to the IsCompound column).

The user can plot multiple variables in one graph, but a variable that is depth dependent cannot be mixed with another variable that is depth independent. Click on 'Graph' when ready.

\subsubsection{The XYWIN program}

FOCUSPEARL uses the graphical program XYWIN. After clicking on the 'graph' button, a message box appears showing the number of selected data-pairs. After a while, the selected graph will be displayed. The user can zoom in with the left mouse button and zoom out to the original size (Edit menu or press F8). This function is not available in predefined graphs.

Graphs can be printed from the XYWIN menu (select Print from the File menu or press Ctrl+P). XYWIN can create output in different formats, such as emf, png, jpg or tiff. 


\section{Using FOCUSPEARL for the FOCUS groundwater scenarios}

FOCUSPEARL supports the application of the FOCUS Groundwater scenarios to assess the leaching of plant protection products to groundwater (FOCUS, 2000; European Commission, 2014). Runs using these scenarios can be prepared with the FOCUS wizard. The FOCUS wizard guides the user through the following steps:

1. Selection of one or more FOCUS crop(s)

2. Selection of one or more FOCUS location(s)

3. Selection of the substance (only parent substances can be selected), the application scheme and the repeat interval for the application scheme (annual, biennial or triennial).

Note that in the FOCUS wizard, the user can only select application schemes or substances that are available in the FOCUSPEARL and SPIN databases, respectively. A new application scheme has to be added to the FOCUSPEARL database first before it can be selected to create runs with the Wizard. A new substance has to be added to the SPIN database first. The FOCUS crops and FOCUS locations have been defined by the FOCUS Groundwater Workgroup and they cannot be edited. Also, the timedomain for the simulations is fixed, depending on the repeat interval of the application scheme.

After running the FOCUS wizard, the user interface has created a new project. Note that a number of combinations are not valid (e.g. vines in Jokioinen), so these will not appear in the project created. The newly created project is a so-called 'fixed substance project', which implies that all runs refer to the same substance. Editing this substance affects all selected runs. As it may be desirable to run the model with different application schemes, each run has got its own application scheme. A plant protection product may be applied in Thiva (Greece) at dates different from those in Hamburg (Germany). The application schemes of the individual runs are copies of the application scheme that has been selected in the wizard procedure.

All runs in the newly created project have already been selected for execution - they can be executed by clicking on the Calculate button. When done, graphs and summary reports can be created.

\subsection{The Wizard for the creation of groundwater assessments}

After starting FOCUSPEARL, the main screen of the interface is shown. Just below the menu bar three buttons are shown, the 'Projects', 'Calculate' and 'Wizard' buttons. To generate groundwater exposure runs, the following procedure has to be followed:

Step 1: Start the FOCUSPEARL wizard by clicking on the 'Wizard' button. A window appears which gives two options for the wizard, which is shown in Figure 3.1. 


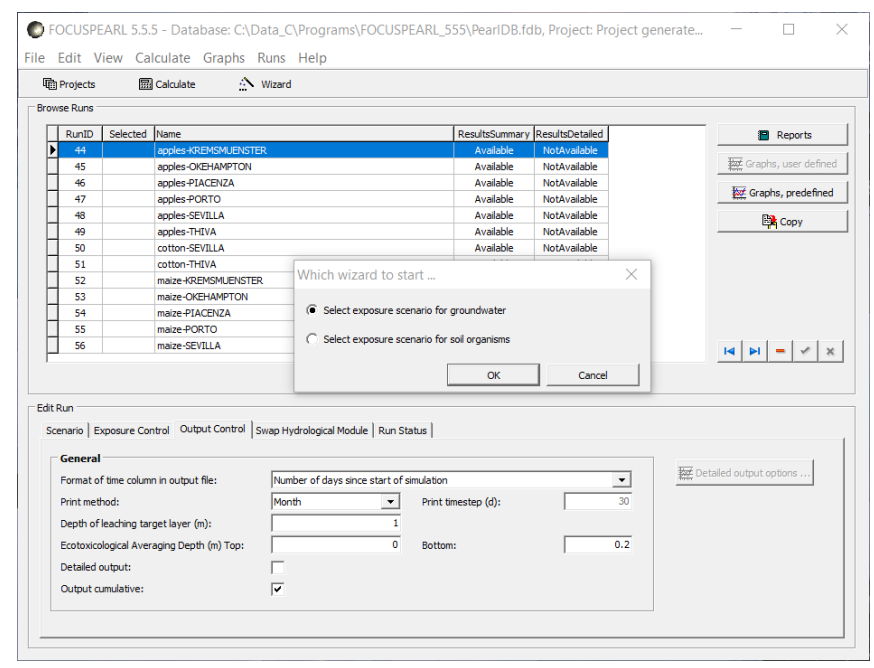

Figure 3.1 The form to specify the type of Wizard: groundwater or soil exposure.

Step 2: Select exposure scenario for groundwater and click on the OK button.

Step 3: Select the crop by a double click on 'Apples', 'Cotton', 'Oil seed rape (winter)', 'Maize' and 'Soybean' in the left column or click on the crop name and then click on the ' $>$ ' button. The result is shown in Figure 3.2. Then click on the 'Next' button.

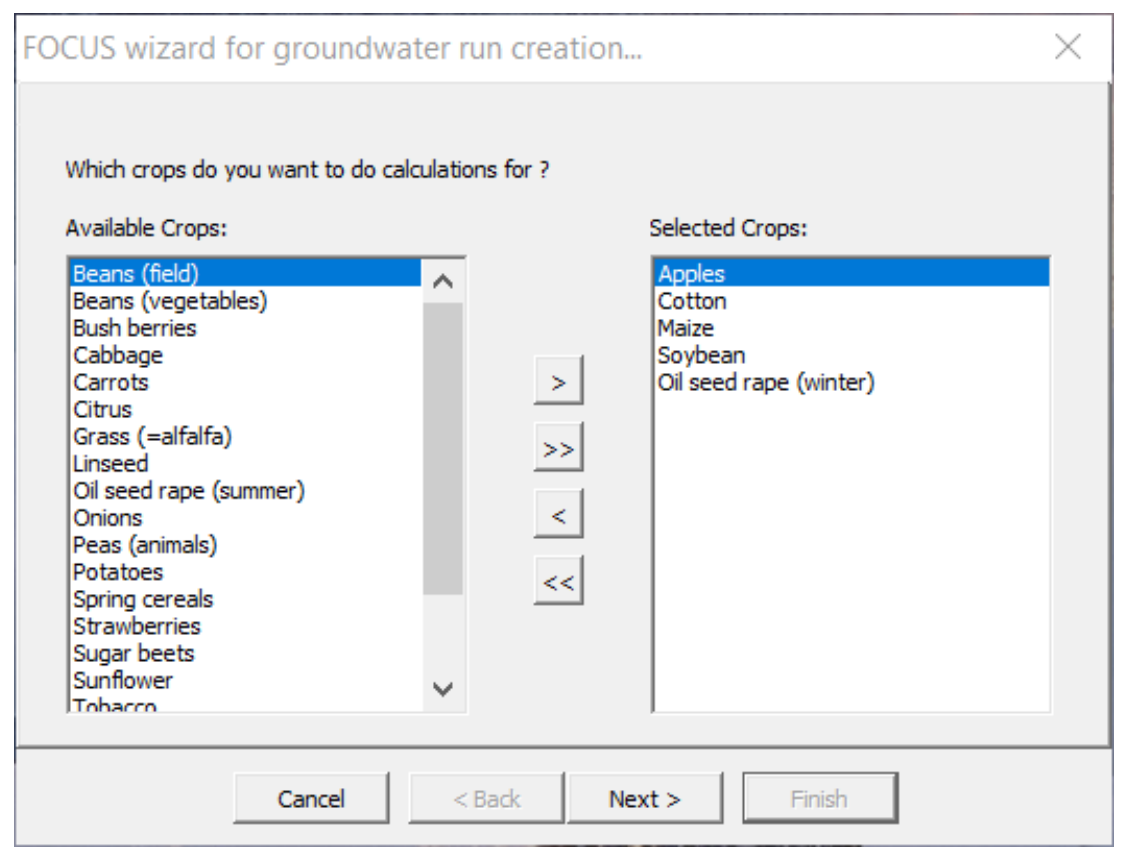

Figure 3.2 The Groundwater wizard; the selection of crops.

Step 4: Select the locations 'Kremsmuenster', 'Okehampton', 'Piacenza', 'Porto', 'Sevilla' and 'Thiva' by a double click on the location name in the left column. The result is shown in Figure 3.3. Then click on the 'Next' button. 


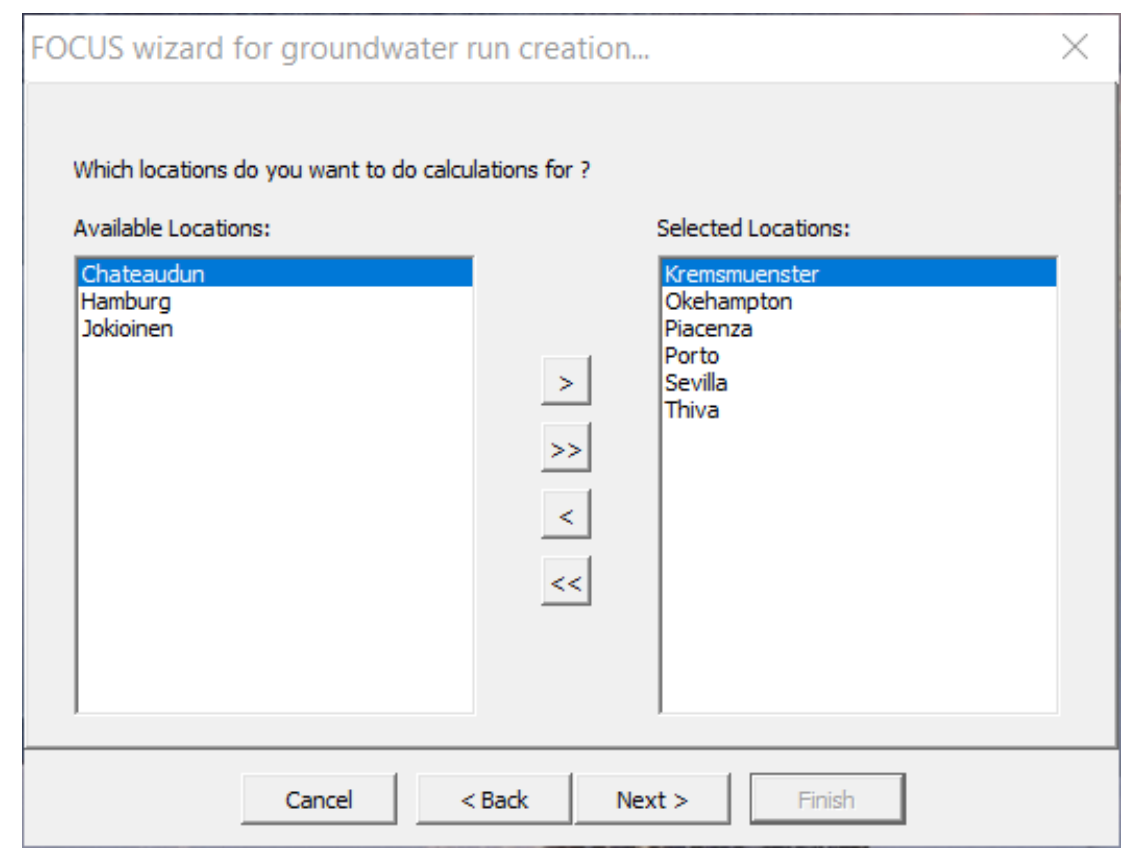

Figure 3.3 The Groundwater wizard; the selection of locations.

Step 5: Select the substance, the application scheme and the repeat interval.

The repeat interval can be 1, 2 or 3 for annual, biennial or triennial applications, respectively. The result is shown in Figure 3.4. It should be noted that only one of the existing substances or applications schemes can be selected. After completion click on the 'Next' button.

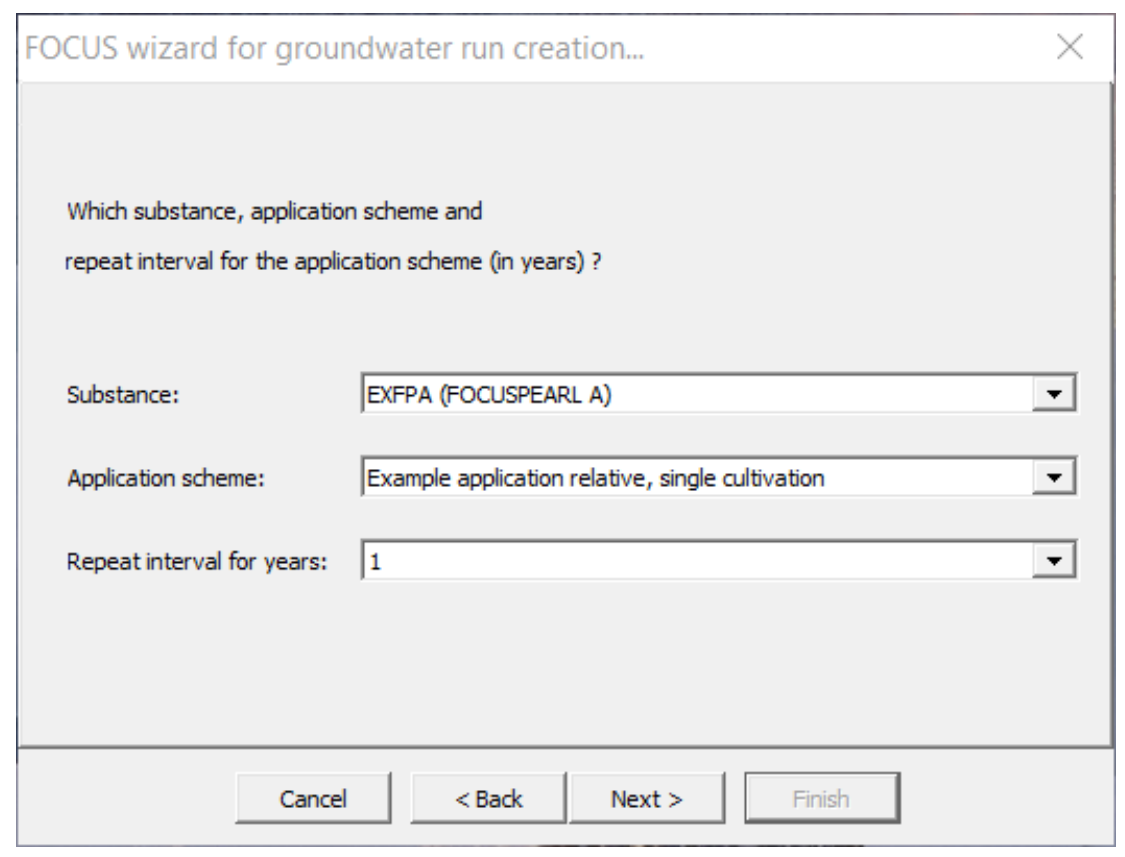

Figure 3.4 The Groundwater wizard; the selection of the substance and its application scheme.

Step 6: Create a new project or select an existing project to which the runs to be created are going to be assigned to. For this example a new project will be created. The resulting screen is shown in Figure 3.5 . 


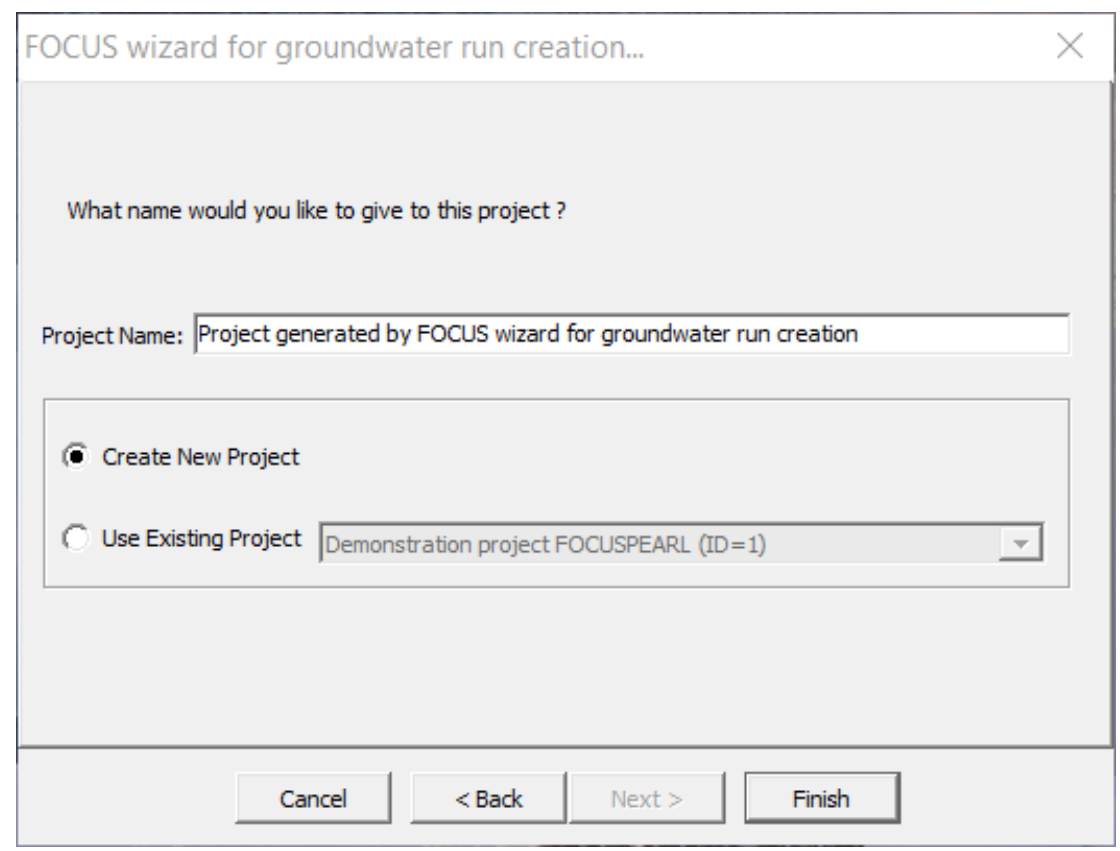

Figure 3.5 The Groundwater wizard; the selection or creation of the project and its name.

Then click on 'Finish'. The user interface starts retrieving the data for the scenario, the substance(s) and the application scheme. For this example 19 runs are created. It should be noted that most of the crops do not occur at every location.

O FOCUSPEARL 5.5.5 - Database: C:\Data_CXPrograms\FOCUSPEARL_555\PearlDB.fdb, Project: Project generate...

File Edit View Calculate Graphs Runs Help

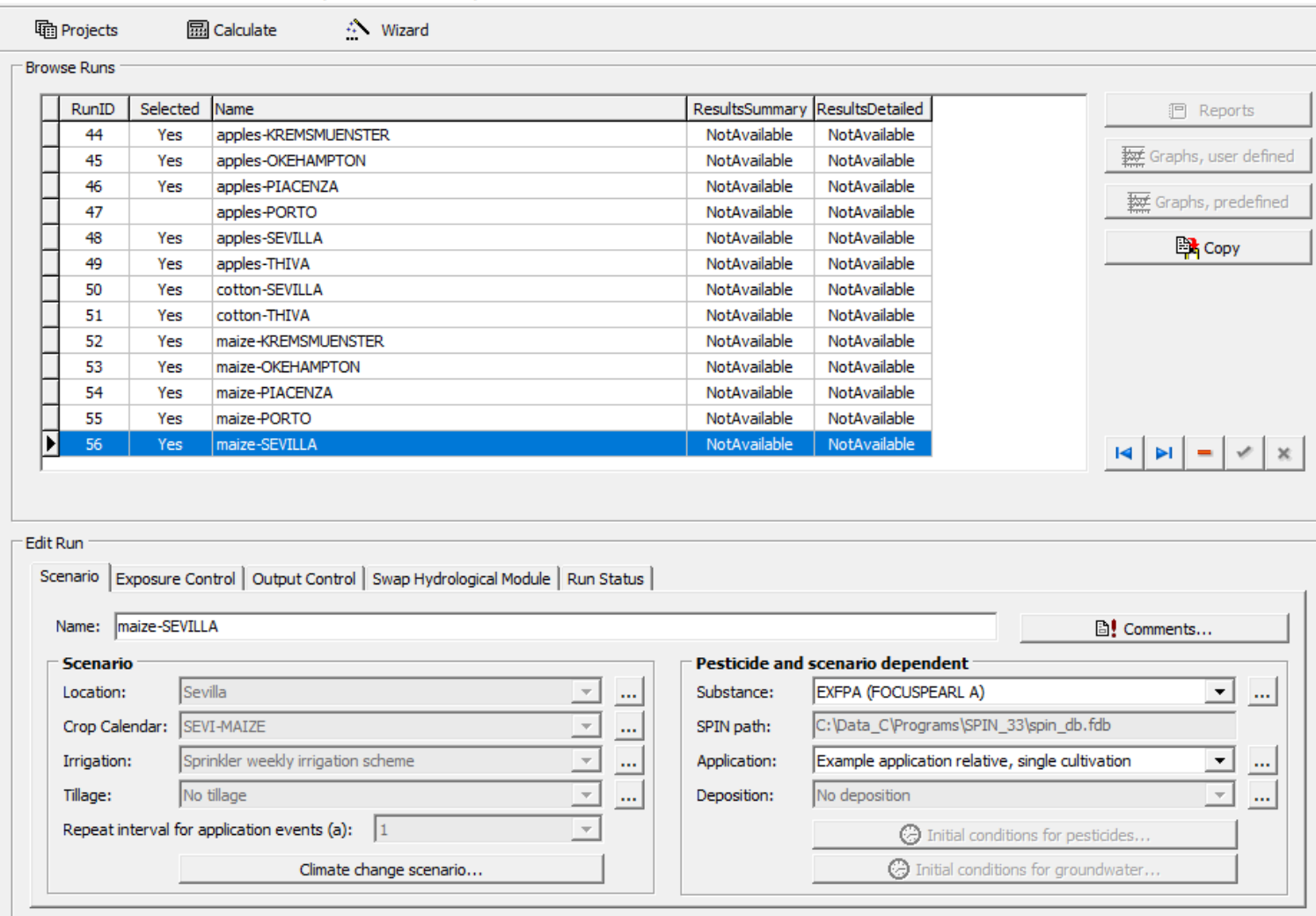

Figure 3.6 The Groundwater wizard; the runs created by the Wizard.

From the screen presented in Figure 3.6 most of the runs specifications are fixed and they cannot be changed. This is not the case for the substance and the application scheme. The user can change the substance and its application scheme for a particular run. 


\subsection{Running the model}

After the creation of the runs using the Wizard, the user can start the calculations by clicking on the button 'Calculate'. Next, the screen with input for multiple run options is shown (Figure 3.7).

In the upper part a checkbox is listed that gives the user the option to stop execution the moment an error occurs. Furthermore, there are three options available to the user for the window type for the model calculations:

- Normal; a window will pop up for each run to show the progress of the run.

- Minimized: all windows are put on the taskbar on the bottom of the screen. After clicking on one of the model run windows on the task bar, it will be presented on the screen of the computer, which allows the user to check the progress,

- Hidden: all model runs are executed on the background.

Using the 'Hidden' option, monitoring of the progress of the model runs is not possible. Only after all runs have been completed or if an error has occurred and the user has selected the checkbox 'Stop execution ...' then the user gets back the control of the user interface.

In the lower section of the form the maximum number of cores that can be used to execute the model runs is listed. This maximum is equal to the total number of cores of the machine minus one. So one core is always available for other tasks on the machine.

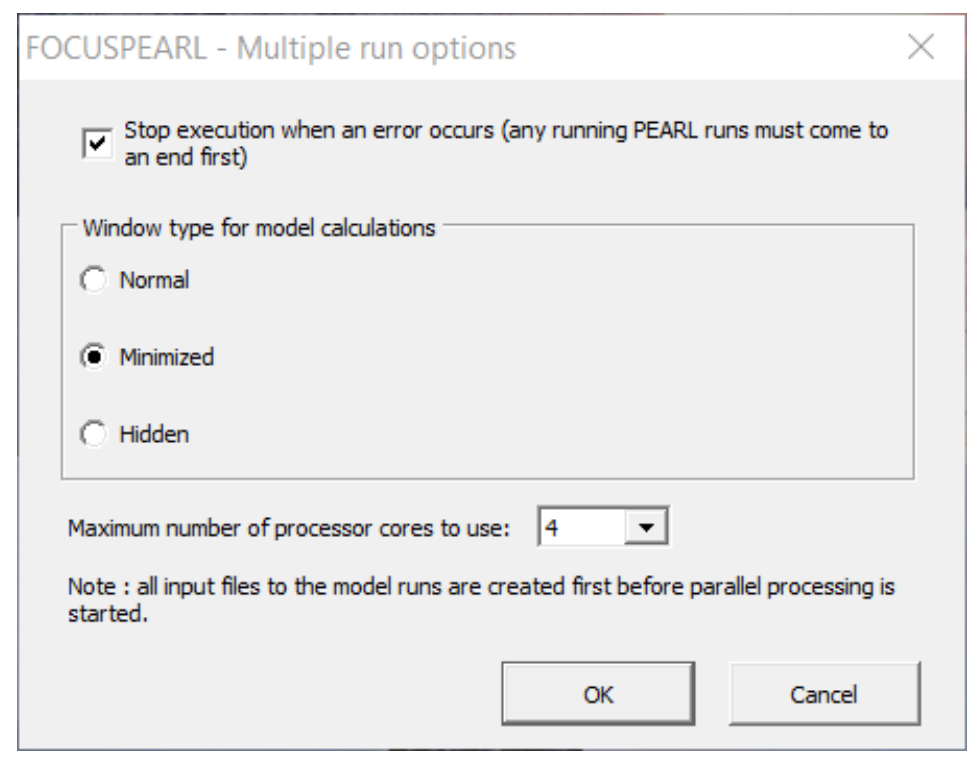

Figure 3.7 The form with the multiple run options.

After all runs selected for execution have been run successfully, the user can view the results of each run. The availability status of the results for the runs in the project is shown in the columns "ResultsSummary" and "ResultsDetailed" (see Figure 3.6). By default the switch for a detailed output file is turned off, so only the summary results will be available.

It is possible to generate only the input files for the runs created by the Wizard. To do this the user has to select the option 'Create only input files' in the Calculate Menu as available at the top of the main screen. After this option has been selected, clicking on the 'Calculate' button only starts the generation of the input files. To execute the runs, the user has to select the option 'Calculate selected runs' in the Calculate menu. 


\subsection{Viewing the results}

On the right-hand side of the main screen the button 'Graphs predefined' gives access to a form from which the user can select one of the standard graph types (see section 2.10.1). These are shown in Figure 3.8 .

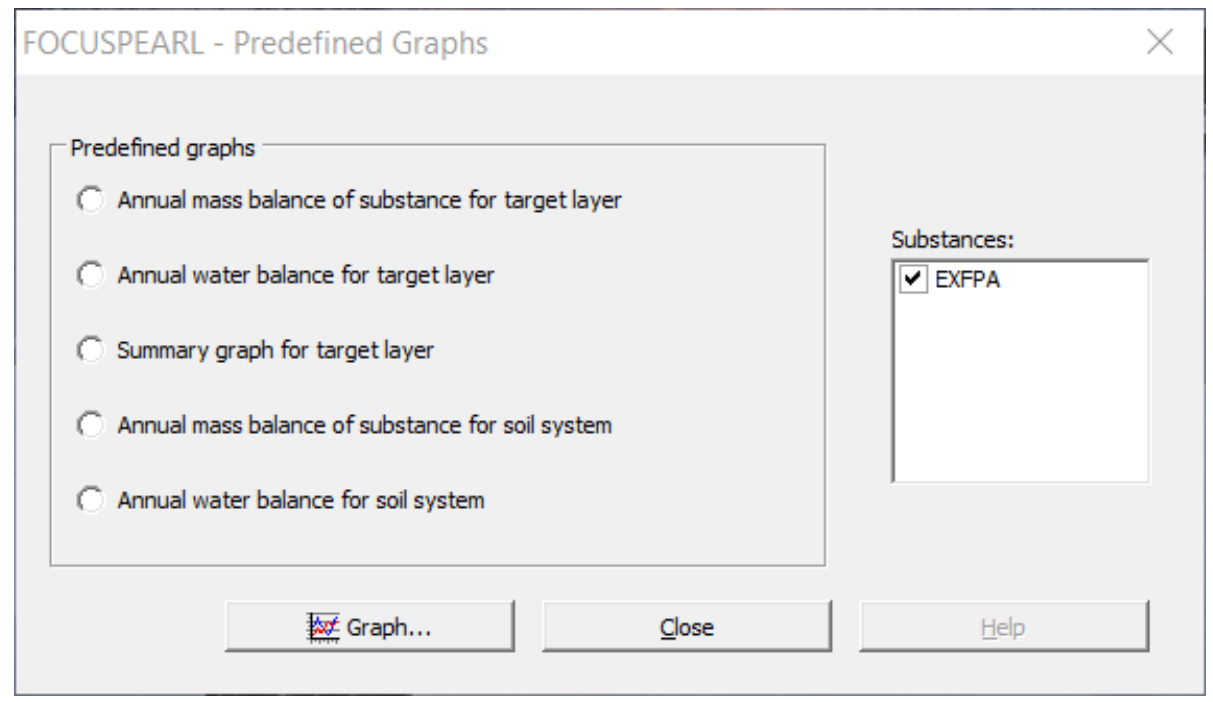

Figure 3.8 The Predefined Graphs Form - the form to select one of the standard graph types.

An example of one of these graphs, i.e. the Summary graph for the target layer is presented in Figure 3.9. The upper graph shows the frequency distribution of the leaching concentration at the target depth. For the FOCUS groundwater scenarios the target depth is $1 \mathrm{~m}$ and the target concentration is the $80^{\text {th }}$ percentile of the leaching concentration at the target depth. For the use of example substance A for Apples in Kremsmuenster the target concentration is calculated to be $7.46 \mu \mathrm{g} \mathrm{L}^{-1}$. This concentration is the average of the annual leaching concentration calculated for the simulation years 1913 and 1914 (indicated by arrows in the graph about the leaching concentrations calculated for the evaluation period. The lower two graphs show the mass leached from the FOCUS layer and the water percolated from this layer for the whole of the evaluation period.

Examples for the other two predefined graphs, i.e. the water balance and the mass balance are shown in Figures 3.10 and 3.11, respectively. Note that in the years 1922 and 1923 there is no water percolating below $1 \mathrm{~m}$, so in these years the leaching concentration is equal to zero. 
apples-KREMSMUENSTER, substance: EXFPA
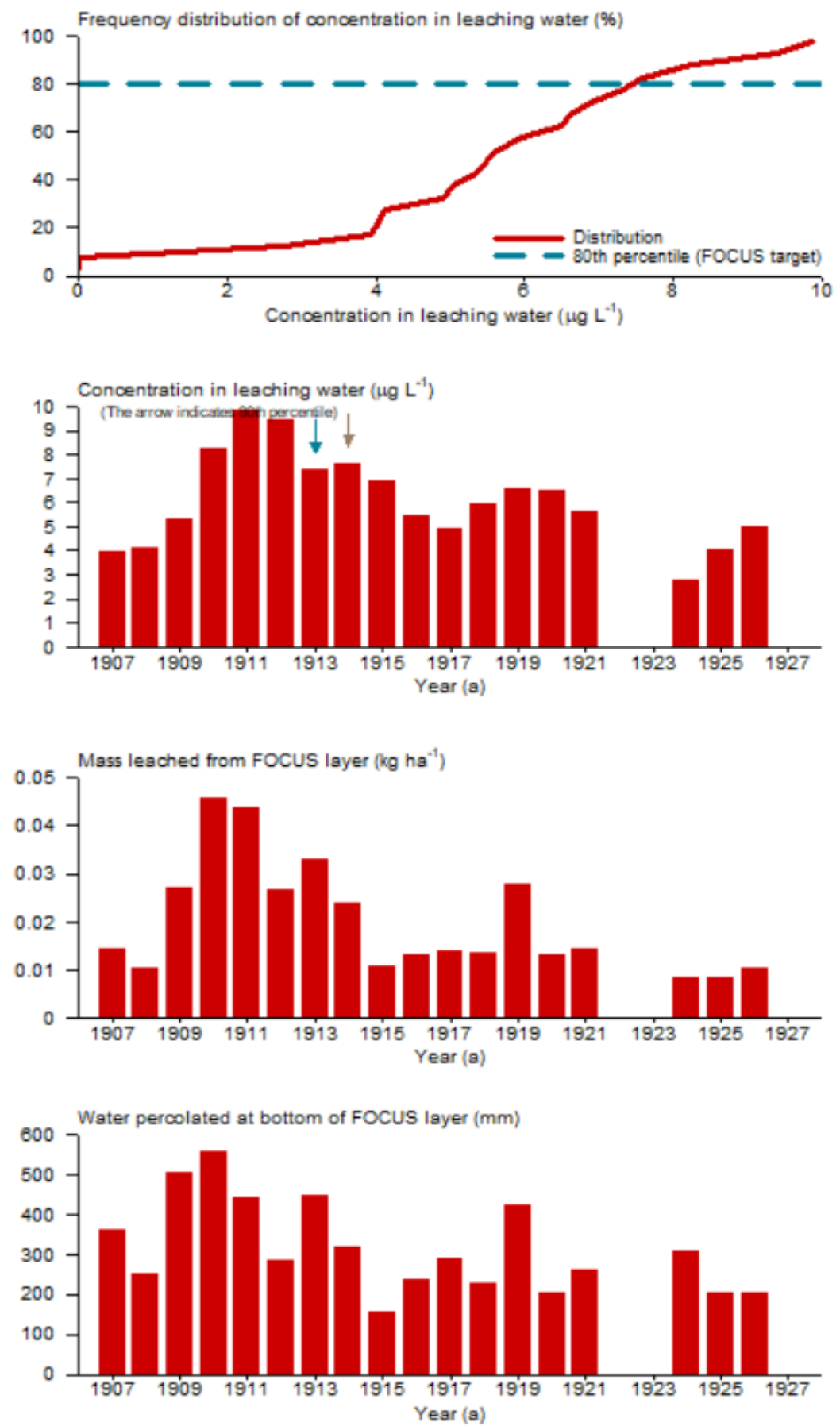

Figure 3.9: Example of a FOCUS Summary graph 
apples-KREMSMUENSTER, substance: EXFPA
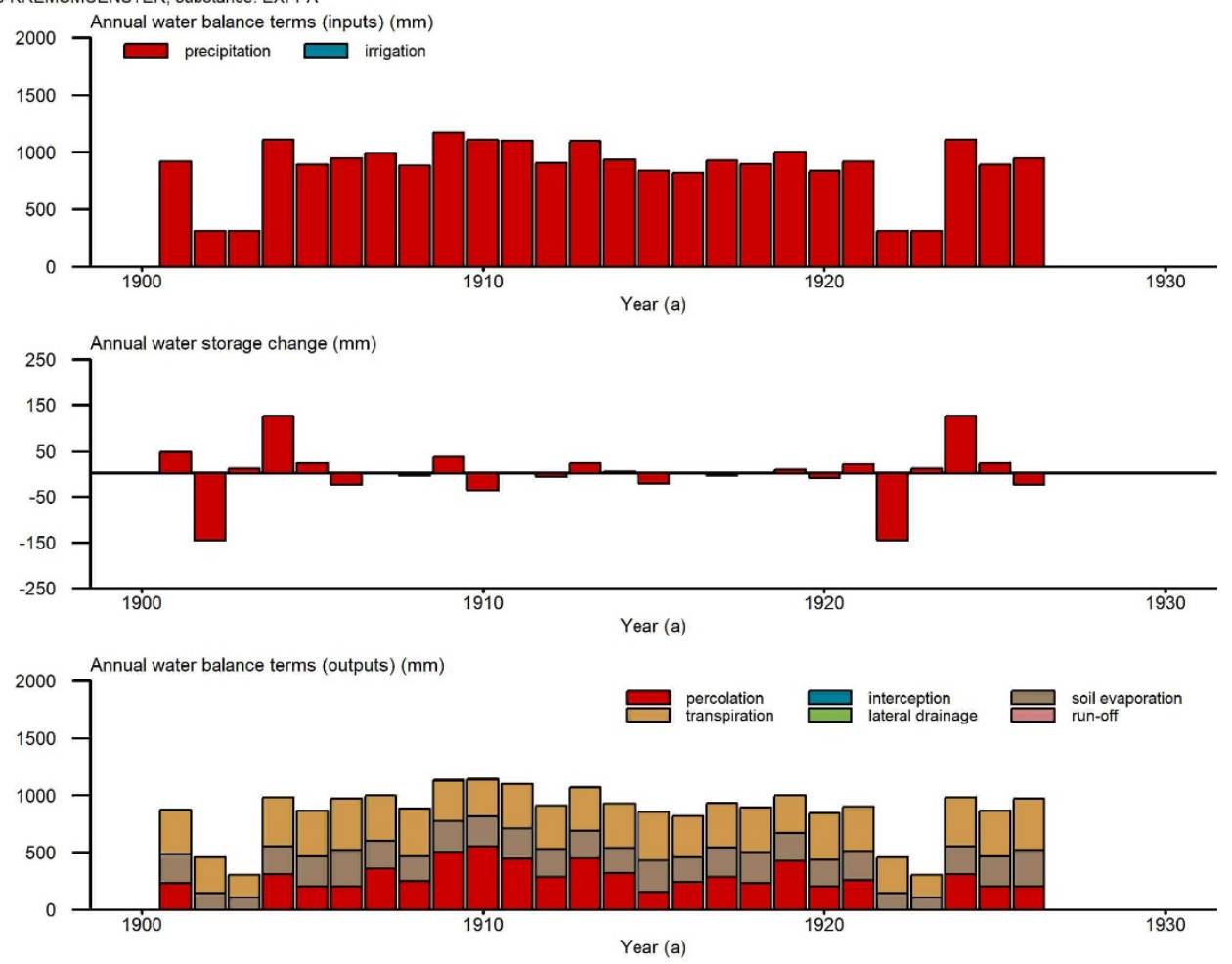

Figure 3.10 Predefined graph: the water balance for the FOCUS target layer $(1 \mathrm{~m})$.

apples-KREMSMUENSTER, substance: EXFPA
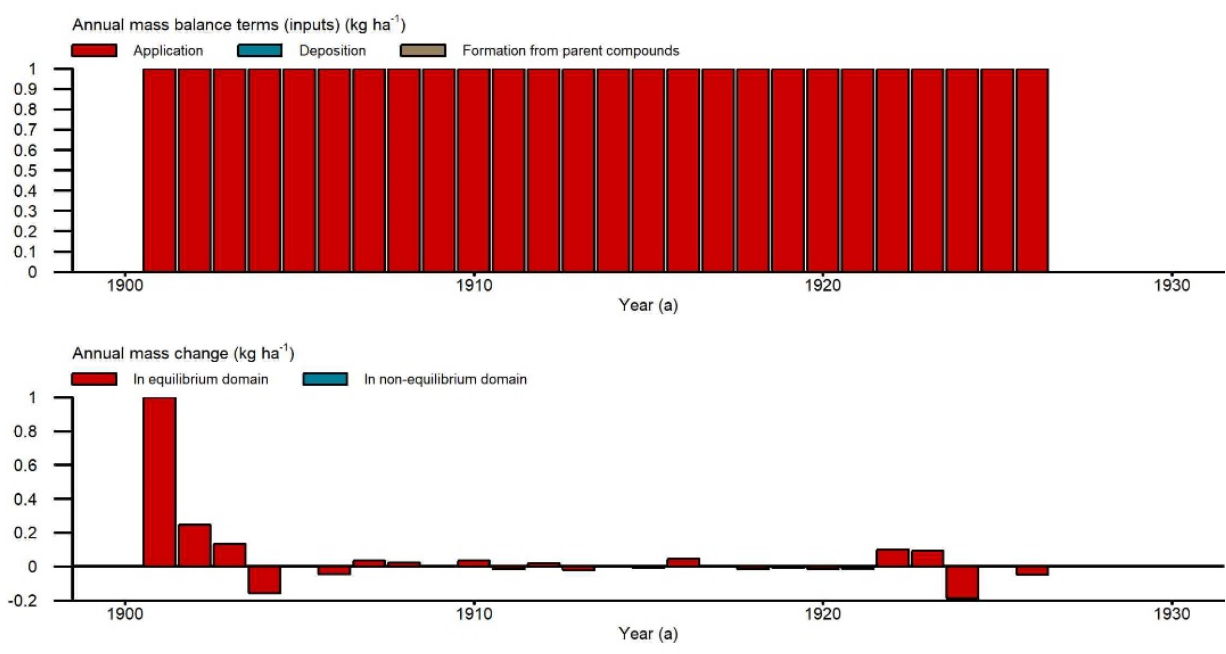

Annual mass balance terms (outputs) $\left(\mathrm{kg} \mathrm{ha}^{-1}\right)$

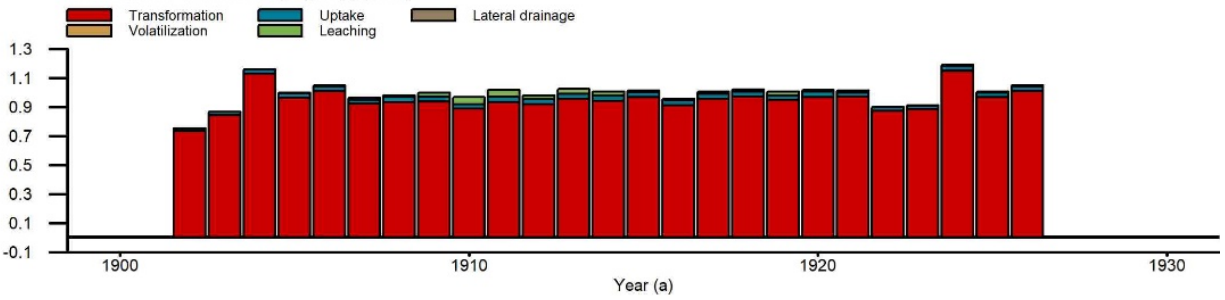

Figure 3.11 Predefined graph: the mass balance for the FOCUS target layer $(1 \mathrm{~m})$. 
Reports on the results of the runs in the project can be generated by clicking on the Report button. Two report options are available (see Figure 3.12): one for the selected run only and one for the target results for all the runs in the project. An example report for a single run, i.e. for substance $A$ for Apples in Kremsmuenster, is shown in Figure 3.13.

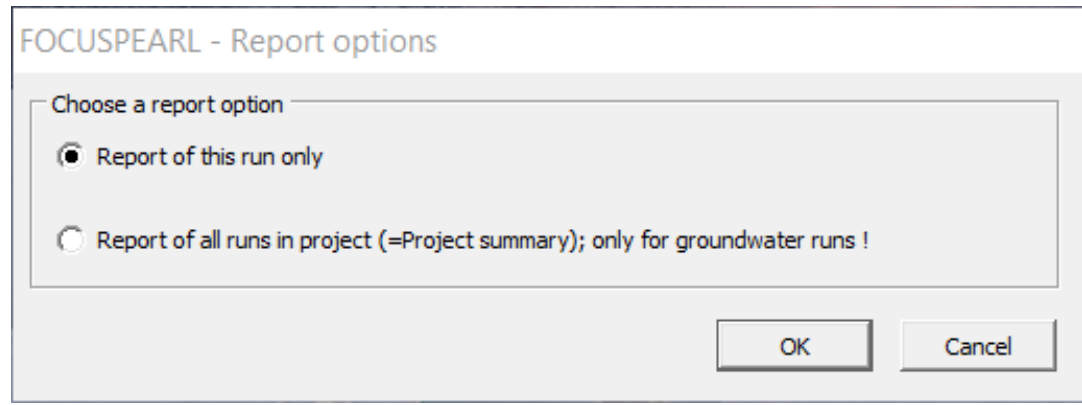

Figure 3.12 Report options for groundwater runs .

A report on all the runs in the project only presents the target concentration for the substances (including metabolites) for each run. This report can be shown in an Internet Browser or it can be copied to the clipboard. 


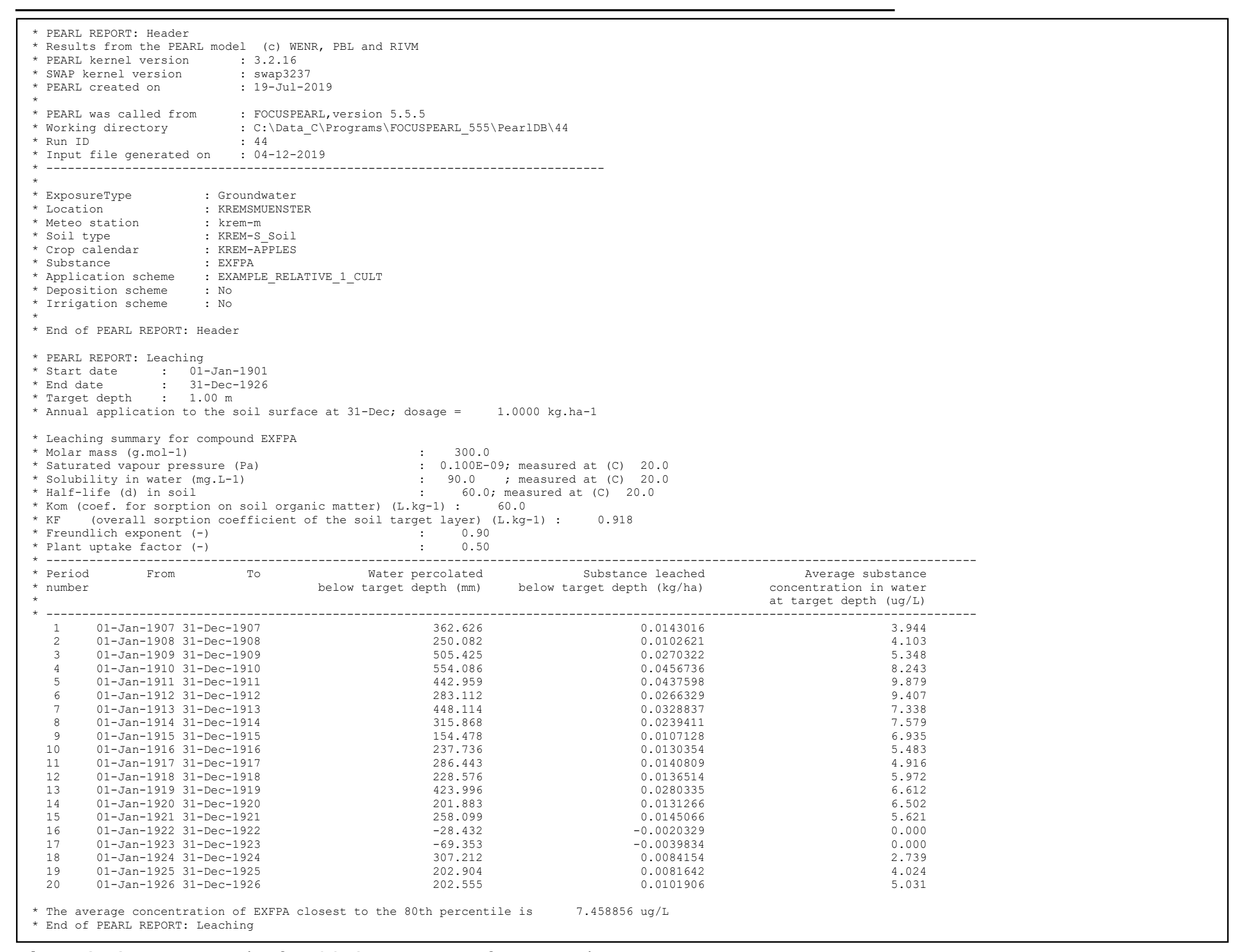

Figure 3.13

Example of a FOCUSPEARL Report for a groundwater assessment 


\section{Using FOCUSPEARL for the EFSA PEC-soil scenarios}

For the assessment of the exposure of organisms in the soil, guidance has been developed (EFSA, 2017). This guidance describes the evaluation procedure at the different tiers. For the assessments in the first two tiers the PERSAM model has been developed (EFSA, 2017). If the evaluation has to be continued at tier 3 , then numerical models have to be used to calculate the exposure at specific sites. The main input data for these tier 3B assessments are generated by PERSAM. The input data are substance specific and they depend on the crop, the EU registration zone, the exposure concentration type, e.g. total content in soil or the concentration in pore water and the application method. Other input data are related to the site for which the tier 3B evaluation has to be done, e.g. the organic matter content in the topsoil and scaling factors for precipitation and temperature. The identification of these sites depends also on the coefficient of sorption to organic matter and the DT50 of the substance. Therefore, the evaluation sites for the parent substance will be different from those for the relevant metabolites. The PERSAM model generates a PERSAM transfer file (ptf) for each substance exposure type - crop - zone combination.

The new version of FOCUSPEARL 5.5.5 facilitates the assessment of the soil exposure at tier 3B based on the ptf files as generated by PERSAM. The current version of PERSAM that needs to be used in combination with FOCUSPEARL 5.5.5 is PERSAM version 3.0. This version can be downloaded from the FOCUS DG SANTE Version Control website. This version should be installed in order to do the soil exposure assessments at tier 3B. An example of a ptf file is presented in Annex 3.

\subsection{The Wizard for the creation of soil exposure assessments in FOCUSPEARL}

After starting FOCUSPEARL, the main screen of the interface is shown. Just below the menu bar three buttons are shown, the 'Projects', 'Calculate' and 'Wizard' buttons. To generate soil exposure runs, the following procedure has to be followed.

Step 1: Start the FOCUSPEARL wizard by clicking on the 'Wizard' button. A window appears which gives two options for the wizard, which is shown in Figure 4.1.

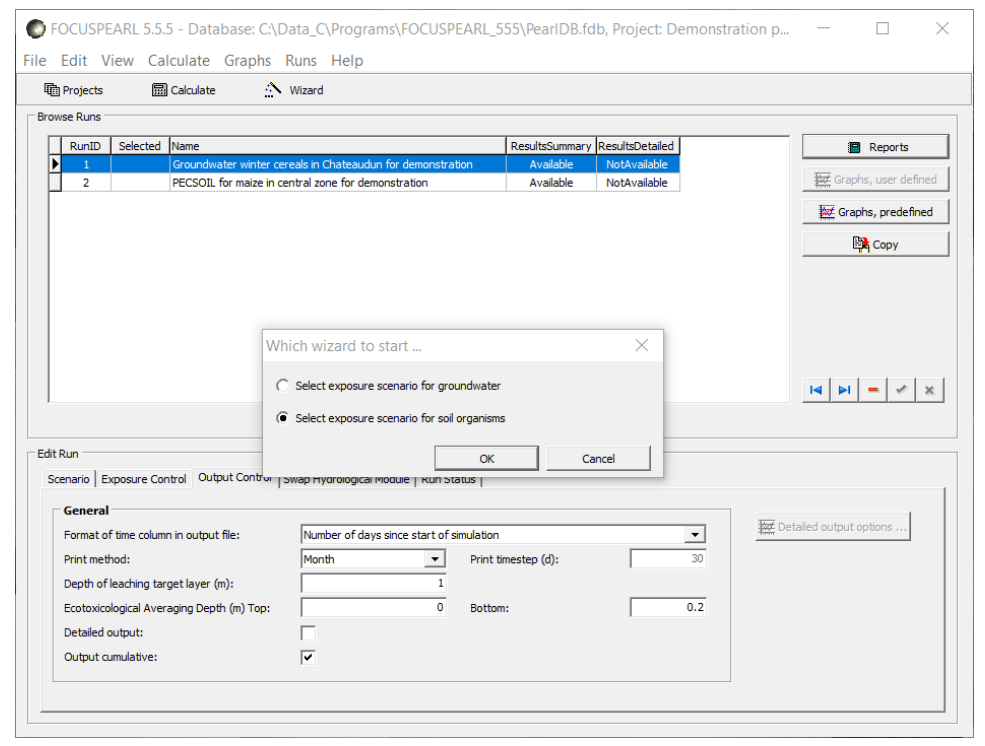

Figure 4.1 The form to specify the type of Wizard: groundwater or soil exposure. 
Step 2: Select exposure scenario for soil organisms and click on the OK button. Next a window appears on the screen to navigate to the folder containing the ptf files created by PERSAM (see Figure 4.2). Then select the ptf files to be imported and click on the 'Open' button. After clicking the 'Open' button the form presented in Figure 4.3 is shown.

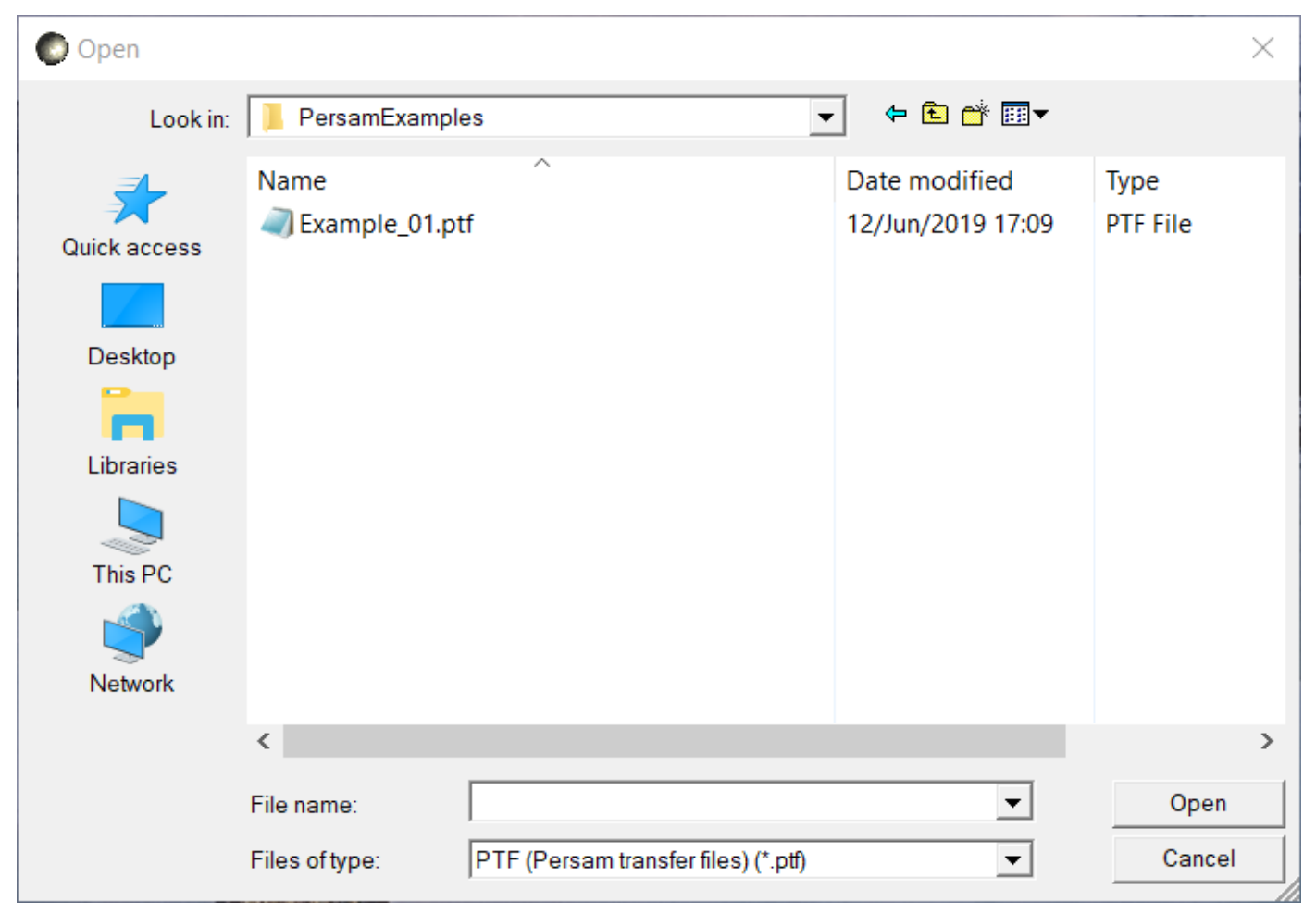

Figure 4.2: The window to navigate and select the PERSAM transfer files.

Step 3: Add other files by clicking on the button 'Add'. Then the 'Open' window as shown in Figure 4.2 appears. After all ptf files have been selected click on the 'Next' button. Then the application type form appears as presented in Figure 4.4.

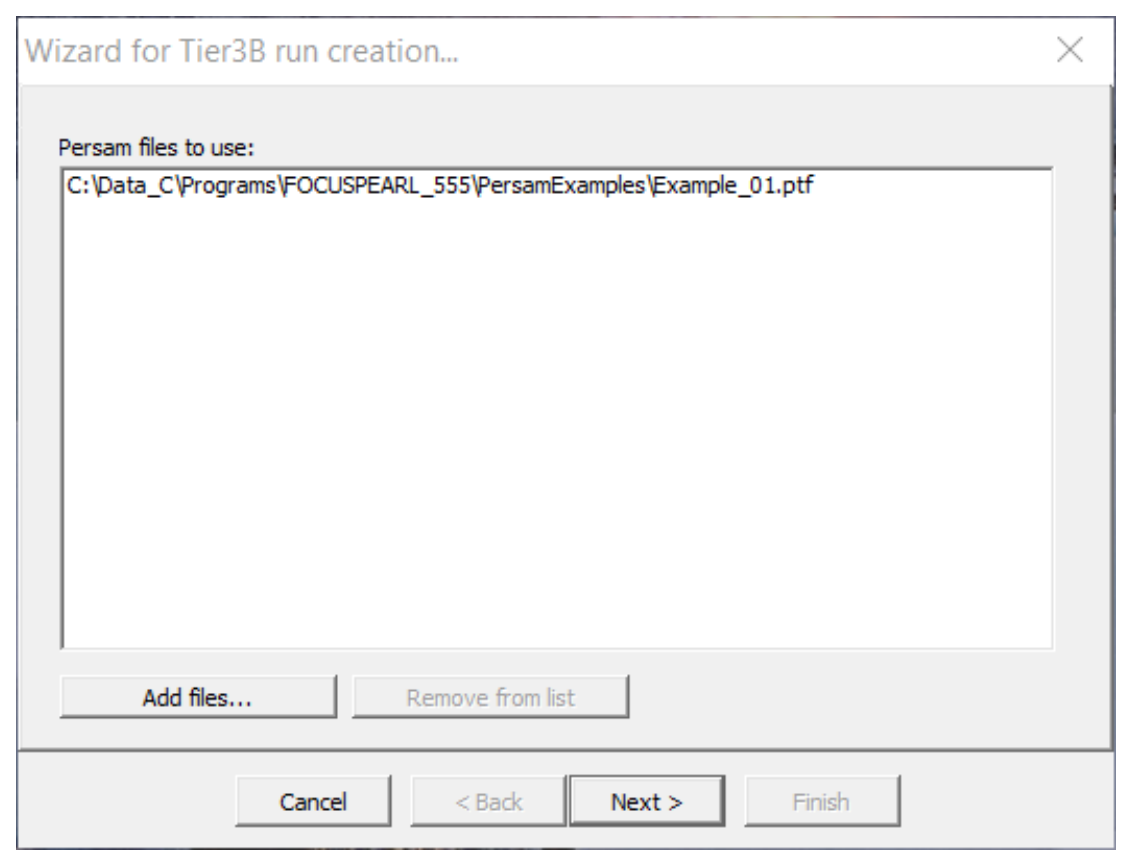

Figure 4.3 The form showing the list of PERSAM transfer files to be imported. 
Step 4: Select the application scheme type and specify the first day of the application scheme.

As shown in Figure 4.4 two options are available: 'Absolute' and 'Relative'. In the form shown the option 'Relative' has been selected. The relative application date can be relative to the emergence of the crop or the crop harvest. To complete the data required for this application type, the number of days before or after the event need to be specified. A negative value implies an application before the crop event.

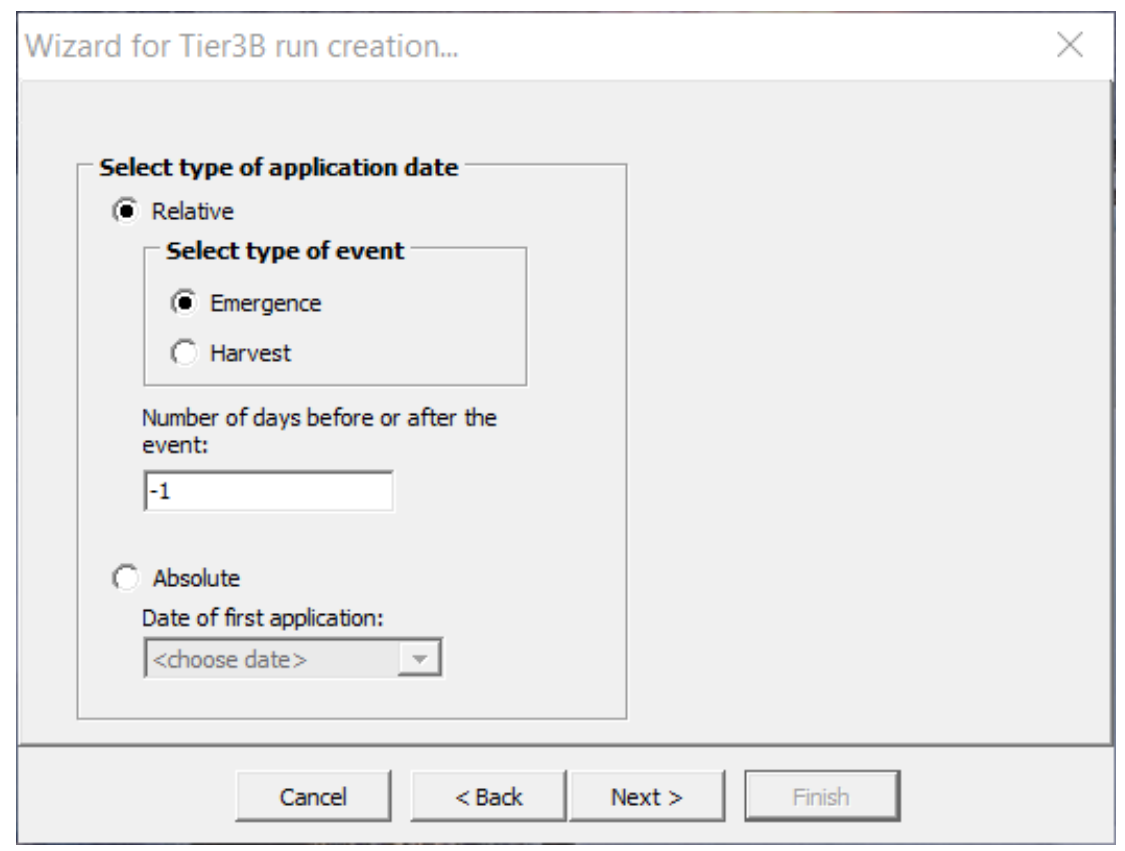

Figure 4.4 The application form to specify the application date type: relative to emergence.

If the user has selected the option 'Absolute', then the user has to enter the date of the first application. An example for the use of this option is shown in Figure 4.5. After completion of this form click on the 'Next' button.

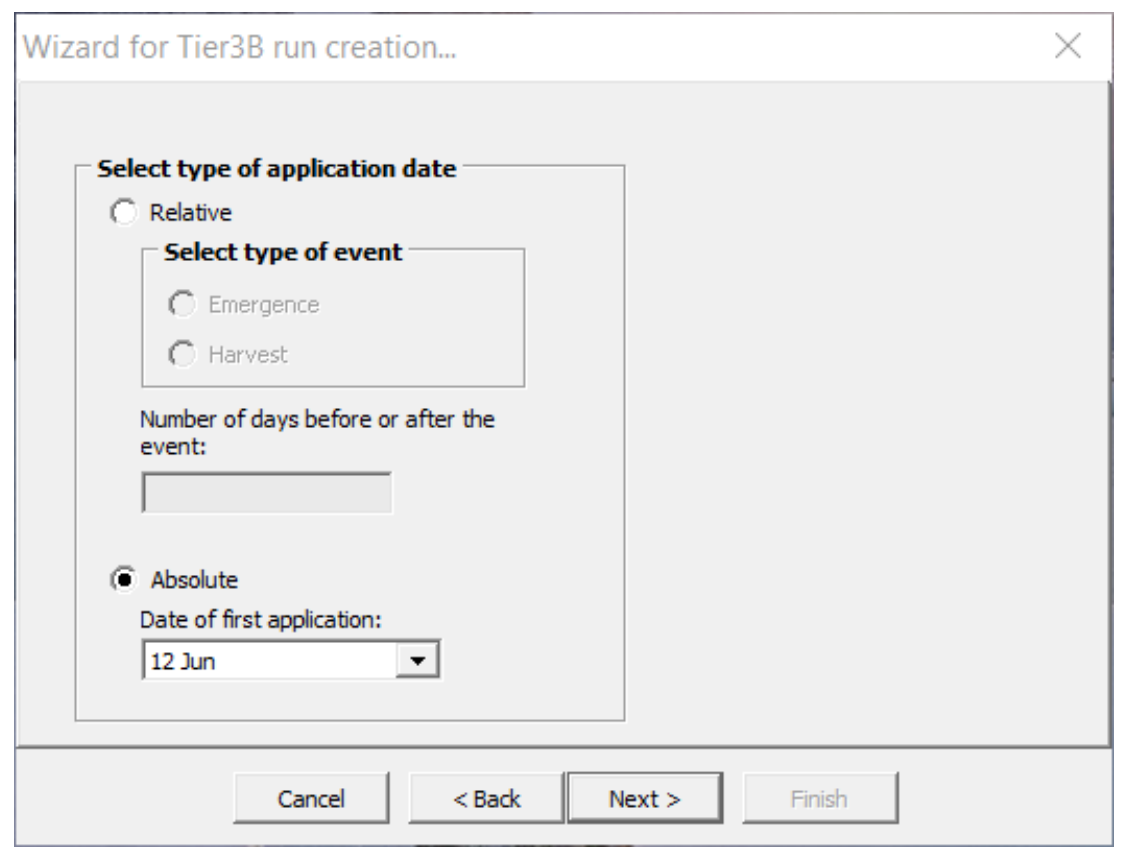

Figure 4.5 The application form to specify the application date type: Absolute - Day and Month.

It should be noted that the application method as well as the rate of application are imported from the PERSAM ptf file. In this file the day number of the first application is always set to zero and if the application scheme contains more applications, then the number of days after the first application is given for this application in the ptf file. 
Step 5: Create a new project or select an existing project to which the runs to be created are going to be assigned to. For this example a new project will be created. The resulting screen is shown in Figure 4.6 .

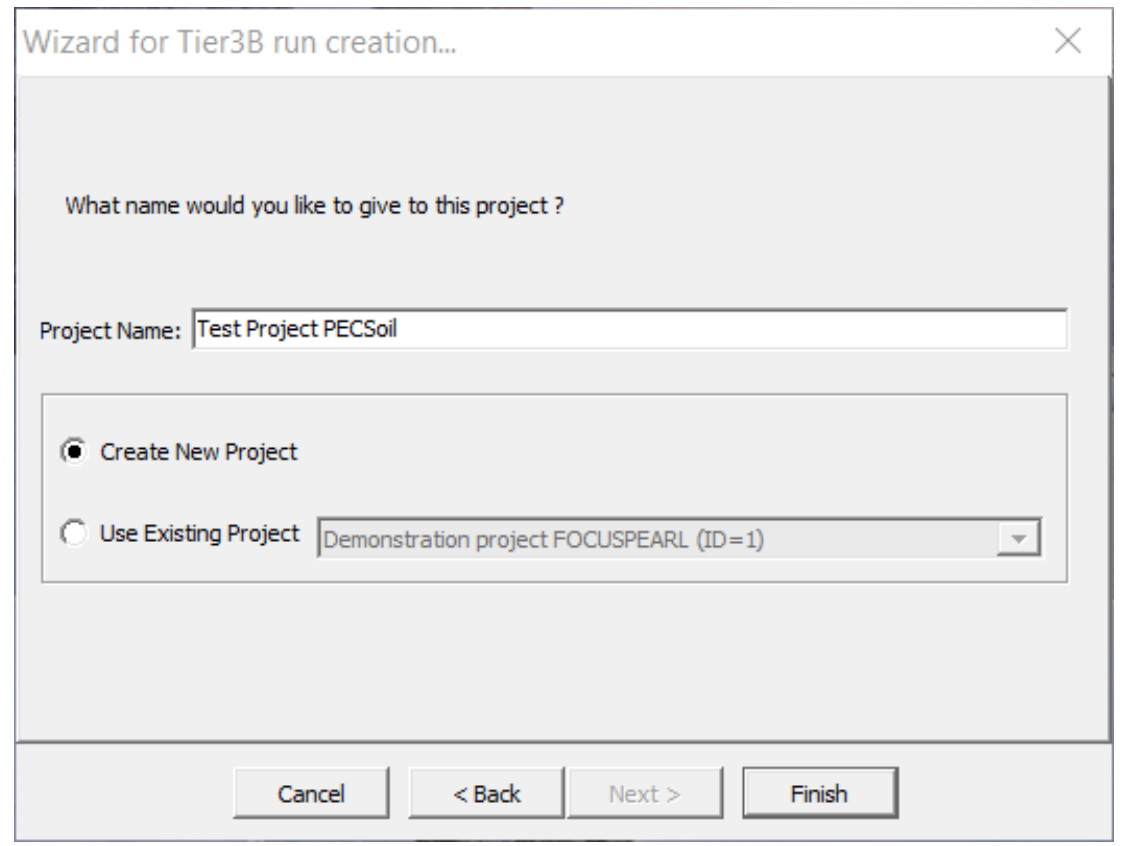

Figure 4.6 The Groundwater wizard; the selection or creation of the project and its name.

Then click on 'Finish'. The user interface starts retrieving the data for the scenario, the substance(s) and the application scheme. In this example only one run is generated as only the example ptf file has been selected. The user interface returns to the main screen showing the new project and the run in this project (see Figure 4.7).

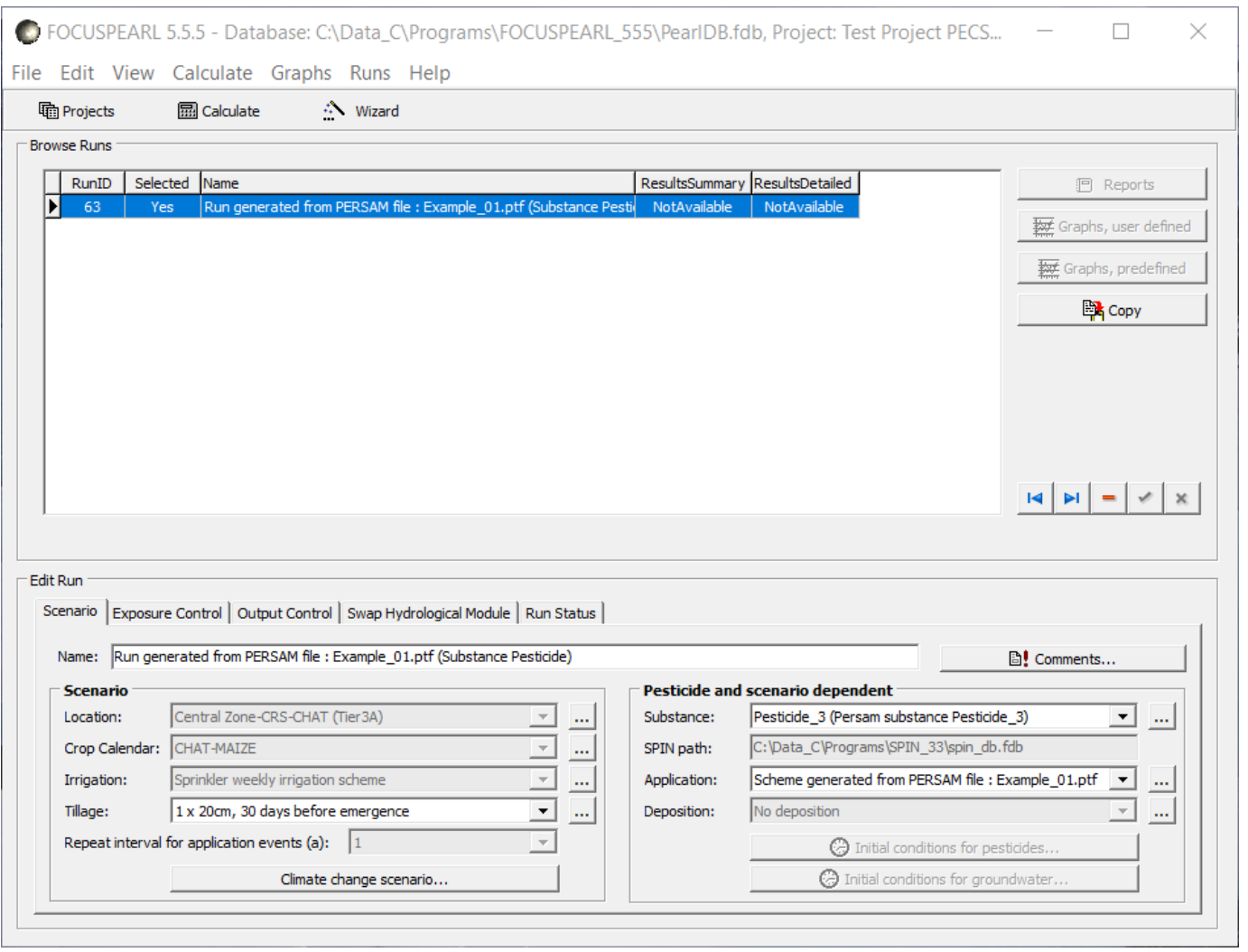

Figure 4.7 The Soil Exposure wizard; the run created by the Wizard. 
Based on the information in the PERSAM ptf files, the following actions are executed by the user interface:

- A new parent substance and if present the metabolites of this compound are created in SPIN.

- An application scheme is created as selected in the wizard with the application method and application rates as specified in the ptf file

- All elements needed to complete the run characteristics: tillage scheme if relevant, FOCUS crop type, irrigation scheme if relevant and the location.

At the bottom of the screen a button 'Climate change scenario' is available to show the scaling factors for temperature and rainfall as specified in the ptf file. It should be noted that the name of the substance as specified in the ptf file is included in the name for this substance in SPIN. As each substance in SPIN must be unique, a number is added to the name of the substance as specified in the ptf. Moreover the name of the ptf file is also included in the description of the run and that of the application scheme.

\subsection{Running the model}

After the creation of the runs using the Wizard, the user can start the calculations by clicking on the button 'Calculate'. Next the screen with input for multiple run options is shown. These options have been explained in section 3.1 (See Figure 3.7).

Upon the successful completion of the runs in the project, the user can view the results of each run. The availability status of the results for the runs in the project is shown in the columns "ResultsSummary" and "ResultsDetailed" (see Figure 4.7). By default the switch for a detailed output file is turned off, so only the summary results will be available.

It is possible to generate only the input files for the runs created by the Wizard. To do this the user has to select the option 'Create only input files' in the Calculate Menu as available at the top of the main screen. After this option has been selected, clicking on the 'Calculate' button only starts the generation of the input files. To execute the runs, the user has to select the option 'Calculate selected runs' in the Calculate menu.

\subsection{Viewing the results}

On the right-hand side of the main screen the button 'Graphs predefined' gives access to a form from which the user can select one of the standard graph types (see section 2.10.1). These are shown in Figure 4.8 .

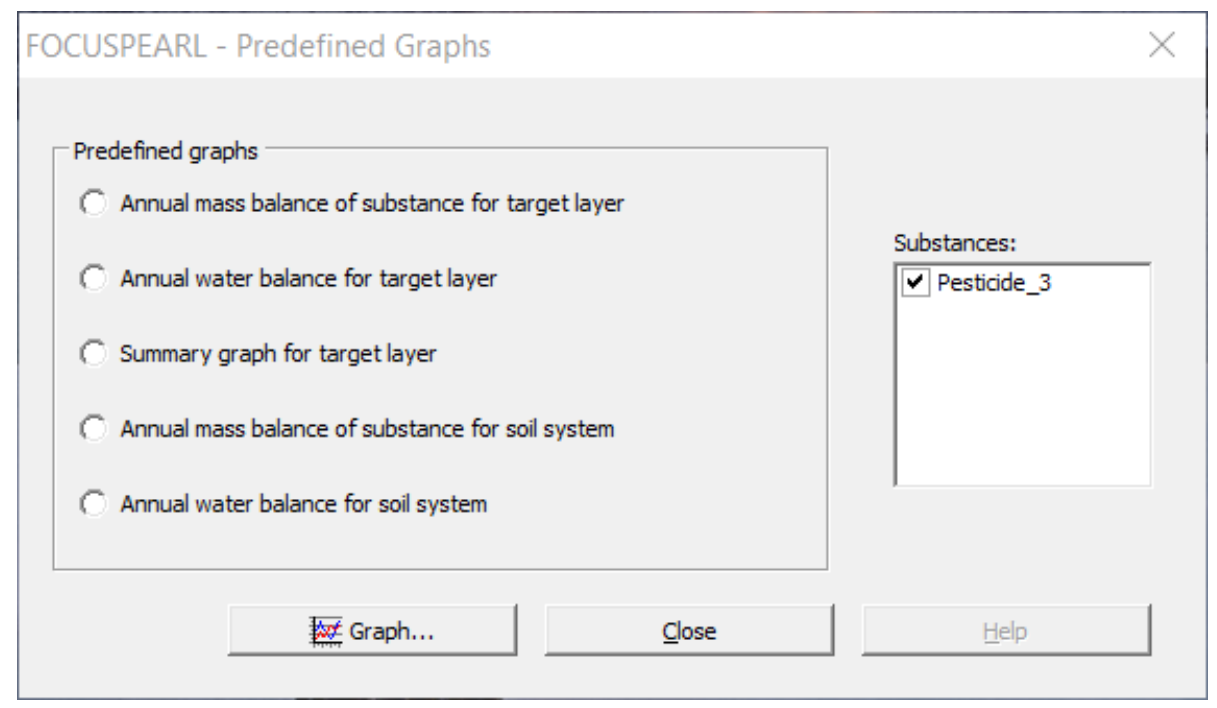

Figure 4.8 The Predefined Graphs Form - the form to select one of the standard graph types. 
An example of one of these graphs, i.e. the Summary graph for the target layer is presented in Figure 4.9. It should be noted that the substance selected for this example has a DT50 in soil of $730 \mathrm{~d}$ and a coefficient for the sorption to organic matter of $1000 \mathrm{~L} \mathrm{~kg}^{-1}$.
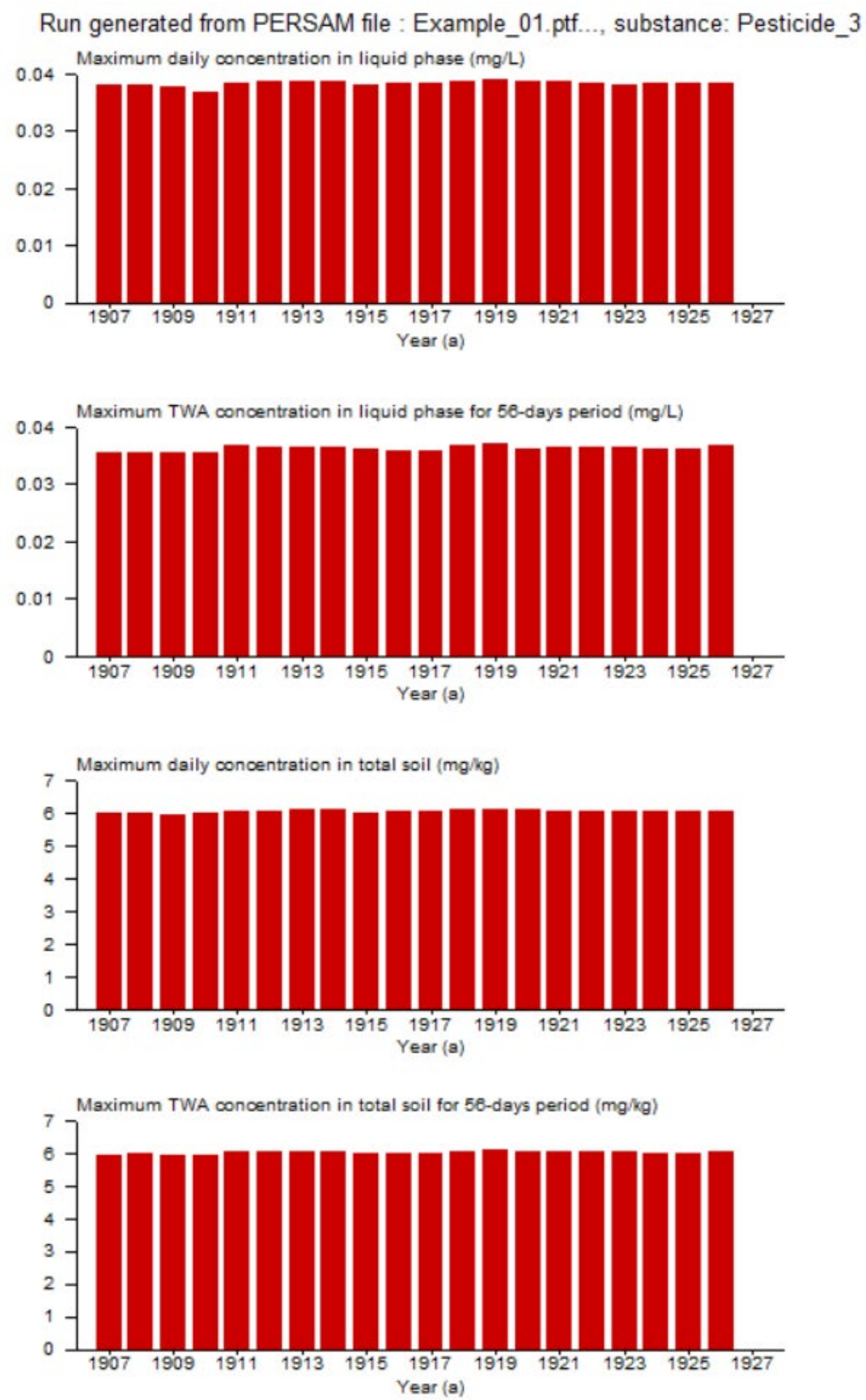

Figure 4.9: Example of a Summary graph for the PEC Soil.

Reports on the results of the runs in the project can be generated by clicking on the Report button (see Figure 3.12). For the soil exposure assessments only report option is available: the option for the selected run only. An example report for a single run, i.e. for substance example pesticide_3 for maize in the Central Zone is shown in Figure 4.10 and 4.11, for the first and second part of this report, respectively. 


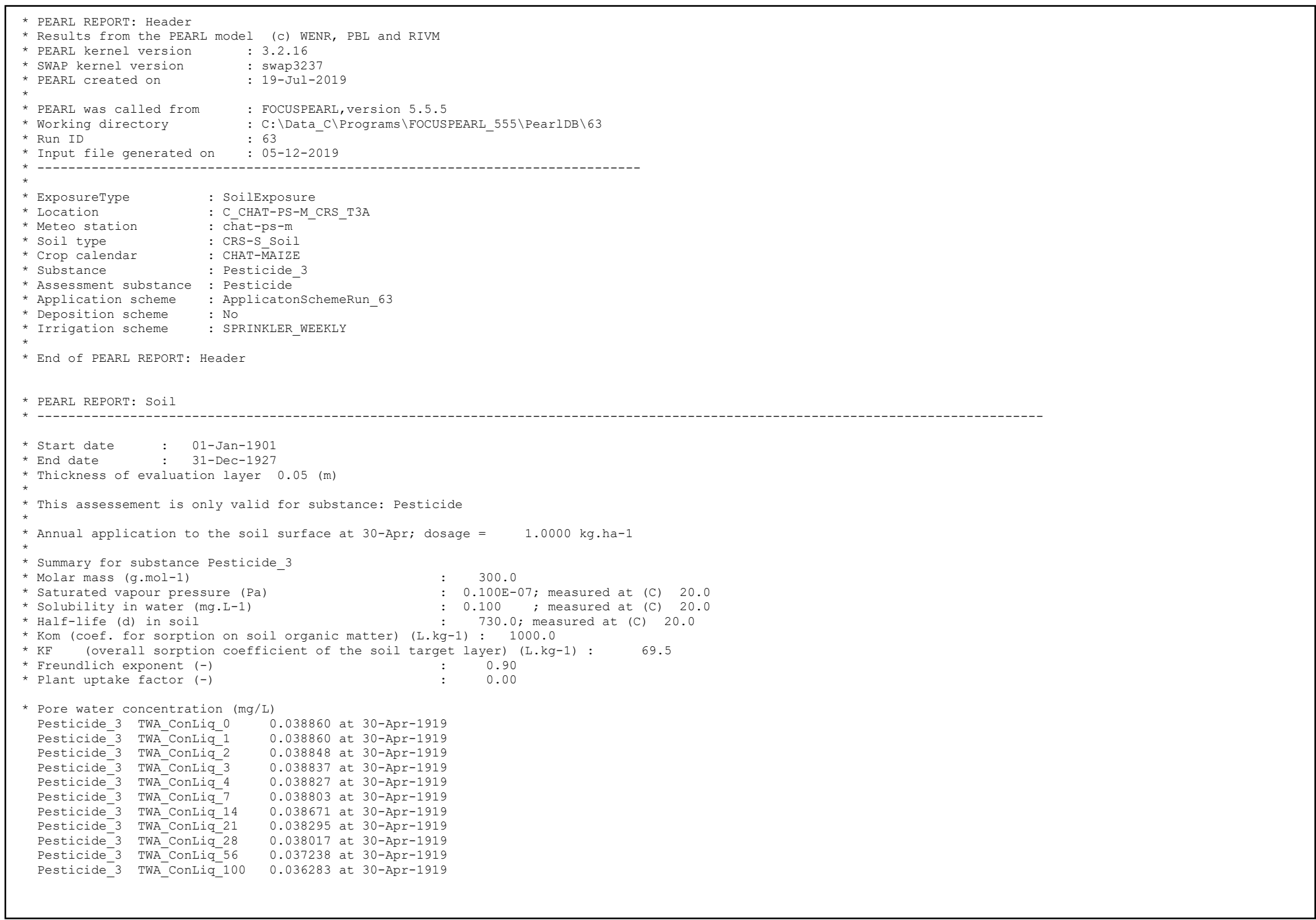

Figure 4.10 


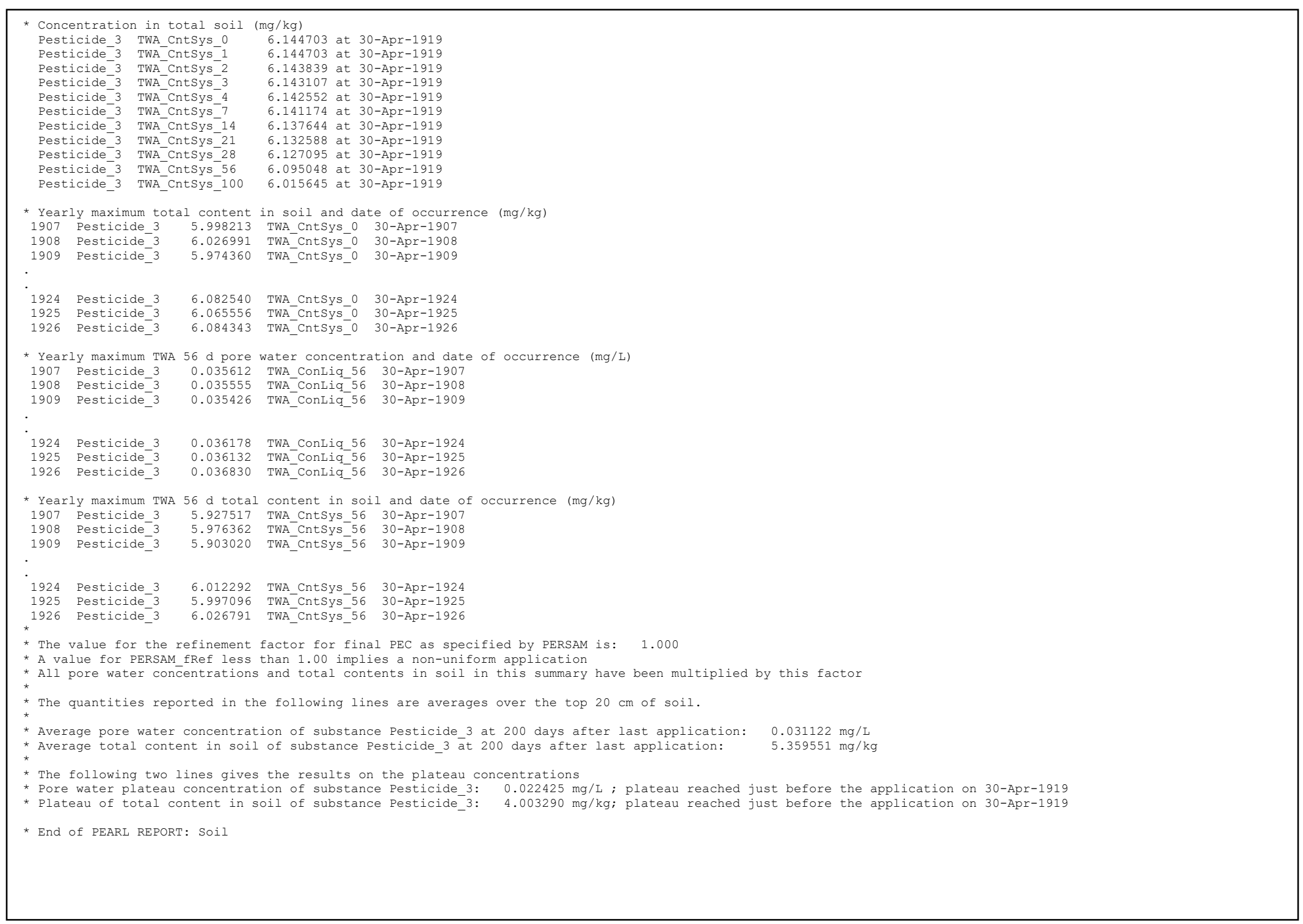

Figure 4.11 Example of a FOCUSPEARL Report for soil exposure assessment - second part 


\section{References}

Allen, R.G., M.E. Wright \& R.D. Burman (1989). Operational estimates of evapotranspiration. Agron. J. (81):650-662.

Boesten, J.J.T.I. \& L. Stroosnijder (1986). Simple model for daily evaporation from fallow tilled soil under spring conditions in a temperate climate. Neth. J. Agric. Sci. (34):75-90.

Bollen, M.J.S., F.H.W.M. Bekhuis, R. Reiling, and E. Scheper (1995). Towards a spatial pattern of the vulnerability of soil and groundwater. rivm report no. 711901012, Bilthoven, the Netherlands. (In Dutch.)

Currie, J.A. (1960). Gaseous diffusion in porous media. 2. Dry granular materials. British J. Applied Physics $11,318-324$.

EFSA (2015). EFSA Guidance Document for predicting environmental concentrations of active substances of plant protection products and transformation products of these active substances in soil. EFSA Journal 2015;13(4):4093, 102 pp., doi:10.2903/j.efsa.2015.4093

EFSA (2017). EFSA Guidance Document for predicting environmental concentrations of active substances of plant protection products and transformation products of these active substances in soil. EFSA Journal 2017;15(10):4982, 115 pp. https://doi.org/10.2903/j.efsa.2017.4982

European Commission (2014). Assessing Potential for Movement of Active Substances and their Metabolites to Ground Water in the EU. Report of the FOCUS Ground Water Work Group, EC Document Reference Sanco/13144/2010 version 3, 613 pp.

Feddes, R.A., P.J. Kowalik \& H. Zaradny (1978). Simulation of field water use and crop yield. Pudoc, Wageningen, The Netherlands.

FOCUS (2000). FOCUS groundwater scenarios in the EU review of active substances. Report of the FOCUS Groundwater Scenarios Workgroup, EC Document Reference Sanco/321/2000 rev.2, 202pp

Horst, M.M.S. ter, W.H.J. Beltman and F. van den Berg, 2016. The TOXSWA model version 3.3. for pesticide behaviour in small surface waters. WOT-technical report 84.

Kroes, J.G., J.C. Van Dam, P. Groenendijk, R.F.A. Hendriks \& C.M.J. Jacobs (2008). SWAP version 3.2. Theory description and user manual. Report 1649. Wageningen UR, Alterra, Wageningen.

Millington, R.J. \& J.P. Quirk (1960). Transport in porous media. In: Transactions 7th Int. Congr. Soil Sci. Soc., Vol. 1: 97-106. F.A. van Baren et al. Elsevier, Amsterdam.

Troeh, F.R., J.D. Jabro \& D. Kirkham (1982). Gaseous diffusion equations for porous materials. Geoderma 27: 239-253.

Van den Berg, F., A. Tiktak, J.J.T.I. Boesten, A.M.A. van der Linden (2016). PEARL model for pesticide behaviour and emissions in soil-plant systems. WOt-technical report 61. Statutory Research Tasks Unit for Nature \& the Environment, Wageningen, $134 \mathrm{pp}$.

Van Heemst, H.D.J. (1986). Crop phenology and dry matter distribution. In: H. van Keulen and J. Wolf (Ed). Modeling of Agricultural Production: Soil, Weather and Crops. p. 13-60.

Van Kraalingen, D., E.L. Wipfler, F. van den Berg, W.H.J. Beltman, M.M.S. ter Horst, J.A. te Roller (2020). SPIN Manual 3.3. In preparation. WOt-technical report 169. Statutory Research Tasks Unit for Nature \& the Environment. 



\section{Justification}

This manual is an update of the manual for the use of FOCUSPEARL 1.1.1 and the addendum for the use of FOCUSPEARL version 4.4.4. The manual had to be updated, because a new version of FOCUSPEARL has been prepared, i.e. FOCUSPEARL v 5.5.5. The authors thank Maarten Braakhekke (Wageningen Environmental Research) for his valuable comments on a draft version of this manual. His comments have been used by the authors to make further improvements to this manual.

This project belongs to the WOT theme 'Agromilieu' with theme leader Erwin van Boekel (WOT Natuur \& Milieu). The project is funded by the Ministry of Agriculture, Nature and Food Quality (project number WOT-04-008-024) with contact person Miranda Meijster. 



\title{
Annex 1 The FOCUSPEARL_555 PEARL input file
}

\author{
* Section 0: Run identification and model version \\ * Section 1: Control section \\ * Section 2: Soil section \\ * Section 3: Weather and irrigation data \\ * Section 4: Boundary and initial conditions of hydrological model \\ * Section 5: Compound section \\ * Section 6: Management section \\ * Section 7: Initial and boundary conditions of pesticide fate model \\ * Section 8: Crop section \\ * Section 9: Output control
}

* Section 0: Run identification

*----------------------------------------

Groundwater

Hamburg

HAMB-S_Soil

HAMB-SÜGARBEET

pest

ExampleScheme

No

No

\section{ExposureType}

Location

SoilTypeID

CropCalendar

SubstanceName

Applicationscheme

Depositionscheme

Irrigationscheme
Scenario identification

Location identification

Soil identification

Crop calendar

Substance name

Application scheme

Deposition scheme

Irrigation scheme

* if ExposureType set to 'SoilExposure' then AssessmentSubstance is reported

pest AssessmentSubstance Name assessment substance

* Section 1: Control section

* Description

* Release type option CallingProgram

* Options can be: FOCUSPEARL, GEOPEARL, DRAINBOW, CHINAPEARL and GEM.

FOCUSPEARL

5.5 .5

Groundwater
CallingProgram

CallingProgramVersion ExposureType
Release type

Version numbers of model, interface and database options are: Groundwater, SoilExposure, Other

* If ExposureType set to 'SoilExposure' then specify ExposureEndPoint and PERSAMLocation

PoreWat ExposureEndPoint Options are PoreWat and Totsol

$54140001890000 \quad$ PERSAMLocation PERSAM XY-coordinates of pixel selected

* Time domain

01-Jan-1901 Timstart

31-Dec-1926 TimEnd

Begin time of simulation [01-Jan-1900|-]

End time of simulation [Timstart/-]

* Specify warming-up period

6 InitYears (y)

$0 \quad$ NumRep (-)

* NumRep only required for ExposureType 'SoilExposure'

* SWAP control

* Options to run SWAP using OptHyd

* OnLine Runs SWAP and then PEARL

* Offline Assumes a pfo file with hydrological output from SWAP

* Automatic Skip SWAP if SWAP run has already been done

* Only

* Standard

* GenerateInput

Run SWAP only and process results in PEARL output format

OnLine

Select the .pfo as specified by the user

Generate the input files for SWAP

Summer SwapID

Option selected to run SWAP

summer

\section{1. $d-5$}

0.1

0.001

9.9

30

* If OptMacropore

0.00001
DelTimSwaMin (d)

DelTimswaMax (d)

ThetaTol (m3.m-3)

GWLTOl (m)

MaxitSwa Dutch surface water standard scenario for

crops

Minimum time step in SWAP $[1 d-8 \mid 0.1]$

Maximum time step in SWAP $[0.01 \mid 0.5]$

Tolerance in SWAP [1e-5|0.01]

Tolerance for groundwater level

Maximum number of iterations in SWAP [1|100] 
* Option to specify output interval. The options are: Hour, Day, Decade Month, Year, Automatic * or Other

* If automatic then output interval calculated - always 1000 steps

Day OptDelTimPrn Option to set output interval

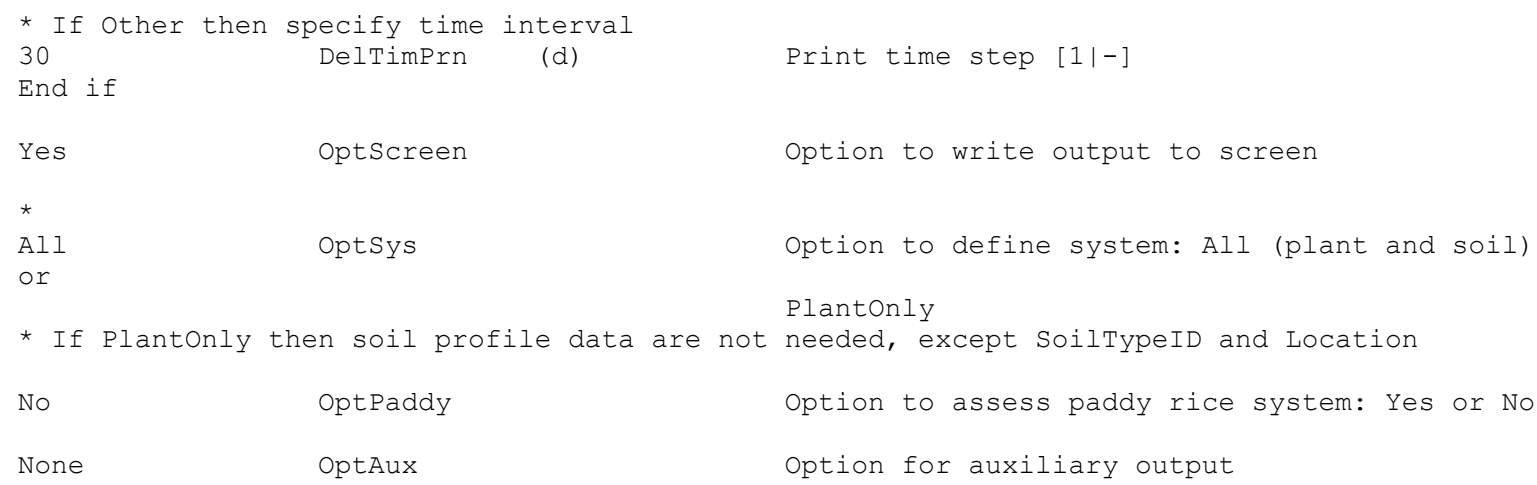

*-----

* Section 2: Soil section

* Description

* The soil profile

* Specify for each horizon:

* Horizon thickness (m)

* The number of soil compartments [1|500]

* Nodes are distributed evenly over each horizon

table Soilprofile

ThiHor NumLay

(m)

$0.01 \quad 5$

$0.29 \quad 29$

0.324

0.156

$0.15 \quad 6$

0.14

$0.5 \quad 10$

end table

* Basic soil parameters

* Specify for each soil horizon:

* Mass content of sand, expressed as a fraction of the mineral soil (kg.kg-1) [0|1]

* Mass content of silt, expressed as a fraction of the mineral soil (kg.kg-1) [0/1]

* Mass content of clay, expressed as a fraction of the mineral soil (kg.kg-1) [0l1]

* Organic matter mass content [0|1]

* pH. pH measured in $0.01 \mathrm{M} \mathrm{CaCl2}$ is preferred (see theory document) (-) [1/13] table horizon Soilproperties

Nr Frasand Frasilt Fraclay Cntom pH

\begin{tabular}{|c|c|c|c|}
\hline$(\mathrm{kg} \cdot \mathrm{kg}-1)$ & $(\mathrm{kg} \cdot \mathrm{kg}-1)$ & $\left(\mathrm{kg} \cdot \mathrm{kg}^{-1}\right)$ & $(\mathrm{kg} \cdot \mathrm{kg}-1)$ \\
\hline 0.683 & 0.245 & 0.072 & 0.026 \\
\hline 0.683 & 0.245 & 0.072 & 0.026 \\
\hline 0.67 & 0.263 & 0.067 & 0.017 \\
\hline 0.962 & 0.029 & 0.009 & 0.0034 \\
\hline 0.998 & 0.002 & 0 & 0 \\
\hline 1 & 0 & 0 & 0 \\
\hline 1 & 0 & 0 & 0 \\
\hline 1 & 0 & 0 & 0 \\
\hline
\end{tabular}

* Parameters of the Van Genuchten-Mualem relationships (B1 + O1)

* Specify for each soil horizon:

* The saturated water content

$(m 3 . m-3) \quad[0 \mid 0.95]$

* The residual water content

$(\mathrm{m} 3 . \mathrm{m}-3) \quad[0 \mid 0.04]$

* Parameter AlphaDry

* Parameter AlphaWet

* Parameter $\mathrm{n}$

$(\mathrm{cm}-1) \quad[1 . d-3 \mid 1]$

$(\mathrm{cm}-1) \quad[1 . d-3 \mid 1]$

* The saturated conductivity

rameter lambda (1)

$(\mathrm{m} \cdot \mathrm{d}-1) \quad[1 . \mathrm{d}-4 \mid 10]$

$(-) \quad[-25 \mid 25]$

* If OptMacropore 'Yes' then specify

* Entry pressure head PreHeaEnt (cm)

* Anisotropy coefficient (-)

* New Staring Series - not used for standard scenario

table horizon VanGenuchtenPar 


\begin{tabular}{|c|c|c|c|c|c|c|c|}
\hline $\mathrm{Nr}$ & $\begin{array}{l}\text { Thetasat } \\
(\mathrm{m} 3 \cdot \mathrm{m}-3)\end{array}$ & $\begin{array}{l}\text { ThetaRes } \\
(\mathrm{m} 3 \cdot \mathrm{m}-3)\end{array}$ & $\begin{array}{r}\text { AlphaDry } \\
(\mathrm{cm}-1)\end{array}$ & $\begin{array}{l}\text { AlphaWet } \\
(\mathrm{cm}-1)\end{array}$ & $(-)$ & $\begin{array}{l}\text { KSat } \\
\qquad(m \cdot d-1)\end{array}$ & $(-)$ \\
\hline 1 & 0.391 & 0.036 & 0.0149 & $9 \quad 0.0298$ & 1.468 & 2.016 & 0.5 \\
\hline 2 & 0.391 & 0.036 & 0.0149 & 0.0298 & 1.468 & 2.016 & 0.5 \\
\hline 3 & 0.37 & 0.03 & 0.0126 & 0.0252 & 1.565 & 2.736 & 0.5 \\
\hline 4 & 0.351 & 0.029 & 0.0181 & 0.0362 & 1.598 & 2.448 & 0.5 \\
\hline 5 & 0.31 & 0.015 & 0.0281 & 0.0562 & 1.606 & 2.448 & 0.5 \\
\hline 6 & 0.31 & 0.015 & 0.0281 & 0.0562 & 1.606 & 2.448 & 0.5 \\
\hline 7 & 0.31 & 0.015 & 0.0281 & 0.0562 & 1.606 & 2.448 & 0.5 \\
\hline 8 & 0.31 & 0.015 & 0.0281 & 0.0562 & 1.606 & 2.448 & 0.5 \\
\hline
\end{tabular}

Input

OptRho

Option for bulk density: Calculate or Input

* If Rhoopt = Input then specify bulk density for each horizon:

table horizon Rho (kg.m-3) [100|2000]

$1 \quad 1500.0$

1500.0

1600.0

1560.0

1620.0

1600.0

1600.0

1600.0

end table

* Eñd If

* If Rhoopt = Calculate then no extra data are needed on bulk density

* Option to include hysteresis

No OptHysteresis Hysteresis option: No, InitWetting InitDrying

* If No or InitDrying then specify minimum pressure head

$0.2 \quad$ PreHeaWetDryMin $(\mathrm{cm}) \quad$ Minimum pressure head to switch drying/wetting

* Maximum ponding depth and boundary air layer thickness (both location properties)

$0.01 \quad$ ZPndMax $\quad(\mathrm{m}) \quad$ Maximum ponding depth [0|1]

* If OptMacropore is 'Yes' then specify boundary pressure head that controls run-off

$0.0 \quad \mathrm{Hb} \quad(\mathrm{cm}) \quad$ Boundary pressure head

$0.001 \quad$ RstSurRunoff (d) Resistance for surface runoff

* End if

* Soil evaporation parameters

1.2 FacEvpsol "Crop factor" for bare soil [0.5/1.5]

* Option to select evaporation reduction method: Boesten or Black

Boesten OptSolEvp Evaporation reduction option

* If Boesten or Black specify soil evaporation parameters

$0.79 \quad$ CofRedEvp ( $\quad$ Parameter in Boesten equation [0/1]

0.01 PrcMinEvp (m.d-1) Minimum rainfall to reset reduction

* Parameter values of the functions describing the relative diffusion coefficients MillingtonQuirk OptCofDifRel MillingtonQuirk, Troeh or Currie

* If MillingtonQuirk:

2.0 ExpDifLiqMilNom (-)

$0.67 \quad$ ExpDifLiqMilDen (-)

2.0 ExpDifGasMilNom (-)

0.67 ExpDifGasMilDen (-)

Exponent in denominator of eqn [0.1/2]

* If Troeh:

0.05 CofDifliqTro

1.4 ExpDifLiqTro

$0.05 \quad$ CofDifGastro

$(-)$

$(-)$

$(-)$

Exponent in nominator of equation [0.1/5]

1.4

$(-)$

Exponent in denominator of eqn

$[0.1 \mid 2]$

* If Currie:

2.5

CofDifLiqCur

$(-)$

ExpDifLiqCur

CofDifGascur

$(-)$

Coefficient in Troeh equation

$[0 \mid 1]$

Exponent in Troeh equation

$[1 \mid 2]$

Coefficient in Troeh equation

$[0 \mid 1]$

Exponent in Troeh equation

$[1 \mid 2]$

2.5

ExpDifGascur

$(-)$

Coefficient in Currie equation

$[0 \mid-]$

3.0

Exponent in Currie equation

$[1 \mid-]$

* End If

Exponent in Currie equation

$[1 \mid-]$

* Dispersion length of solute in liquid phase [0.5Delz|1]

Table horizon LenDisLiq (m)

10.05

20.05

30.05 
* Ponding of water on soil surface: Constant or TimeDependent

Constant OptPnd Option for ponding of water

* If TimeDependent specify file with data on ponding depth

Fileid PondingDepthFile

* Section 2a: Macropore section

* Only required if OptMacropore set to 'Yes'

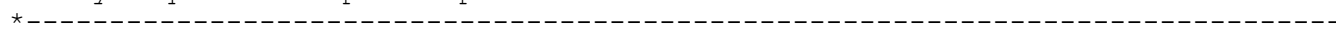

No OptMacropore Simulate macropore flow (Yes|No)

\section{* Section 3: Weather and irrigation data}

* Description

\section{*------------}

hamb-m

Input
Meteostation

OptEvp
Maximum 7 characters.

Evapotranspiration: Input, Penman, PenmanMonteith or Makkink

* if ExposureType set to 'Soilexposure' then specify OptCov

LAI OptCov Option to calculate interception: LAI or Covsol (Soil Cover)

$\begin{array}{lll}52.0 & \text { Lat } & \text { Latitude of meteo station }[-60 \mid 60] \\ 10.0 & \text { Alt } & \text { Altitude of meteo station }[-400 \mid 3000]\end{array}$

* Initial lower boundary soil temperature [-20|40]

* Upper boundary temperature is read from meteo file

12.6 TemLbosta

* Irrigation section

No OptIrr

* Options for OptIrr are:

* No: no irrigation

* Surface: Surface irrigation, irrigation depth spec. by user

* Surface Auto: Surface irrigation, irrigation depth calc. by model

* Sprinklēr: Sprinkler irrigation, irrigation depth spec. by user

* Sprinkler_Auto: Sprinkler irrigation, irrigation depth calc. by model

* Sprinkler_Weekly: Sprinkler irrigation, irrigation depth calc. by user

FileName IrrigationData

Name of file with irrigation data

* Irrigation data have to be provided in a file station.irr (e.g. debilt.irr);

* Maximum number of characters in filename is 7.

* If RepeatHydrology is set to Yes, the first year is required only

* Format of the file should be as below:

* table IrrTab (mm)

* 01-Aug-1980 10.0

* end table

$\begin{array}{lll}1.0 & \text { FacPrc }(-) & \text { Correction factor for precipitation } \\ 0.0 & \text { DifTem (C) } & \text { Correction for temperature } \\ 1.0 & \text { FacEvp }(-) & \text { Correction factor for evapotranspiration } \\ \text { Daily } & \text { OptMetInp } & \text { option for meteorological data: Hourly or }\end{array}$

Daily

* Options for the calculation of the resistance of air to volatilisation; options are Laminar

* or Aerodynamic

* If set to 'Aerodynamic' then OptResBou is also required: options are Hicks or Wang

* If set to 'laminar' then ThiAirBoulay required

Laminar OptTraRes

If set to 'Laminar' then specify thickness boundary air layer

0.01 ThiAirBoulay (m) Boundary air layer thickness [1e-6/1]

* If set to 'Aerodynamic' then OptResBou is also required: options are Hicks or Wang

Hicks OptResBou (-) Option to calculate resistance boundary layer

$0.01 \quad$ LenRghmtLcl (m) Specify local roughness length

$\begin{array}{lll}10.0 & \text { ZMeaWnd } & (\mathrm{m})\end{array}$

* End if

No

No OptRainfallEvents

Option to consider rainfall events

* If set to 'Yes' then specify duration of events

$0.1 \quad$ LenRainfall (d) 
* Section 4: Boundary and initial conditions of hydrological model

* Section 4a: Lower boundary flux conditions

* Description

* Initial condition

$-200.0 \quad$ ZGrwtevsta

$(\mathrm{cm})$

Initial groundwater level [-5000|0]

* Choose one of the following options for the bottom boundary:

* GrwLev Flux Cauchy FncGrwLev Dirichlet Zeroflux FreeDrain Lysimeter

FncGrwLev OptLbo Lower boundary option selected

* If LboOpt $=$ GrwLev specify file with groundwater level data

* FileId LowerBoundaryfile

* Read from LowerBoundaryFile (FileId.bot)

* table GrwLev (cm)

* $01-J a n-1901-100.0$

* 31-Dec-1926 -100.0

* end_table

* End if

* If Lboopt $=$ Flux then specify flux lower boundary option

* Options for bottom flux can be Sine or Table

* Headonly OptBotFlux

* If Optbotflux = Sine then specify average, amplitude and day of maximum

* $-0.250 \quad$ FlvLiqLboAvg (m.a-1) Average annual lower boundary flux [-1|1]

* $0.10 \quad$ FlvLiqLboAmp (m) Amplitude of lower-boundary flux [0|0.5]

* 01-Oct DayFlvLiqLboMax

* If Optbotflux = Table then specify file with flux data

* FileId LowerBoundaryfile

* End if

* If Lboopt = Cauchy then specify lower boundary option

* Options for bottom flux can be Sine, HeadOnly or HeadAndFlux

* Headonly OptBotFlux

OptNoResVert

* NoDrains OptShapeGrwLev

* -0.8200

HeaDraBase

Option selected for bottom flux

* 5.0

RstAgt

Switch on or switch off vertical resistance

* If OptBotflux = Sine then specify average, amplitude and day of maximum

$-1.4 \quad$ HeaAgfAvg (m) Mean hydraulic head of aquifer [-10|10]

0.2 HeaAqfAmp (m) Amplitude of aquifer hydraulic head [0|10]

01-May DayHeaAqfMax (d) Day with maximum head [01-Jan|31-Dec]

* If OptBotflux Headonly or HeadAndFlux specify file with data

* Lower boundary conditions

BBW LowerBoundaryFile

* If Headonly then read data on Head from LowerBoundaryfile (FileId.bot)

* table HeaAgfAve (cm)

* $01-J a n-1901-100.0$

* 31-Dec-1926 -100.0

* end table

* End ${ }^{-}$if

* If HeadAndFlux then read data on Head and Flux from LowerBoundaryFile (FileId.bot)

* table HeaAqfAve QBot

* 01-Jan-1901 -100.0 0.003

* 31-Dec-1926 -100.0 0.005

* end table

* End if

* If LboOpt $=$ FncGrwLev (flux boundary condition - flux is a function of groundwater level)

$\begin{array}{llll}-0.01 & \text { CoffncGrwLev } & (\mathrm{m} . \mathrm{d}-1) & \text { Coefficient in Q(h) relationship [-1|1] } \\ -1.4 & \text { ExpFncGrwLev } & (\mathrm{m}-1) & \text { Exponent in Q(h) relationship [-100|100] }\end{array}$

* Lboopt $=$ Dirichlet the read data on pressure head boundary condition from file FileId.bot

* FileId

* table h $(\mathrm{m})$

* $01-\mathrm{Jan}-1.0$

* 31-Dec -1.0

* end_table

* Section 4b: Local drainage fluxes to ditches and drains

No OptDra

o NumDraLev
Pressure head $[-1 e 4 \mid 1 e 4]$ 
* If OptDra $=\backslash$ No then NumDraLev cannot be zero.

* Section 5: Compound section

* Description

* Compounds. First compound is the parent pesticide, the others are metabolites. table compounds

pest

end table

200.0 Molmas pest (g.mol-1) Molar mass [10|10000]

* Name assessment substance relevant for ExposureType option 'SoilExposure'. In that case only the results of the assessment substance (parent or one of the metabolites) can be reported for the exposure assessment.

pest Assessmentsubstance Name assessment substance

* Transformation table (parent-daughter relationships)

table FraPrtDau (mol.mol-1)

end table

* Example for a pesticide with three metabolites, named "met1", "met2" and "met3":

* Reaction 1: pest is transformed into met1 (25\%)

* Reaction 2: pest is transformed into met2 (44\%)

* Reaction 3: met1 is transformed into met3 (63\%)

* table FraprtDau (mol.mol-1)

* 0.25 pest $\rightarrow$ met 1

* 0.44 pest $\rightarrow$ met 2

* 0.63 met $1->\operatorname{met} 3$

* end_table

* Transformation rate parameters

EqlDom_Input OptDT50_pest

Option for DT50: Input or Calculate in equilibrium domain (EqlDom) or in liquid phase only (LiqPhs)

$50.0 \quad$ DT50Ref_pest (d) Half-life time [1|1e6]

20.0 TemRefTra pest (C) Temperature at which DT50 is measured [5/30]

$0.70 \quad$ ExpliqTra_pest (-) Exponent for the effect of liquid [0/5]

OptimumConditions OptCntLiqTraRef pest OptimumConditions or NonoptimumConditions

1.0 CntLiqTraRef pest (kg.kg-1) Liq. content at which DT50 is measured [0/1]

65.4 MolentTra_pest (kJ.mol-1) Molar activation energy [0|200]

* Two options for input possible for FaczTra: interpolate or horizon

* If 'horizon' option selected then specify factor for each horizon

* If 'interpolate' option selected then specify factor and depth

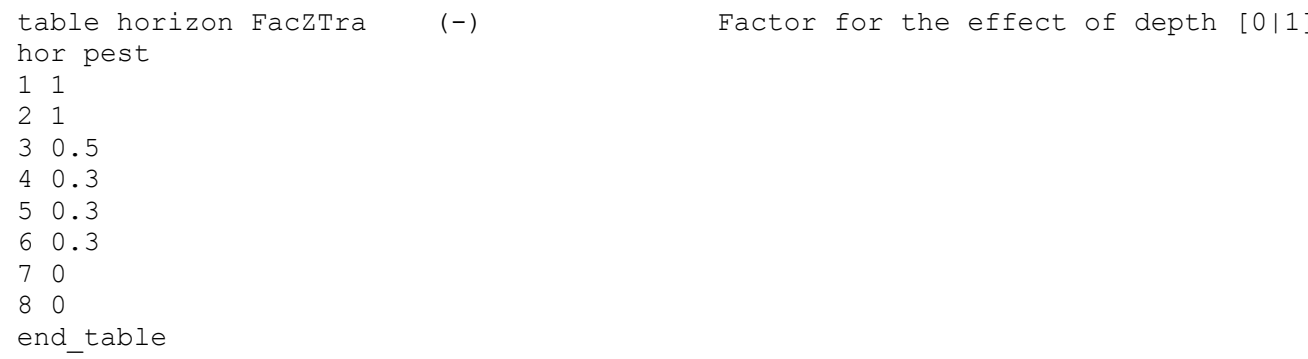

* Freundlich equilibrium sorption pH-independent OptCoffre pest

ConLigRef pest

. 9 (n)

ExpFre_pest

$(\mathrm{mg} \cdot \mathrm{L}-1)$

pH-dependent, pH-independent, Coffre

0.9

* If pH-independent (use the coefficient for sorption on organic matter):
70.0 KomEql_pest (L.kg-1)
coef. eql. sorption on org. matter [0|1e9]

7000.0

KomEqlMax pest

$(\mathrm{L} . \mathrm{kg}-1)$

Coef. eql. sorption on org. matter in dry soil [0|1e9]

* If pH-dependent (use pKa value and coefficient for sorption on organic matter):
374.7
7.46
KomEqlAcid pest ( L. kg-1)
Coef. for eql. sorption on om - acid [0|1e9]
4.6 KomEqlBase pest ( L. kg-1) Coef. for eql. sorption on om - base [0|le9]
0.6 pKa pest
$(-)$ Coef. for influence of $\mathrm{pH}$ on sorption [0|14] pHCorrection
$(-)$ $\mathrm{pH}$ correction $[-2 \mid 1]$

* If Coffre (specify the depth dependence and the coefficient for equilibrium sorption): 1.0 KSorEql_pest (L.kg-1) Coef. for equilibrium sorption [0/1e9]
0.0 Molentsor_pest
(kJ.mol-1) 
* Two options for input possible for FaczSor: interpolate or horizon

* If 'horizon' option selected then specify factor for each horizon

* If 'interpolate' option selected then specify factor and depth

table horizon FaczSor

$(-)$

Factor for the effect of depth

$[0 \mid 1]$

hor pest

$1-99$

$2-99$

$3-99$

$4-99$

$5-99$

$6-99$

$7-99$

$8-99$

end table

* End If

* Gas/liquid partitioning

$0.0 \quad$ PreVapRef

20.0

TemRefVap_pest

MolEntVap pest

SlbWatRef pest

33.0

TemRefSlb_pest

20.0

MolEntSlb pest

(Pa) Saturated vapour pressure [0|2e5]

(C) $\quad$. measured at [0|40]

(kJ.mol-1) Molar enthalpy of vaporisation [-200|200]

40.0

$\mathrm{mg} \cdot \mathrm{L}-1$

(C)

Solubility in water [1e-9|1e6]

* Non-equilibrium sorption

0.00 CofDesRat_pest (d-1)

$0.5 \quad$ FacSorNeqEqI_pest (-)

.. measured at [0|40]

(kJ.mol-1) Molar enthalpy of dissolution [-200|200]

* Uptake

0.5

FacUpt_pest

$(-)$

Desorption rate coefficient

Coffreneq/CoffreEql [0|-]

* Canopy processes

Lumped

OptDspCrp_pest

Coefficient for uptake by plant

$[0 \mid 10]$

* If Lumped:

Lumped, Specified or Calculated

1. $d 6$

DT50DspCrp_pest

(d)

* If Specified:

$1 . \mathrm{d} 6$

$1 . d 6$

DT50PenCrp_pest

DT50VolCrp pest

DT50TraCrp_pest

(d)

(d)

(d)

* If Calculated:

1. $d 6$

$1 . d 6$

500.0

0.0

0.2

of

DT50PenCrp_pest

DT50TraCrp pest

RadGloRef

(d)

(d)

FraDepRex

(W. m-2)

FacTraDepRex

0.2

of

FacVolDepRex

$(-)$

0.2

of

FacPenDepRex

$(-)$

FacWasDepRex

* End If

1. $d-4$

FacWasCrp_pest

$(m-1)$

Half-life at crop surface [1|1e6]

Half-life due to penetration [1|1e6]

Half-life due to volatilization [1|1e6]

Half-life due to transformation [1|1e6]

Half-life due to penetration [1|1e6]

Half-life due to photo-transformation [1|1e6]

Global solar radiation for DT50TraCrp

Fraction of deposit with reduced exposure

Factor for the effect of restricted exposure

deposit on transformation

Factor for the effect of restricted exposure

deposit on volatilisation

Factor for the effect of restricted exposure

deposit on penetration

Factor for the effect of restricted exposure

deposit on wash-off

Wash-off factor $[1 e-6 \mid 0.1]$

* Diffusion of solute in liquid and gas phases

4. $3 d-5$

0.43

CofDifWatRef pest (m2.d-1)

20.0

CofDifAirRef pest (m2.d-1)

Reference diff. coeff. in water [10e-5/3e-4]

TemRefDif_pest (C)

Diff. coeff measured at temperature [10|30]

* Section 6: Management section

* Description

$1.0 \quad$ ZTgt

$1 \quad$ DelTimEvt

(m)

Depth of target layer [0.1|Z(N)-1]

Event table:

Repeat interval of events [NoRepeat|1|2|3] 
* Column 1: Date* Column 2: Event type: AppSolSur, AppSolInj, AppSolTil, AppCrpUsr, AppCrpLAI

* and ApplfLess

* AppsolSur, AppSolinj, AppSolTil cannot be combined with OptSys set to Plantonly

* Application to stem : to be added

* If relative date then format is xx-yyy-zzz

* $x x$ : cropnumber in calendar year

* Yyy: event, Emg (=Emergence) or Har (=Harvest)

* If absolute then format is dd-mmm-yyyy (day - month - year), e.g. 07-Jun-1980

* zzz: days before event (-zzz) or after event (+zzz)

* If Event = AppSolSur (

* Column 3: Dosage (kg/ha) [0|-]

* If EventType = AppCrp (application to the crop canopy):

* Column 3: Dosage (kg/ha) [0|-]

* Column 4: Optional: Fraction of dosage applied to the crop canopy (-) [0|1]

* Column 5: Optional: Ffield - fraction of dosage lost by fast dissipation (-) [0|1]

* Required for application by spraying; not required for application by

* injection (AppSolInj) or incorporation (AppSolTil)

* If EventType = AppLfLess (application to the stem):

* Column 3: Dosage ( $\mathrm{kg} / \mathrm{ha}) \quad[0 \mid-]$

* Column 4: Fraction of dosage intercepted by stem (-) [0|1]

* Column 5: Ffield - fraction of dosage lost by fast dissipation (-) [0|1]

* Column 5 is only required for ExposureType 'SoilExposure'

* End If

table Applications

01-Emg-001 AppSolsur 1.0

end table

* Tillage table - can be empty

* Specify date (dd-mmm-yyy) or day in year (dd-mmm) and tillage depth (m)

* table TillageDates

* 15 -Oct 0.2

* end table

* Tillage cannot be combined with optsys set to Plantonly

table TillageDates

15 -oct 0.20

end table

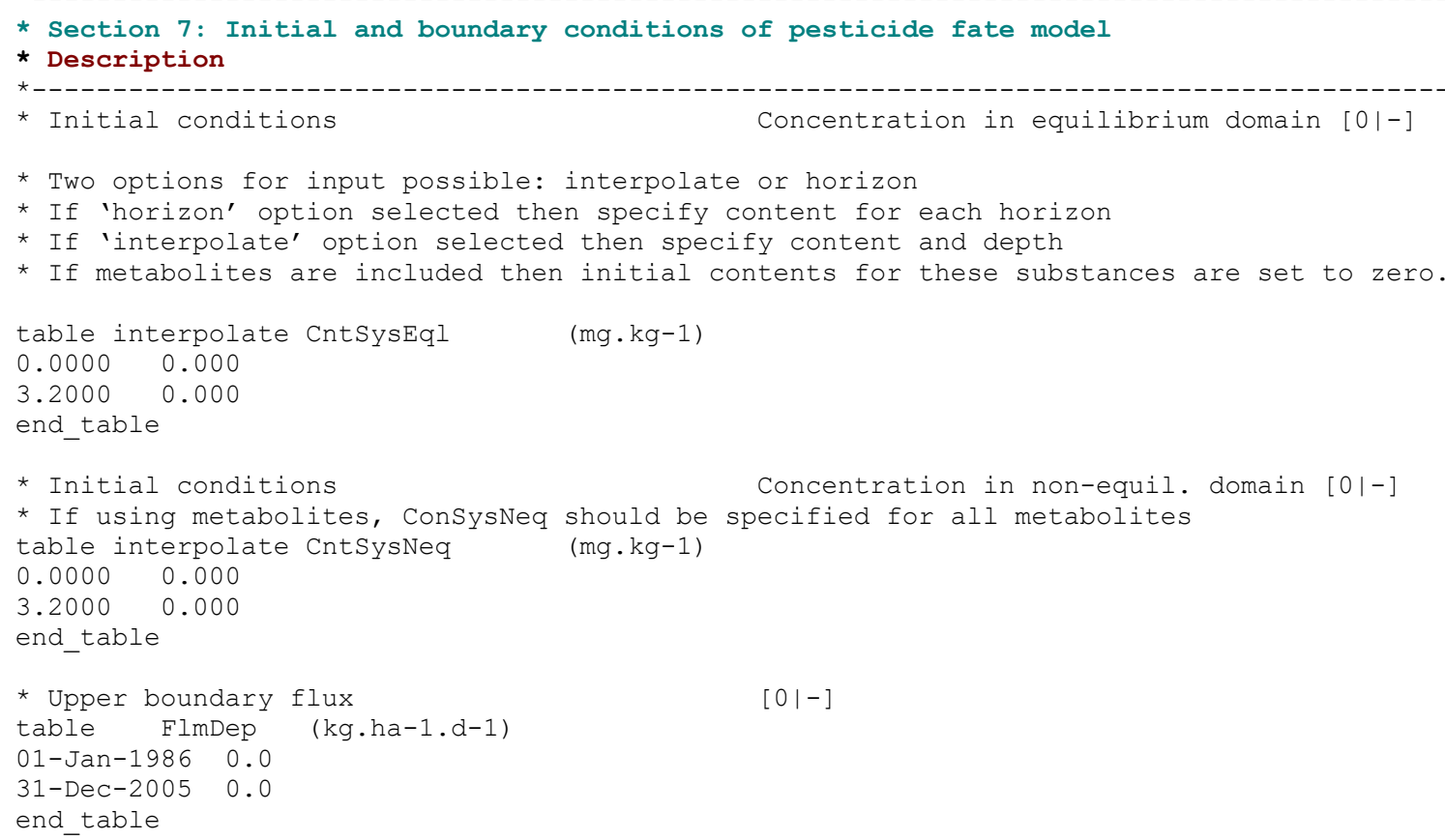

* Emergence and harvest date of crop.

* Note: Length of growing season must be constant for one crop 
* If repeat crops: Specification of year not required

table Crops

15-Apr 08-Oct SUGARBEET1

end_table

* Crop cycle fixed or variable (calculated from temperature sum)

Fixed OptLencrp

Fixed or Variable

* If OptLenCrp = Variable:

$\begin{array}{llll}0.0 & \text { TemSumSta_SUGARBEET1 } & \text { (C) } & \text { Start value of temperature sum [-10|20] } \\ 0.0 & \text { TemSumEmgÄnt_SUGARBEET1 } & \text { (C) } & \text { Sum from emergence to anthesis [0|1e4] }\end{array}$

0.0 TemSumAntMat SUGARBEET1 (C) Sum from anthesis to maturity [0|le4]

* End If

If only plant compartment is considered (Optsys set to 'Plantonly') then specify fraction of soil covered by the crop

$0.765 \quad$ FraCovCrpInp (-) Eraction of soil covered by the crop [0|1]

End if

* Crop parameters as a function of development stage

* Column 1: Development stage: $0=$ emergence; 1 = harvest

* Column 2: LAI: Leaf Area Index

* Column 3: FacCrp: Crop factor

* Column 4: ZRoot: Rooting depth

* Column 5: HeightCrp: Crop height

* LAI FacCrp zRoot HeightCrp

table CrpPar SUGARBEET1

$\begin{array}{lllll}0.0 & 0.0 & 1.0 & 0.0 & 0.0 \\ 0.78 & 4.2 & 0.87 & 1.2 & 0.0 \\ 1.0 & 4.2 & 0.87 & 1.2 & 0.0\end{array}$

end_table

* Root density table (first column is relative depth)

* Column 1: Relative depth $0=$ soil surface; $1=\operatorname{DepRoot~(-)}$ [0|1]

* Column 2: Root density distribution

$(-) \quad[0 \mid 1]$

Table RootDensity_SUGARBEET1

$\begin{array}{ll}0.00 & 1.00 \\ 1.00 & 1.00\end{array}$

1.00
end table

* Crop water use

$-10.0$

$-25.0$

$-320.0$

$-600.0$

$-16000.0$

HLIm1 SUGARBEET1 (cm)

HLim2 SUGARBEET1 (cm)

HLim3U_SUGARBEET1 (cm)

HLIm3L SUGARBEET1 ( $\mathrm{cm})$

HLim4_SUGARBEET1 (cm)

RstEvpCrp SUGARBEET1 (s.m-1)

CofExtDif_SUGARBEET1 (-)

CofExtDir SUGARBEET1 (-)

ZTensioMeter SUGARBEET1 (m)

FraCovStm_SUGARBEET1 (-)

PreHeaIrrsta SUGARBEET $1 \quad(\mathrm{~cm})$

CofIntCrp_SUG̈ARBEET1 (cm)

IrgThreshōld SUGARBEET1 (mm)
$(-)$

$(\mathrm{m} 2 \cdot \mathrm{m}-2)-[0 \mid 12]$

$(-) \quad[0 \mid 2]$

(m) $\quad[0 \mid 10]$

(m) $\quad[0 \mid 10]$

1.0

0.2

$-100.0$

1. $d-4$

15.0

\begin{abstract}
Anaerobiosis point [-100/0]
Wet reduction point [-1000/0]

Dry reduction point $[-10000 / 0]$

Dry reduction point $[-10000 \mid 0]$

Wilting point [-16000/0]
\end{abstract}

Min. canopy resistance [0|1000]

Soil cover fraction for crop without leaves

Constant in Braden eq for interception [0|1]

Threshold of moisture deficit to allow

irrigation

* Section 9: Output control

* Description

* First, specify the time format in the output file:

* Daysfromsta : Print number of days since start of simulation

* Daysfrom1900 : Print number of days since 1900

* Years : Print years

Daysfromsta DateFormat Format of time column in output file

Yes OptDelOutFiles

Yes PrintCumulatives

* Specify type of report required

* Leaching report is not relevant if only Plant compartment is considered

* If ExposureType set to 'Groundwater' then LeachingReport set to Yes, else set to No

* If ExposureType set to 'SoilExposure' then SoilReport set to Yes, else set to No

* If ExposureType set to 'Other', then LeachingReport, SoilReport, DrainageReport and

* AirReport set to No

$\begin{array}{ll}\text { Yes } & \text { LeachingReport } \\ \text { No } & \text { DrainageReport }\end{array}$

No AirReport

Summary report for leaching assessment

Summary report for drainage assessment

Summary report for volatilisation assessment 
* If ExposureType set to 'SoilExposure' then specify IntPostApp

* IntPostApp - Interval (days) after last application for additional output on soil exposure

$124 \quad$ IntPostApp $(d)$

Interval (days) after last application

* If OptReport set to SoilReport
0.0 ZEADTOP
(m)
Depth of the top of the layer for exposure of
0.2
ZEADBot
(m)
Depth of the bottom of the layer for exposure
of

soil organisms (Ecological Averaging Depth)

* Else

0.2

ThiLayPer

(m)

Target depth for persistence

* End if

If LeachingReport set to 'Yes' then specify target percentile

80.0 TargetPercentil

End if

() Percentile for leaching assessment

* Specify dates for vertical profiles of main state variables, e.g. concentration in liquid * phase; table can be empty

table Verticalprofiles

end table

* Format of the ordinary output - use FORTRAN notation:

* e is scientific notation, $g=$ general is general notation

* Then follow the number of positions

* Then the number of digits

g12.4 RealFormat

Format of ordinary output

* If OptSys is set to 'All' (Soil and Plant) then specify the nodal heights for which output is requested

* Options are 'table', None or All

table OutputDepths (m)

0.05

0.1

0.2

0.3

0.4

0.5

0.75

1.0

2.0

end table

* Finally, specify for all variables whether output is wanted (Yes or No)

* As PEARL can potentially generate large output files, it is recommended to minimise

* the number of output variables

* Section I : Output from the SWAP model, version 2.0.9e

* Meteorological data

$\begin{array}{lll}\text { No } & \text { print_VelWnd } & \text { wind speed } \\ \text { No } & \text { print_TemAir } & \text { air temperature }\end{array}$

* General variables

$\begin{array}{ll}\text { No } & \text { print_GrwLev } \\ \text { No } & \text { print_LAI } \\ \text { No } & \text { print_ZRoot } \\ \text { No } & \text { print_FacCrpEvp } \\ \text { No } & \text { print_FraCovCrp } \\ \text { No } & \text { print_AvoLiqErr } \\ \text { No } & \text { print_StoCap } \\ \text { No } & \text { print_AvoLiqSol } \\ \text { No } & \text { print_ZPnd }\end{array}$

Groundwater level (m)

Leaf Area Index (m2.m-2)

Rooting depth (m)

Crop factor (-)

Soil cover (-)

Water balance error (m)

Phreatic storage capacity (m3.m-2)

Amount of water in soil

Ponding depth (m)

* If OptMacropore set to 'Yes'

No

No

No

* End if

* State variables

$\begin{array}{ll}\text { No } & \text { print_Tem } \\ \text { No } & \text { print_Eps } \\ \text { No } & \text { print_Theta } \\ \text { No } & \text { print_PreHea }\end{array}$

print AvoMacIca

print_AvoMacByp

print AvoLiqIca

print AvoLiqByp

print_GrwLevByp

print PreHea
Soil temperature (C)

Volumic air content (m3.m-3)

Volumic soil water content (m3.m-3)

Soil water pressure head (m) 
* Volumic volume rates (m3.m-3.d-1) No print_VvrLiqDra

No print_VvrLiqupt

* If OptMacropore set to 'Yes'

No print_VvrLiqDraByp

No print_VvrLiqMicByp

No print VvrLiqMicIca

* End if

* Volume fluxes (m3.m-2.d-1)

No print_FlvLiq

No print_FlvLiqPrC

No print FlvLiqIrr

No print_FlvLiqLbo

No print_FlvLiqInf

No print_FlvLiqEvpIntPrc

No print_FlvLiqEvpIntIrr

No print FlvLiqEvpSol

No print FlvLiqEvpSolPot

No print_FlvLiqTrp

No print FlvLiqTrpPot

No print_ElvLiqCanDrp

* If drainage is considered: OptDra $>=1$ No

No

No

No

No

No

No

No

* End if

No

No

* I No

No

No

No
$1)$

No

1)

No

No

1)

No

* End if

* Section II : Output from the PEARL model

* Remark: All fluxes are averages over the print interval

* Time step

$\mathrm{No}$

print_DelTimPrl

Average time-step during the print interval

* Section II a: Output for the soil compartment; OptSys = All (Plant and Soil compartment)

Volumic volume rate of drainage

Volume flux of water uptake
Volume flux of vertical soil water flow

Volume flux of precipitation

lume flux of water in irrigation

Volume flux of water leaching from the soil system

Volume flux at lower boundary (m.d-1)

vaporation flux of intercepted rainfall

Volume flux of evaporation from the soil surface

of transpiration by plant roots

, potential

Volume flux of drainage to level 1

Volume flux of drainage to level 2

Volume flux of drainage to level 3

Volume flux of drainage to level 4

Volume flux of drainage to level 5

Volume flux of lateral discharge - level 1 (m.d-1)

Drainage from micropore and macropore domain

Volume flux of lateral discharge - level 2 (m.d-1)

Drainage from micropore and macropore domain

Volume flux of lateral discharge - level 3 (m.d-1)

Drainage from micropore and macropore domain

Volume flux groundwater recharge

Groundwater flux (m.d-1)

Direct infiltration into ic domain (m.d-1)

Infiltration by runoff into ic domain (m.d-1)

(m.d-1)

Exchange flux between micropores and bypass (m.d-

Exchange flux between bypass and matrix (m.d-1)

Exchange flux between micropores and ic dom. (m.d-

Exchange flux between ica and matrix (m.d-1)
No

print_AmaErrMic

$\begin{array}{ll}\text { * Mass balance } & (\mathrm{kg} \cdot \mathrm{m}-2) \\ \text { No } & \text { print_AmaEqlPro } \\ \text { No } & \text { print_AmaEqlTil } \\ \text { No } & \text { print_AmaEqlTgt } \\ \text { No } & \text { print_AmaNeqPro } \\ \text { No } & \text { print_AmaNeqTil } \\ \text { No } & \text { print_AmaNeqTgt } \\ \text { No } & \text { print_AmaSysPro } \\ \text { No } & \text { print_AmaSysTil } \\ \text { No } & \text { print_AmaSysTgt } \\ \text { No } & \text { print_AmaAppSol } \\ \text { No } & \text { print_AmaEorPro }\end{array}$

Areic numerical mass error in soil matrix (micropore domain

Areic mass in equilibrium domain of profile Areic mass in equilibrium domain of tillage layer

Areic mass in equilibrium domain of target layer Areic mass in non-eql. domain of profile Areic mass in non-eql. domain of tillage layer Areic mass in non-eql. domain of target layer Areic mass of pesticide in the system

Areic mass of pesticide in the tillage layer Areic mass of pesticide in the target layer Areic mass applied to the soil system

Areic mass of formation 


$\begin{array}{ll}\text { * If drainage is considered: OptDra }>=1 \\ \text { No } \\ \text { print_AmaDra_1 } \\ \text { No } & \text { print_AmaDra_2 } \\ \text { No } & \text { print_AmaDra_3 } \\ \text { No } & \text { print_AmaDra_4 } \\ \text { No } & \text { print_AmaDra_5 } \\ \text { No } & \text { print_AmaDraPro } \\ \text { * End if } & \end{array}$

Areic mass of pesticide transformation

Areic mass of pesticide uptake

Areic mass of runoff from the field

Areic mass of deposit at soil surface

Areic mass of runoff infiltrating the bypass domain Areic mass of runoff infiltrating the ic domain Areic mass of drainage from the bypass domain Areic mass of drainage from the micropore domain Areic mass of exchange between ica and matrix Areic mass of exchange between bypass and matrix Areic mass of exchange between ica and matrix Areic mass of exchange between bypass and matrix Areic mass in the bypass domain

Areic mass in the internal catchment domain

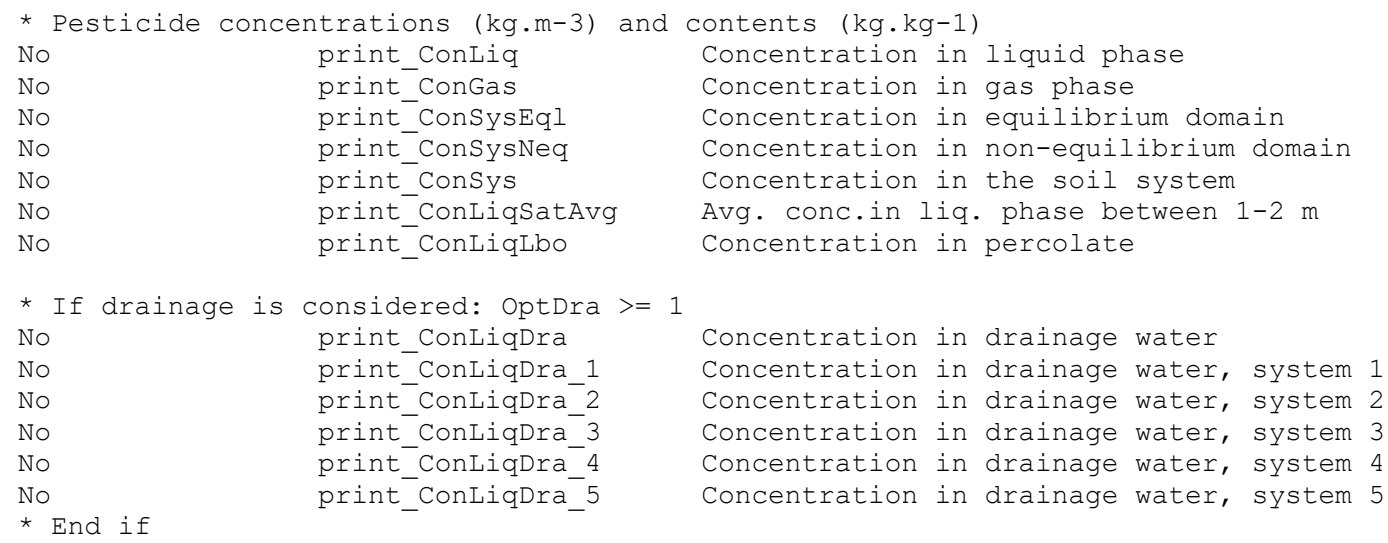

Areic mass of drainage to level 1 Areic mass of drainage to level 2 Areic mass of drainage to level 3 Areic mass of drainage to level 4 Areic mass of drainage to level 5 Areic mass of lateral discharge

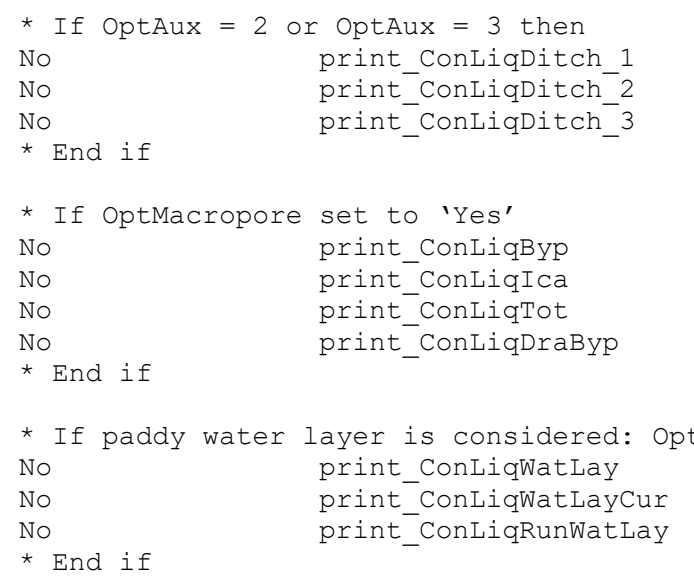

Concentration in surface water from level 1 Concentration in surface water from level 2 Concentration in surface water from level 3

Concentration in the bypass domain Concentration in the internal catchment domain Total concentration (mean of matrix and macropore) concentration in drainage water from bypass domain

$\begin{array}{lc}\text { * If OptReport set to SoilReport } \\ \text { No } & \text { print_ConLiqEAD } \\ \text { No } & \text { print_CntSysEAD } \\ \text { No } & \text { print_ConLiqTWA7D() } \\ \text { No } & \text { print_ConLiqTWA14D() }\end{array}$

print_ConLiqTWA21D( )

print_ConLiqTWA28D( )

print_ConLiqTWA56D()
Liquid concentration in target layer soil exposure Content in layer soil exposure Time-weighted liquid concentration for 7 day period in persistency layer

Time-weighted liquid concentration for 14 day period in persistency layer

Time-weighted liquid concentration for 21 day period in persistency layer

Time-weighted liquid concentration for 28 day period in persistency layer

Time-weighted liquid concentration for 56 day 
* Volatilisation concepts

* if OptTraRes $=1$, concept of laminar air boundary resistance

No

* End if

* If OptTraRes $=2$, concept of aerodynamic resistance

$\begin{array}{lll}\text { No } & \text { print_RstAer } & \text { aerodynamic resistance } \\ \text { No } & \text { print_RstBou } & \text { boundary resistance } \\ \text { No } & \text { print_VelFriLcl } & \text { friction velocity }\end{array}$

* End if

print FlmLiq

print_FlmGas

print Flmsys

print FlmLiqLbo

print_FlmLiqInfSys

Pesticide mass flux in gas phase

Total pesticide mass flux (FlmLig+FlmGas)

Accumulated mass flux at the lower boundary

Accumulated mass flux of pesticide infiltration

Accumulated mass flux of pesticide volatilisation

Resistance to transport through laminar air layer $(\mathrm{s} . \mathrm{m}-1)$

* End of Section II a

* Section II b: Output for the plant compartment

* Remark: Optsys can be 'All' or 'Plantonly'

*-------------------------------------------------------

* General

*---------------

$\begin{array}{lll}\text { No } & \text { print_AmaCrp } & \text { Areic mass of pesticide at the canopy } \\ \text { No } & \text { print_AmaAppcrp } & \text { Areic mass of pesticide applied to the canopy } \\ \text { No } & \text { print_AmaDspCrp } & \text { Areic mass rate of pesticide dissipation } \\ \text { No } & \text { print_AmaHarCrp } & \text { Areic mass rate of pesticide removal by harvest } \\ \text { No } & \text { print_AmaWasCrp } & \text { Areic mass rate of pesticide wash-off } \\ \text { No } & \text { print_FlmDepCrp } & \text { Areic mass rate of pesticide deposited on canopy }\end{array}$

Specific

If competing processes are considered: OptDspcrp > 1

No print_AmaVolcrp

canopy

print AmaPenCrp No print_AmaTraCrp

Areic mass of pesticide volatilised from crop

Areic mass penetrated into the crop canopy Areic mass transformed on the crop canopy

End if

If competing processes are considered and volatilisation dependent on meteorological conditions: OptDspCrp $=3$

$\begin{array}{ll}\text { No } & \text { print_AmaCrpFex } \\ \text { No } & \text { print_AmaCrpRex } \\ \text { No } & \text { print_AmaVolCrpFex } \\ \text { No } & \text { print_AmaVolCrpRex }\end{array}$

with

No

No

No into

No
print_AmaWasCrpFex print AmaWasCrpRex

print AmaPenCrpFex

print_AmaPenCrpRex
Areic mass fully exposed at the crop canopy

Areic mass with reduced exposure at the crop canopy

Areic mass of pesticide volatilised

Areic mass of pesticide volatilised from deposit

reduced exposure

Areic mass of wash-off from fully exposed deposit Areic mass of wash-off from deposit with reduced exposure

Areic mass of fully exposed pesticide penetrated

the plant

Areic mass of pesticide penetrated into the plant 
End if

* End of Section II b

* End of PEARL input file

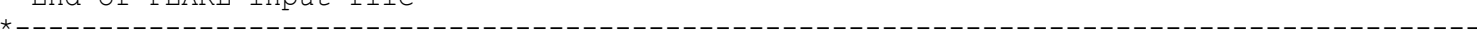




\section{Annex 2 Description of the weather data file}

The weather data file consists of 11 columns. Depending on the value of OptEvp (see page 24), one or more columns can be left blank. See Table A 2.1

Table A 2.1 Contents of the weather data file

\begin{tabular}{|c|c|c|c|}
\hline \multirow[t]{2}{*}{ Column name } & \multicolumn{3}{|c|}{ Required in the case of OptEvp = } \\
\hline & Penman & Makkink & Input \\
\hline $\begin{array}{l}\text { Meteostation code. The Meteostation code must be the same } \\
\text { as the code specified in the Meteostation record of the PEARL } \\
\text { file }\end{array}$ & Yes & Yes & Yes \\
\hline Day, between 1 and 31 & Yes & Yes & Yes \\
\hline Month, between 1 and 12 & Yes & Yes & Yes \\
\hline Year, between 1900 and 3000 & Yes & Yes & Yes \\
\hline Daily global radiation $\left(\mathrm{kJ} \mathrm{m}^{-2} \mathrm{~d}^{-1}\right)$, between 0 and $510^{6}$ & Yes & Yes & No \\
\hline Minimum daily temperature $\left({ }^{\circ} \mathrm{C}\right)$, between -50 and 35 & Yes & Yes & Yes \\
\hline Maximum daily temperature $\left({ }^{\circ} \mathrm{C}\right)$, between -30 and 60 & Yes & Yes & Yes \\
\hline Average vapor pressure $(\mathrm{kPa})$, between 0 and 10 & Yes & No & No \\
\hline Average windspeed $\left(\mathrm{m} \mathrm{s}^{-1}\right)$, between 0 and 50 & Yes & No & No \\
\hline Daily precipitation $\left(\mathrm{mm} \mathrm{d}^{-1}\right)$, between 0 and 1000 & Yes & Yes & Yes \\
\hline Reference evapotranspiration $\left(\mathrm{mm} \mathrm{d}^{-1}\right)$, between 0 and 100 & No & No & Yes \\
\hline
\end{tabular}

If a column is left blank, -99.9 should be specified. 



\title{
Annex 3 The format of the PERSAM transfer (ptf) file
}

\author{
* PERSAM Transfer file \\ * Generated on 09/10/2019_11:02
}

South RegZone Regulatory zone (options: North, Centre, South)

TotSol TypeofeP Type of endpoint (options: TotSol, PoreWat)

53920002285000 Location X/Y coordinates

P SubstānceAss Substance assessed (options: P, M1A, M1B, M1C, M1D, M2A, M2B, M2C, M2D)

1 fRef (-) Refinement factor for final PEC

10 PERSAMCropNr PERSAM crop number

VeryFine SoiltypeId Soil texture (options: Coarse, Medium, MediumFine, Fine, VeryFine, Organic)

0.0325 Cntomsca $(\mathrm{kg} \cdot \mathrm{kg}-1)$ Topsoil organic matter content

6.90 pHInp (-) Topsoil pH

$594 \operatorname{PrC}(\mathrm{mm})$ Mean annual precipitation

10.1 Temp (C) Mean annual temperature

substance 4 Name $P$ Substance name

-99 Name_M̄1A ------II------

- 99 Name $\mathrm{M} 1 \mathrm{~B}$

-99 Name M1C

- 99 Name M1D

-99 Name_M2A ------II------

-99 Name_M2B ------II------

-99 Name_M2C ------II------

-99 Name_M2D ------II------

300 MolMás P (g.mol-1) Molar mass

-99 MolMas_M1A (g.mol-1) ----II----

-99 MolMas_M1B (g.mol-1) ----II----

-99 MolMas_M1C (g.mol-1) ----II----

-99 MolMas_M1D (g.mol-1) ----II----

-99 MolMas_M2A (g.mol-1) ----II----

-99 MolMas_M2B (g.mol-1) ----II----

-99 MolMas_M2C ( $9 . \mathrm{mol}-1)$----II----

-99 MolMas_M2D ( $9 . m o l-1)$----II----

-99 P $\rightarrow$ MîA (-) Molar formation fraction

$-99 \mathrm{P}->\mathrm{M} 1 \mathrm{~B}(-)$----------II----------

$-99 \mathrm{P}->\mathrm{M} 1 \mathrm{C}(-)---------\mathrm{II}---------$

$-99 \mathrm{P}->\mathrm{M} 1 \mathrm{D}(-) \quad---------\mathrm{II}---------$

-99 M1A $->$ M2A (-) ----------II---------

-99 M1A $->$ M2B (-) ----------II---------

$-99 \mathrm{M} 1 \mathrm{~A}->\mathrm{M} 2 \mathrm{C}(-)$

$-99 \mathrm{M} 1 \mathrm{~A}->\mathrm{M} 2 \mathrm{D}(-)$

$-99 \mathrm{M} 1 \mathrm{~B}->\mathrm{M} 2 \mathrm{~A}(-)$

$-99 \mathrm{M} 1 \mathrm{~B}->\mathrm{M} 2 \mathrm{~B}(-)$

$-99 \mathrm{M} 1 \mathrm{~B}->\mathrm{M} 2 \mathrm{C}(-)$

$-99 \mathrm{M} 1 \mathrm{~B}->\mathrm{M} 2 \mathrm{D}(-)$

$-99 \mathrm{M} 1 \mathrm{C}->\mathrm{M} 2 \mathrm{~A}(-)$

$-99 \mathrm{M} 1 \mathrm{C}->\mathrm{M} 2 \mathrm{~B}(-)$

$-99 \mathrm{M} 1 \mathrm{C}->\mathrm{M} 2 \mathrm{C}(-)$

$-99 \mathrm{M} 1 \mathrm{C}->\mathrm{M} 2 \mathrm{D}(-)$

$-99 \mathrm{M} 1 \mathrm{D}->\mathrm{M} 2 \mathrm{~A}(-)$

-99 M1D $\rightarrow$ M2B (-)

$-99 \mathrm{M} 1 \mathrm{D} \rightarrow \mathrm{M} 2 \mathrm{C}(-)$

-99 M1D $\rightarrow$ M2D (-)

31 DT50Ref P (d) Half-life time

-99 DT50Réf_M1A (d) ------II------

-99 DT50Ref M1B (d) ------II------

-99 DT50Ref_M1C (d)

-99 DT50Ref ${ }^{-}$M1D

-99 DT50Ref_M2A

-99 DT50Ref - M2B

-99 DT50Ref-M2C

-99 DT50Ref-M2D

(d) ------II------

(d)

(d)

(d)

$-----1 I-----$

$------I I------$

(d) ------II------

65.4 MolEntTra_P (kJ.mol-1) Molar activation energy 
-99 MolEntTra M1A (kJ.mol-1) ----------II----------

-99 MolEntTra_M1B (kJ.mol-1) ---------II----------

-99 MolEntTra_M1C (kJ.mol-1) ----------II----------

-99 MolEntTra_M1D (kJ.mol-1) ---------II----------

-99 MolEntTra_M2A (kJ.mol-1) ----------II----------

-99 MolEntTra_M2B (kJ.mol-1) ---------II----------

-99 MolEntTra M2C (kJ.mol-1) ---------II----------

-99 MolEntTra M2D (kJ.mol-1) ---------II----------

31 KomEql_P (I. kg-1) Coef. eql. sorption on org. matter

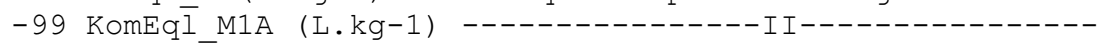

-99 KomEql_M1B (L.kg-1) --

$-99 \mathrm{KomEqI}$ M1C (L.kg-1) -------------II-------------

$-99 \mathrm{KomEqI}$ M1D (L.kg-1) --------------II--------------

-99 KomEqI_M2A (L.kg-1) -------------II-------------

-99 KomEql_M2B (L.kg-1) -------------II--------------

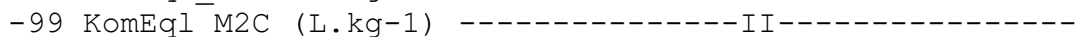

-99 KomEqI_M2D (L.kg-1) ---------------II---------------

$0.00 E 0$ ZEADTTO (m) Top of the evaluation depth

0.0500 ZEADBot (m) Bottom of the evaluation depth

1 DelTimevt (a) Repeat interval of events (options: 1, 2, 3)

49 IntPostApp (d) Time interval for post-application PEC (days after last application)

AppCrpUsr OptApp Application (options: AppSolSur, AppCrpUsr, AppSolInj, AppSolTil)

0 ZApp (m) Application depth (incorporation or injection)

3 NrApp (-) Number of applications events

* Application table (day - rate (kg.ha-1) - crop interception (fraction of dosage, dimensionless))

table Applications

01.2000000000000000 .300

$140.8000000000000000 \quad 0.600$

$210.4000000000000000 \quad 0.600$

end_table 


\section{Published documents in the Technical reports series of the Statutory Research Tasks Unit for Nature \& the Environment.}

113 Arets, E.J.M.M., J.W.H van der Kolk, G.M. Hengeveld, J.P. Lesschen, H. Kramer, P.J. Kuikman \& M.J. Schelhaas (2018). Greenhouse gas reporting for the LULUCF sector in the Netherlands. Methodological background, update 2018

114 Bos-Groenendijk, G.I. en C.A.M. van Swaay (2018) Standaard Data Formulieren Natura 2000-gebieden; Aanvullingen vanwege wijzigingen in Natura 2000aanwijzingsbes/uiten

115 Vonk, J. , S.M. van der Sluis, A. Bannink, C. van Bruggen, C.M. Groenestein, J.F.M. Huijsmans, J.W.H. van der Kolk, L.A. Lagerwerf, H.H. Luesink, S.V. Oude Voshaar \& G.L. Velthof (2018.) Methodology for estimating emissions from agriculture in the Netherlands - update 2018. Calculations of $\mathrm{CH} 4$, NH3, N2O, NOx, PM10, PM2.5 and CO2 with the National Emission Model for Agriculture (NEMA)

116 IJsseldijk, L.L., M.J.L. Kik, \& A. Gröne (2018). Postmortaal onderzoek van bruinvissen (Phocoena phocoena) uit Nederlandse wateren, 2017. Biologische gegevens, gezondheidsstatus en doodsoorzaken.

117 Mattijssen, T.J.M. \& I.J. Terluin (2018). Ecologische citizen science; een weg naar grotere maatschappelijke betrokkenheid bij de natuur?

118 Aalbers, C.B.E.M., D. A. Kamphorst \& F. Langers (2018). Bedrijfs- en burgerinitiatieven in stedelijke natuur. Hun succesfactoren en knelpunten en hoe de lokale overheid ze kan helpen slagen.

119 Bruggen, C. van, A. Bannink, C.M. Groenestein, J.F.M. Huijsmans, L.A. Lagerwerf, H.H. Luesink, S.M. van der Sluis, G.L. Velthof \& J. Vonk (2018). Emissies naar lucht uit de landbouw in 2016. Berekeningen met het model NEMA

120 Sanders, M.E., F. Langers, R.J.H.G. Henkens, J.L.M. Donders, R.I. van Dam, T.J.M. Mattijssen \& A.E. Buijs (2018). Maatschappelijke initiatieven voor natuur en biodiversiteit; Een schets van de reikwijdte en ecologische effecten en potenties van maatschappelijke initiatieven voor natuur in feiten en cijfers

121 Farjon, J.M.J., A.L. Gerritsen, J.L.M. Donders, F. Langers \& W. Nieuwenhuizen (2018). Condities voor natuurinclusief handelen. Analyse van vier praktijken van natuurinclusief ondernemen

122 Gerritsen, A.L., D.A. Kamphorst \& W. Nieuwenhuizen (2018). Instrumenten voor maatschappelijke betrokkenheid. Overzicht en analyse van vier cases

123 Vullings, L.A.E., A.E. Buijs, J.L.M. Donders, D.A. Kamphorst, H. Kramer \& S. de Vries (2018). Monitoring van groene burgerinitiatieven; Analyse van de resultaten van een pilot en nulmeting in vier gemeenten

124 Boonstra, F.G., Th.C.P. Melman, W. Nieuwenhuizen \& A. Gerritsen (2018). Aanpak evaluatie stelselvernieuwing agrarisch natuurbeheer; Uitgangspunten en opties voor een beleidsevaluatie

125 Vullings, L.A.E., A.E. Buijs, J.L.M. Donders \& D.A. Kamphorst (2018). Monitoring van groene burgerinitiatieven; Methodiek, indicatoren en ervaring met pilot en nulmeting.

126 Beltman, W.H.J., M.M.S. ter Horst, P.I. Adriaanse \& A. de Jong (2018). Manual for FOCUS_TOXSWA v5.5.3 and for expert use of TOXSWA kernel v3.3; User's Guide version 5

127 Van der Heide, C.M. \& M.M.M. Overbeek (2018). Natuurinclusief handelen en ondernemen. Scopingstudie 'Bedrijven, economie en natuur'

128 Langers, F. (2018). Recreatie in groenblauwe gebieden; Actualisatie van CLO-indicator 1258 (Bezoek aan groenblauwe gebieden) op basis van data van het Continu Vrijetijdsonderzoek uit 2015

129 Glorius, S.T., I.Y.M. Tulp, A. Meijboom, L.J. Bolle and C. Chen (2018). Developments in benthos and fish in gullies in an area closed for human use in the Wadden Sea; 2002-2016

130 Kamphorst, D.A \& T.J.M. Mattijssen (2018)

Scopingstudie Vermaatschappelijking van natuur. Een overzicht van onderzoek bij Wageningen Universiteit \& Research voor het Planbureau voor de Leefomgeving en het ministerie van Landbouw, Natuur en Voedselkwaliteit

131 Breman, B.C., T.J.M. Mattijssen \& T.M. Stevens (2018). Natuur 2.0. Het natuurdebat op social media.

132 Vries, S. de \& W. Nieuwenhuizen (2018) HappyHier: hoe gelukkig is men waar?; Gegevensverzameling en bepaling van de invloed van het type grondgebruik, deel II

133 Kistenkas, F.H., W. Nieuwenhuizen, D.A. Kamphorst \& M.E.A. Broekmeyer (2018). Natuur- en landschap in de Omgevingswet.

134 Michels, R, V. Diogo, W.H.G.J. Hennen, L.F. Puister (2018). Instrumentarium Kosten Natuurbeleid 2018 - Status A; IKN versie 3.0

135 Sanders, M.E. (2018). Voortgang realisatie natuurnetwerk. Technische achtergronden bij de digitale Balans van de Leefomgeving 2018

136 Koffijberg K., J.S.M. Cremer, P. de Boer, J. Nienhuis, K. Oosterbeek \& J. Postma (2018). Broedsucces van kustbroedvogels in de Waddenzee in 2017

137 Egmond, F.M. van, S. van der Veeke, M. Knotters, R.L. Koomans, D. Walvoort, J. Limburg (2018). Mapping soil texture with a gamma-ray spectrometer: comparison between UAV and proximal measurements and traditional sampling; Validation study

138 Glorius, S.T., A. Meijboom, J.T. Wal van der, J.S.M. Cremer (2018). Ontwikkeling van enkele 
droogvallende mosselbanken in de Nederlandse Waddenzee; situatie 2017.

139 Berg, F. van den, A. Tiktak, D.W.G. van Kraalingen, J.G. Groenwold \& J.J.T.I. Boesten (2018). User manual for GeoPEARL version 4.4.4.

140 Kuiters, A.T., G.A. de Groot, D.R. Lammertsma, H.A.H. Jansman \& J. Bovenschen (2018). Genetische monitoring van de Nederlandse otterpopulatie; Ontwikkeling van populatieomvang en genetische status $2017 / 2018$

141 Müskens G.J.D.M., M.J.J. La Haye, R.J.M. van Kats \& A.T. Kuiters (2018). Ontwikkeling van de hamsterpopulatie in Limburg. Stand van zaken voorjaar 2018

142 Glorius, S.T. (2018). Ontwikkeling van de bodemdiergemeenschap in de geulen van referentiegebied Rottum; Tussenrapportage twaalf jaar na sluiting (najaar 2017).

143 Brouwer, F., F. de Vries en D.J.J. Walvoort (2018). Basisregistratie Ondergrond (BRO); Actualisatie bodemkaart: herkartering van de bodem in Flevoland

144 Knotters, M. en F.M. van Egmond (2018). Selectie van inwinningstechnieken voor bodemdata; Selecteren vanuit de (onderzoeks)vraag

145 Stuyt, L.C.P.M., M. Knotters, D.J.J. Walvoort, F. Brouwer \& H.T.L. Massop (2018). Basisregistratie Ondergrond - Gd-kartering Laag-Nederland 2018; Provincie Flevoland

146 Arets, E.J.M.M., J.W.H van der Kolk, G.M. Hengeveld, J.P. Lesschen, H. Kramer, P.J. Kuikman \& M.J. Schelhaas (2019). Greenhouse gas reporting of the LULUCF sector in the Netherlands. Methodological background, update 2019

147 Bruggen, C. van, A. Bannink, C.M. Groenestein, J.F.M. Huijsmans, L.A. Lagerwerf, H.H. Luesink, S.M. van der Sluis, G.L. Velthof \& J. Vonk (2019). Emissies naar lucht uit de landbouw in 2017. Berekeningen met het model NEMA.

148 Lagerwerf, L.A., A. Bannink, C. van Bruggen, C.M. Groenestein, J.F.M. Huijsmans, J.W.H. van der Kolk, H.H. Luesink, S.M. van der Sluis, G.L. Velthof \& J. Vonk (2019). Methodology for estimating emissions from agriculture in the Netherlands. Calculations of CH4, NH3, N2O, NOx, NMVOC, PM1O, PM2.5 and CO2 with the National Emission Model for Agriculture (NEMA) - update 2019

149 Bakker, G., M. Heinen, H.P.A. Gooren, W.J.M. de Groot, F.B.T. Assinck \& E.W.J. Hummelink (2019). Hydrofysische gegevens van de bodem in de Basisregistratie Ondergrond (BRO) en het Bodemkundig Informatie Systeem (BIS); Update 2018.

150 IJsseldijk, L.L., M.J.L. Kik, \& A. Gröne (2019). Postmortaal onderzoek van bruinvissen (Phocoena phocoena) uit Nederlandse wateren, 2018. Biologische gegevens, gezondheidsstatus en doodsoorzaken.
151 Daamen, W.P., A.P.P.M. Clerkx \& M.J. Schelhaas (2019). Veldinstructie Zevende Nederlandse Bosinventarisatie (2017-2021); Versie 2.0.

152 Bikker, P., L.B. Šebek, C. van Bruggen \& O. Oenema (2019). Stikstof- en fosfaatexcretie van gangbaar en biologisch gehouden landbouwhuisdieren. Herziening excretieforfaits Meststoffenwet 2019.

153 Berg, F. van den, H. Baveco \& E.L. Wipfler (2019). User manual for SAFE (Select Application date For Evaluation) to support the use of the GEM scenarios for cultivations in glasshouses; Version 1.1

154 Os, J. van, L.J.J. Jeurissen en H.H. Ellen (2019). Rekenregels pluimvee voor de Landbouwtelling; Verantwoording van het gebruik van het Identificatie\& Registratiesysteem

155 Brouwer, F. \& D.J.J. Walvoort (2019). Basisregistratie Ondergrond (BRO) - Actualisatie bodemkaart; Herkartering van de veengebieden in Eemland

156 Sanders, M.E., R.J.H.G. Henkens \& D.M.E. Slijkerman (2019). Convention on Biological Diversity; Sixth National Report of the Kingdom of the Netherlands.

157 Kuiters, A.T., G.A. de Groot, D.R. Lammertsma, H.A.H. Jansman, J. Bovenschen, M.C. Boerwinkel \& M. Laar (2019). Genetische monitoring van de Nederlandse otterpopulatie; Ontwikkeling van populatieomvang en genetische status 2018/2019.

158 Sanders, M.E. \& H.A.M. Meeuwsen (2019). Basisbestand Natuur en Landschap

159 Visser, T., H.A.M Meeuwsen \& Th.C.P. Melman (2019). MNP-(Model for Nature Policy) Agrarisch; Uitwerking voor scenario's uit de Natuurverkenning 2020.

160 Jong, A. de, A. Poot \& P.I. Adriaanse (2019). Impact analysis for the purpose of the introduction of DROPLET version 1.3.2

161 Westerink, J., T.A. de Boer, M. Pleijte \& R.A.M. Schrijver (2019). Kan een goede boer natuurinclusief zijn?; De rol van culturele normen in een beweging richting natuurinclusieve landbouw.

163 Haas, W. de, J.L.M. Donders, T.J.M. Mattijssen (2019) Natuur in conflict; Botsende waarden, waarheden en belangen in het natuurbeheer.

164 Berg, F. van den, A. Tiktak, D. van Kraalingen \& J.J.T.I. Boesten (2019). User manual for FOCUSPEARL version 5.5.5.

165 Glorius, S.T., A. Meijboom, J. Schop \& J.T. van der Wal (2019). Ontwikkeling van enkele droogvallende mosselbanken in de Nederlandse Waddenzee; situatie 2018.

166 Pedroli, B, During, R. (2019). De paradox van een maakbare natuur - ingebakken en omstreden; Betekenis culturele identiteit voor draagvlak natuurbeleid en -beheer.

167 Walvoort, D.J.J., M. Knotters, F.M. van Egmond (2019). Interpolatie, aggregatie en desaggregatie van ruimtelijke bodemgegevens in de Basisregistratie Ondergrond 



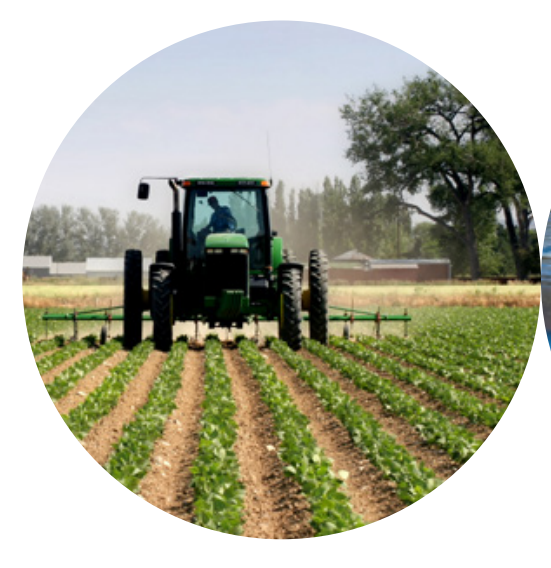

Theme Agri-Environment Wettelijke Onderzoekstaken Natuur \& Milieu

P.O. Box 47

6700 AA Wageningen

T (0317) 485471

E info.wnm@wur.nl

ISSN 2352-2739

www.wur.nl/wotnatuurenmilieu

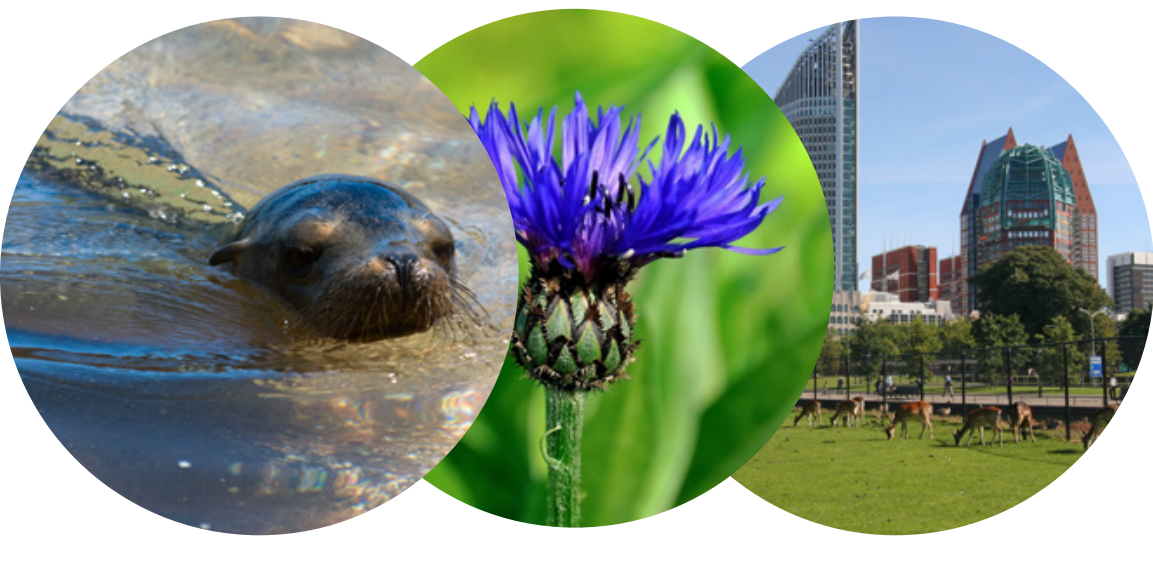

The mission of Wageningen University and Research is "To explore the potential of nature to improve the quality of life". Under the banner Wageningen University \& Research, Wageningen University and the specialised research institutes of the Wageningen Research Foundation have joined forces in contributing to finding solutions to important questions in the domain of healthy food and living environment. With its roughly 30 branches, 5,000 employees and 10,000 students, Wageningen University \& Research is one of the leading organisations in its domain. The unique Wageningen approach lies in its integrated approach to issues and the collaboration between different disciplines.

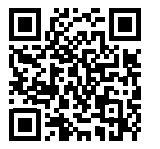

